\title{
مـبـد أ الاتـفــاق أ رسطو
}

\author{
ولاء توفيق فرح
}

كلية الآداب - جامعة القاهرة

$$
\text { تحت إثراف: }
$$

أ.د. محمد حمدى إبراهيم

كلية الآداب - جامعة القاهرة

يقدم أرسطو تعريفا كلاسيا للماهية الإنسانية مؤداه أن الإنسان كائن حي يمتلاك اللوجوس

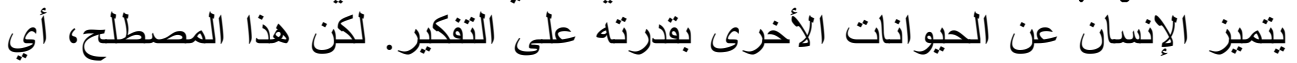

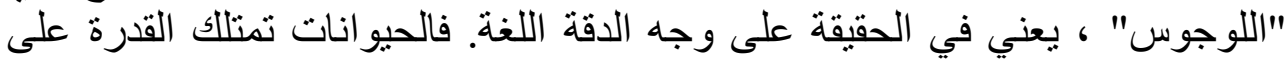

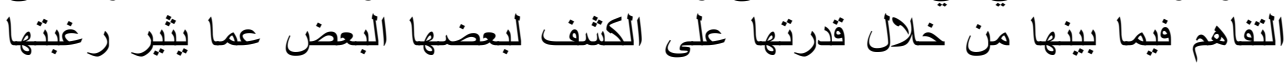

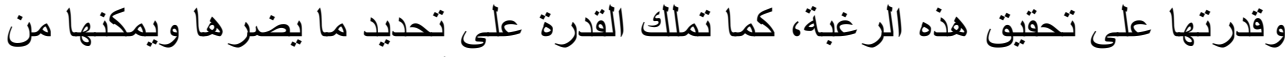

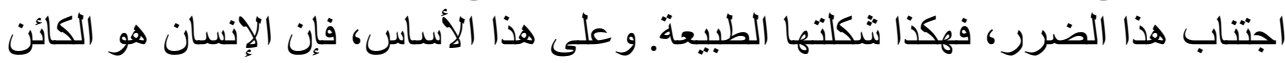

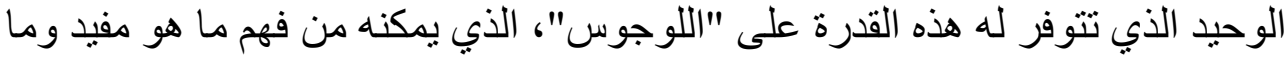

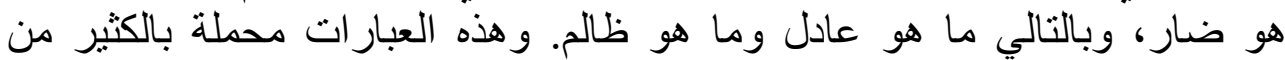

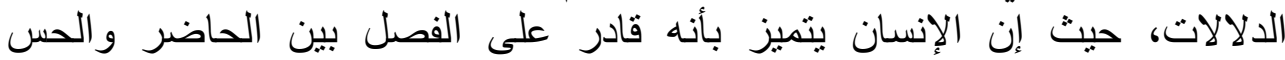

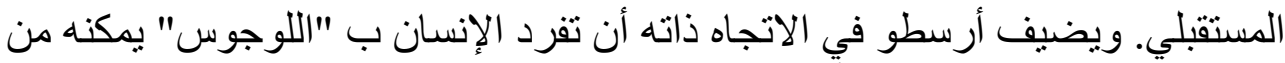

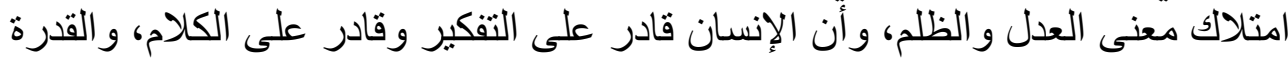

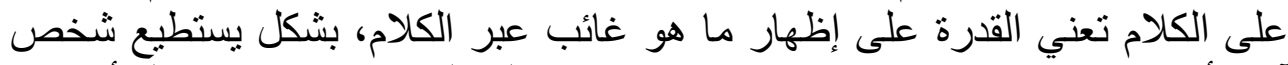

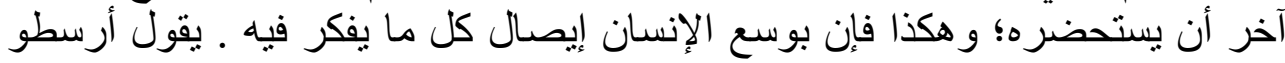

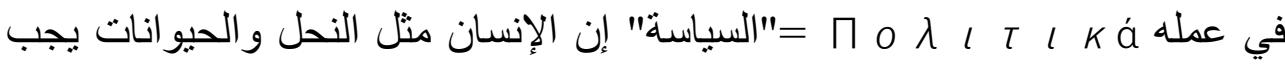

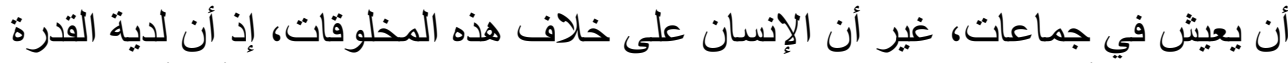

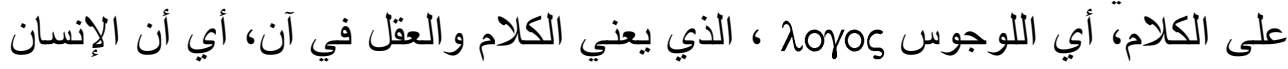

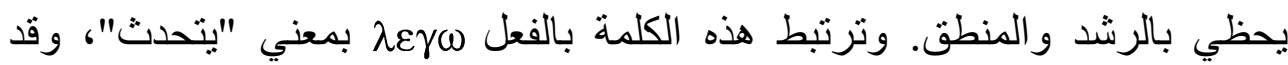

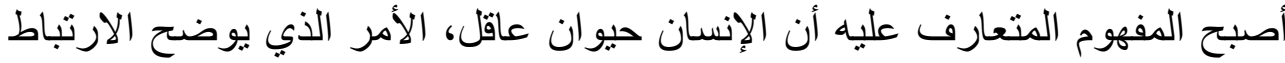
المنطقي بين اللغة والعقل. فالغرض من الكلام الذي تمت نسبته إلى الإنسان بالطبيعة الإنيان 


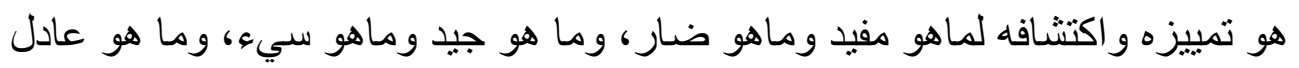

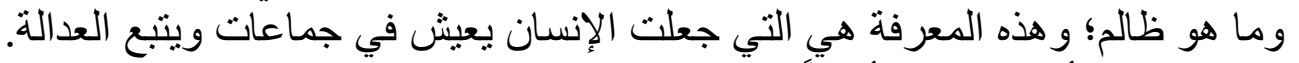

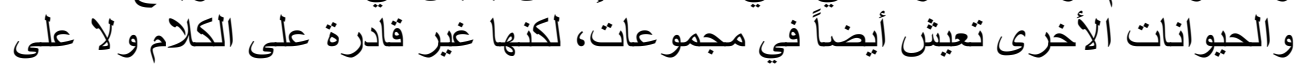

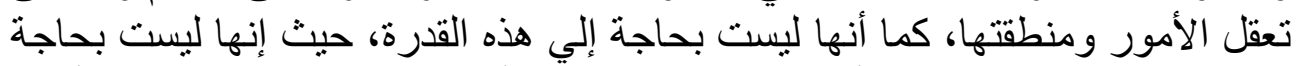

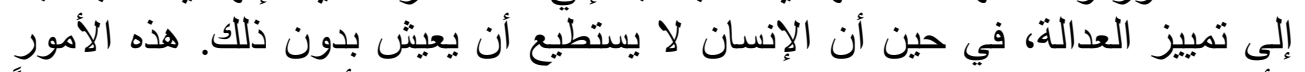

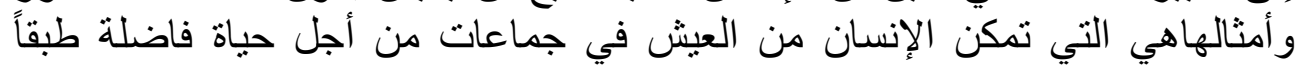

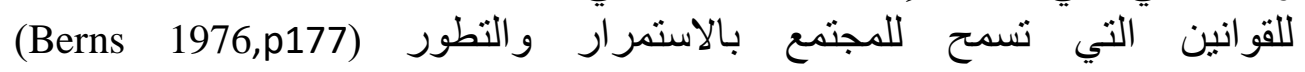
.(Aristotle, П o $\lambda$ l T l ká1253a8-19)

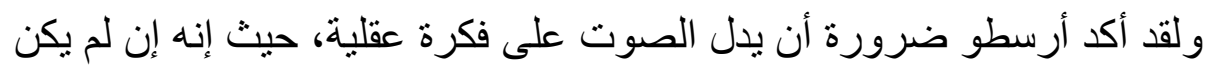

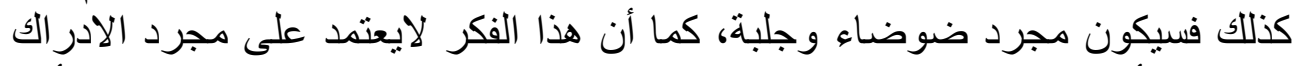

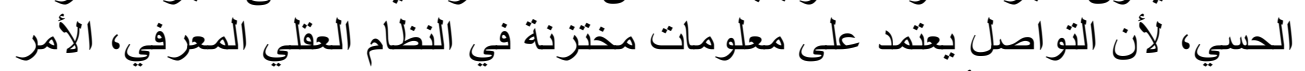

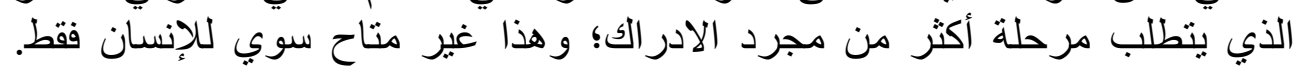

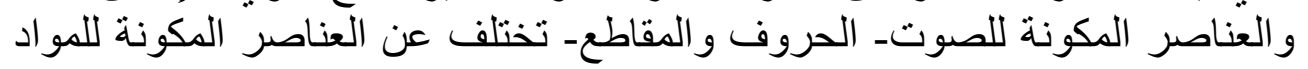

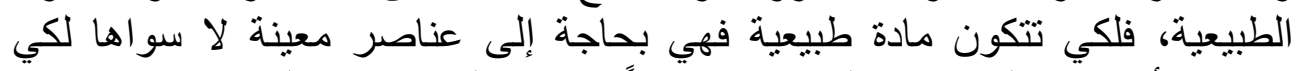

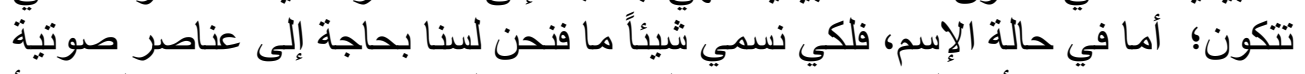

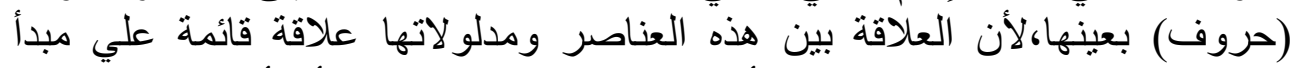

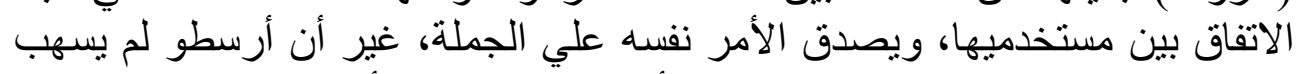

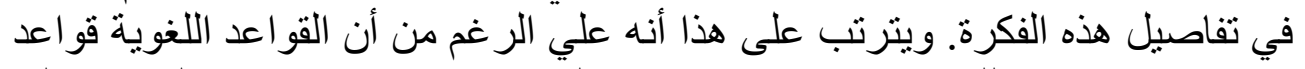

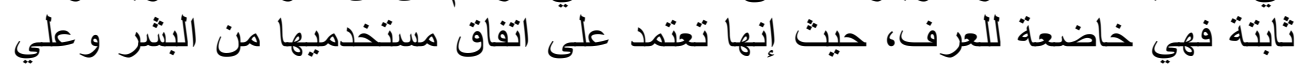

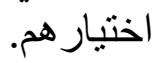

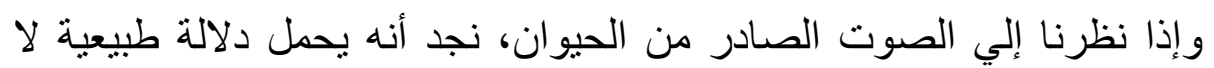

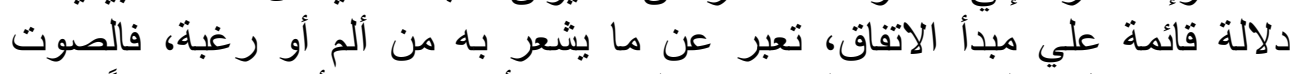

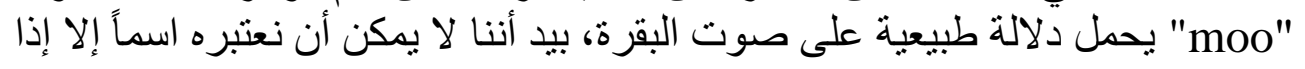

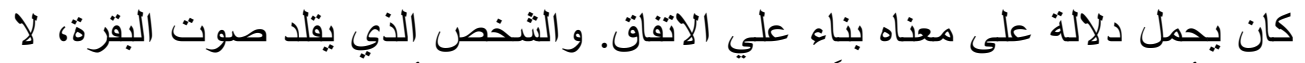

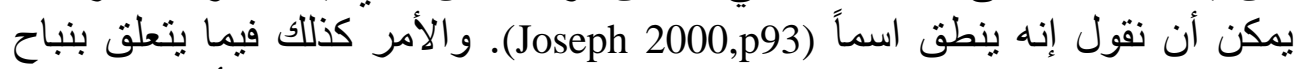

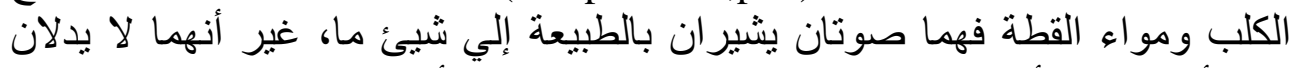

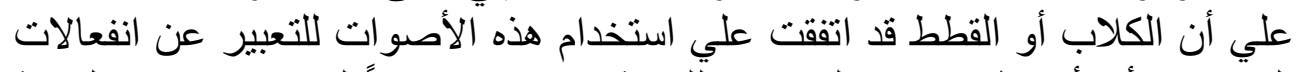

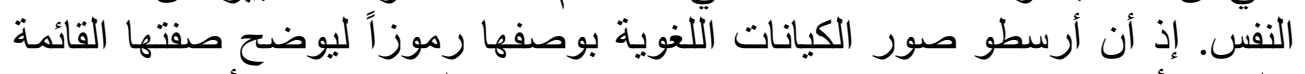

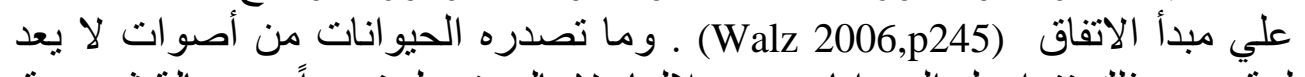

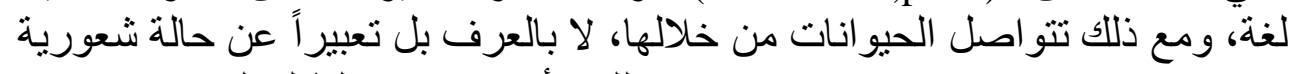
(Cuypere and Willems 2008,p318) 


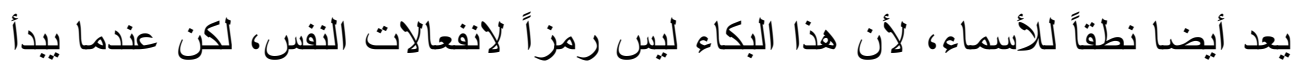

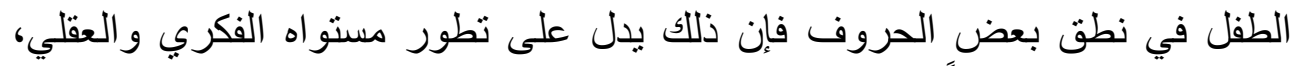

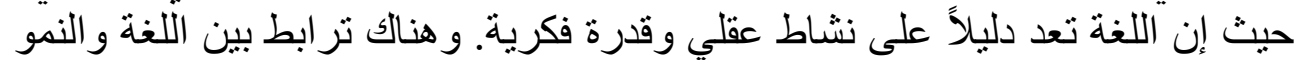

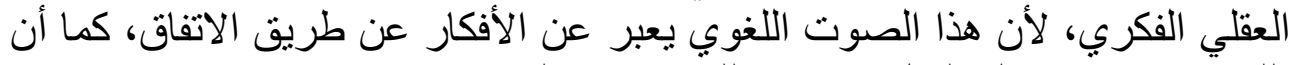
اللغة تعبر عن ادر الك العقل الإنساني للموجودات الخارجية (Walz 2006,p248).

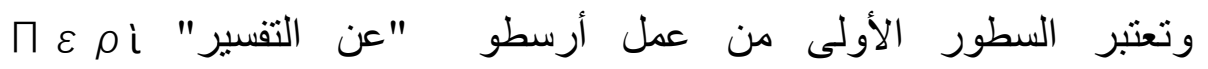

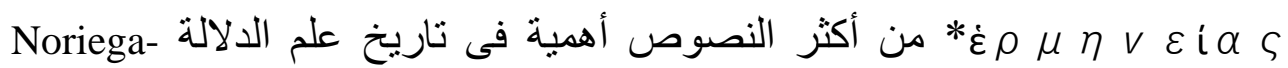

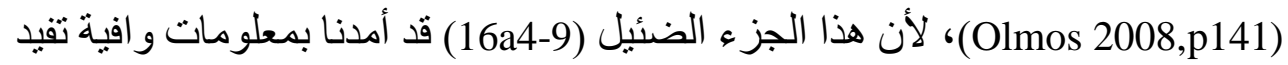

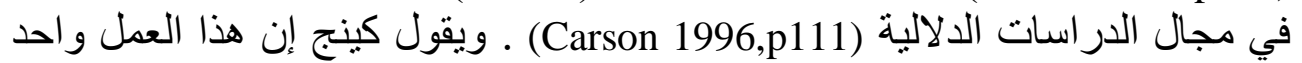

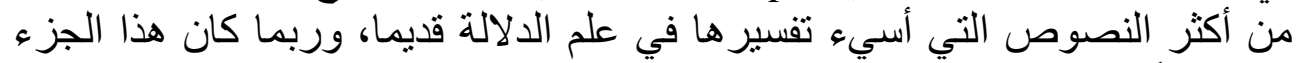

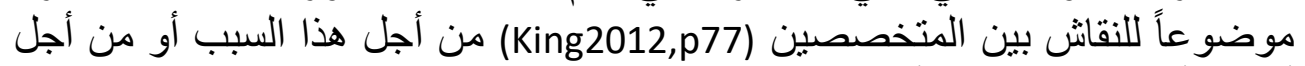
أسباب أخري. ويعد فكر أرسطو عن اللغة في هذا العمل

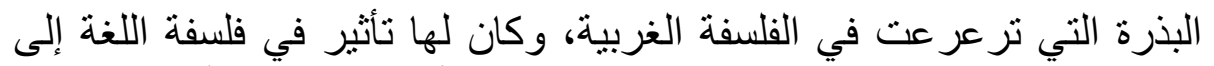

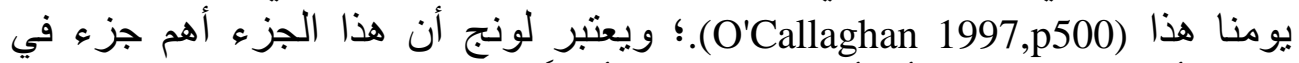
نظرية أرسطو اللغوية، وأنه أكثر النصوص تأثير أ في تاريخ علم الدالة النة .(Long 2011,p74)

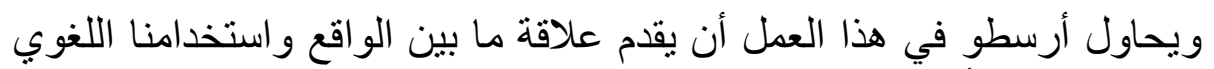

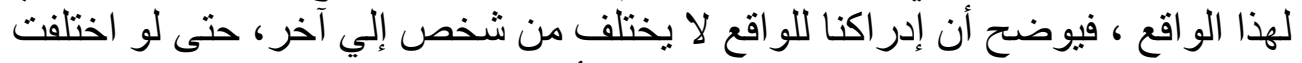

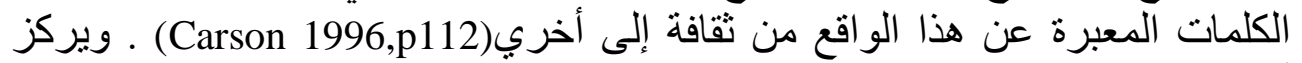

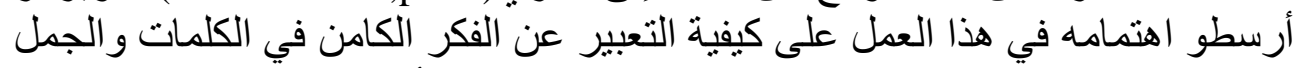

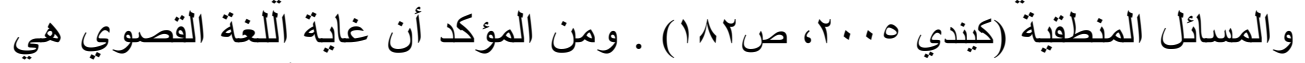

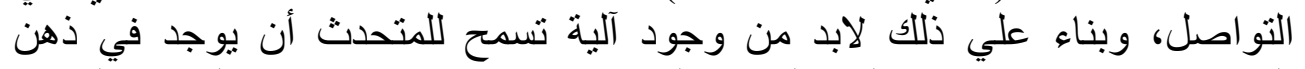

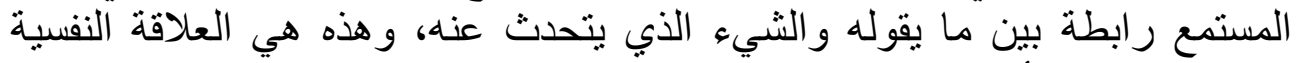
اللغوية في فلسفة أرسطو (Carson 1996,p106).

"E $\sigma \tau l \quad \mu \dot{\varepsilon} V \quad O \tilde{u} V \quad \tau \dot{\alpha} \quad \dot{\varepsilon} V \quad \tau \tilde{n} \quad \phi \omega v \tilde{n} \quad \tau \tilde{\omega} V \quad \dot{\varepsilon} V \quad \tau \tilde{n} \quad \psi U \chi \tilde{n}$ $\pi \alpha \theta \eta \mu \dot{\alpha} \tau \omega v \sigma \dot{u} \mu \beta O \lambda \alpha, k \alpha i t \dot{\alpha} \gamma \rho \alpha \phi \dot{o} \mu \varepsilon v \alpha \tau \tilde{\omega} V \dot{\varepsilon} V \tau \tilde{n}$ $\phi \omega v \tilde{n} . k \alpha i \ddot{\omega} \sigma \pi \varepsilon \rho \sigma \dot{u} \delta \dot{\varepsilon} \gamma \rho \dot{\alpha} \mu \mu \alpha \tau \alpha \pi \tilde{\alpha} \sigma l \tau \dot{\alpha} \alpha \dot{u} \tau \dot{\alpha}, O \dot{u} \delta \dot{\varepsilon}$ $\phi \omega v \alpha i \quad \alpha i \quad \alpha \dot{u} \tau \alpha i$. $\tilde{\omega} v \quad \mu \dot{\varepsilon} v \tau O l \quad \tau \alpha \tilde{u} \tau \alpha \quad \sigma \eta \mu \varepsilon \tilde{\imath} \alpha$ $\pi \rho \dot{\omega} \tau \omega v, \tau \alpha \dot{u} \tau \grave{a} \pi \tilde{\alpha} \sigma l \quad \pi \alpha \theta \dot{\eta} \mu \alpha \tau \alpha \tau \tilde{\eta} \varsigma \quad \psi u \chi \tilde{\eta} \varsigma, \quad k \alpha \dot{i} \tilde{\omega} v$ 
ouv $\theta \dot{\eta} k \eta$

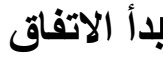

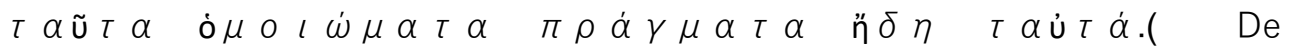
interpretatione.16a4-9)

* اصطلح المتخصصون على تسمية كتابه" ؟

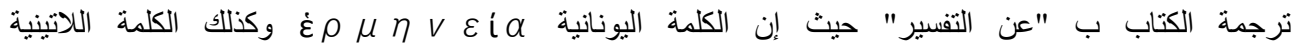
Interpretatione " إن (الألفاظ) الموجودة في الصوت فئلان دلالات علي الانفعالات التي في النفس، كما أن (الكلمات)

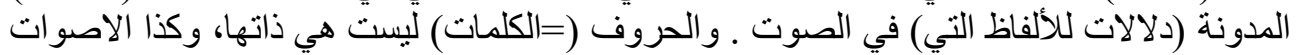
ليست هي ذانها عند جميع (البشر)، في حين الهي أن انفعالات النفس ذاتها هي دلآلات عن تلاتك (الأشياء) الأولي و هي مماتلة لهذه الأشياء ذاتها."

وفي هذا الجزء يبدأ أرسطو بتعريف الكلمات على أنها رموز صوتية

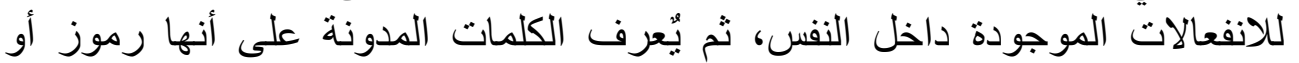

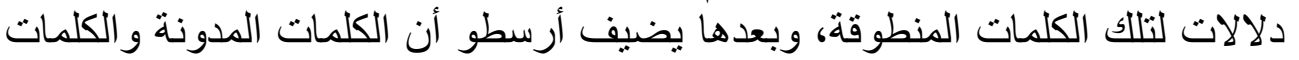

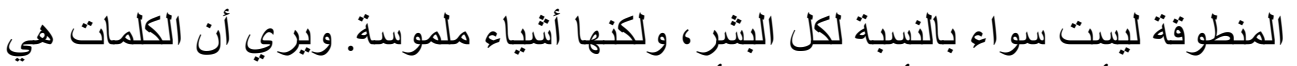

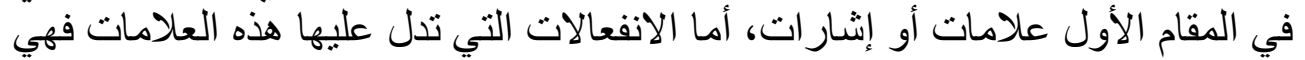

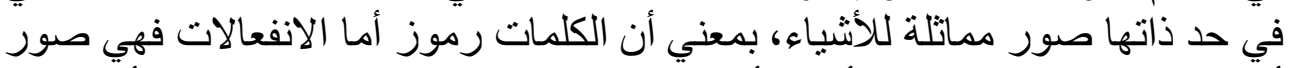

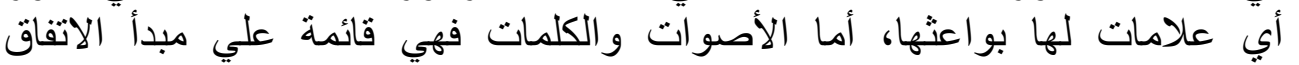

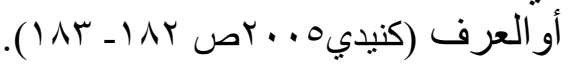

وينبغي أن نؤكد أن انفعالات النفس ليست خاضعة لحكمنا وسيطرتنا، حيث إنها

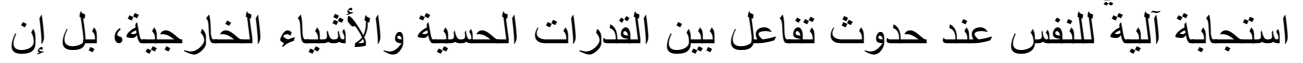

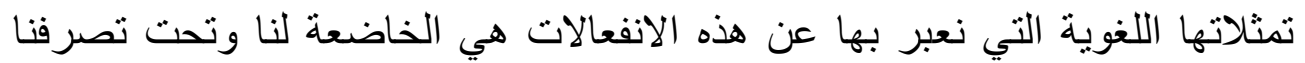

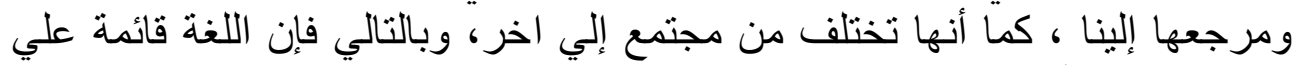

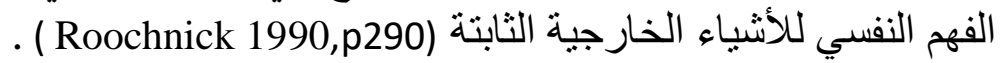

ويتضح لنا من النص السابق أن مبدأ الاتفاق في اللغة عند أرسطو يتطلب الحديث

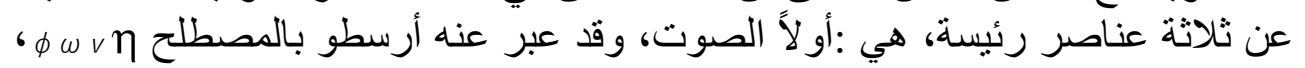

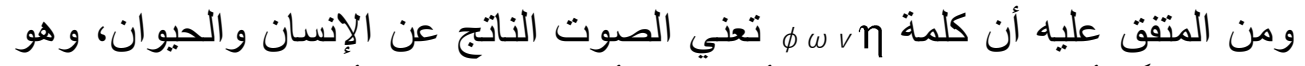

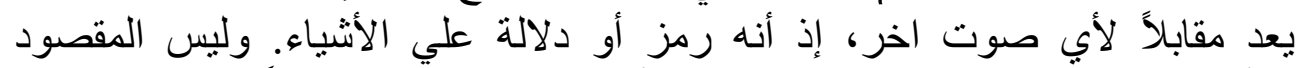

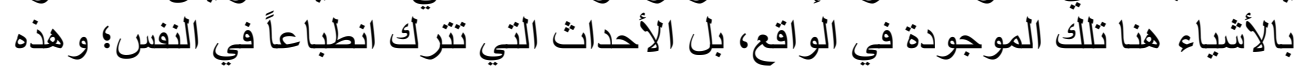

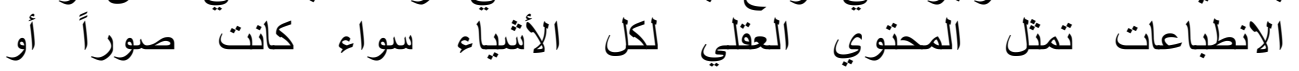

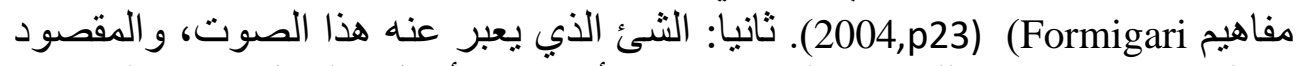

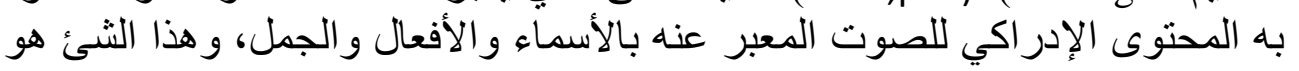


الانفعالات العناصر جميعاً يمكن التعبير عنها بمصطلح المنلث الدالالي يمكن أن نقدم شكلاً توضيحياً عن مفهوم أرسطو للألالة اللغوية علي النحو النحو

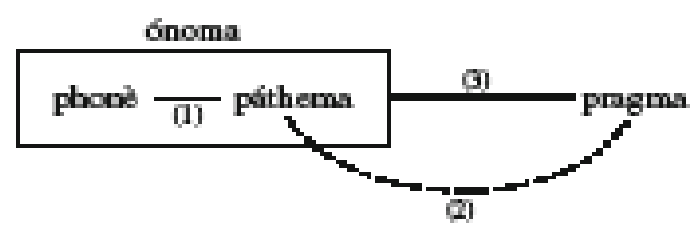

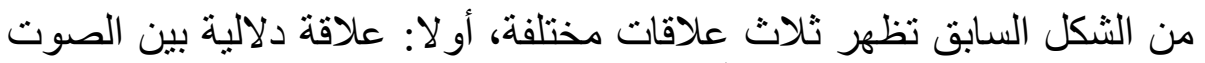

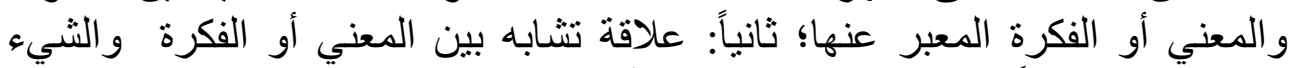

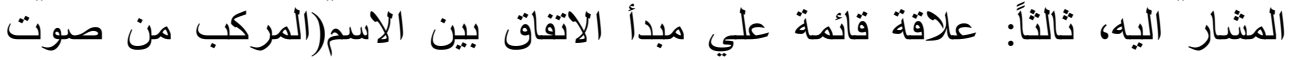
ومعني) و الثيء المشار إليه (Cuypere and Willems 2008,p323).

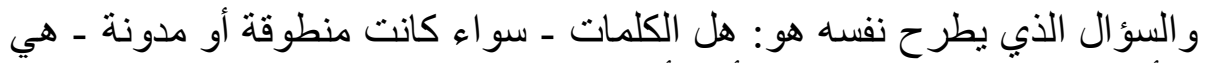

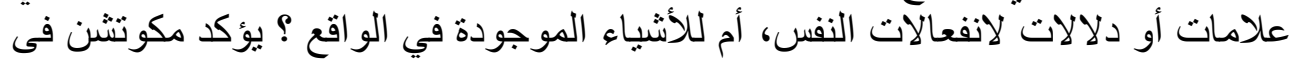

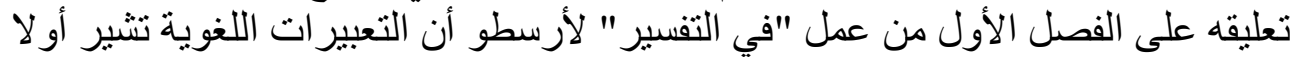

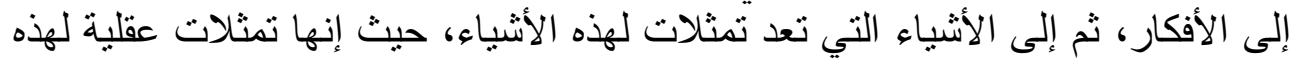

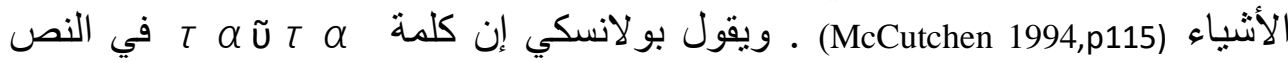

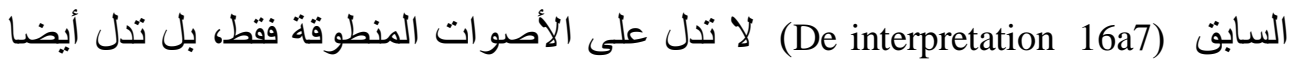

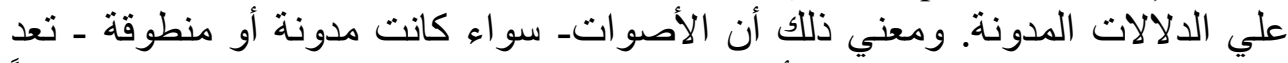

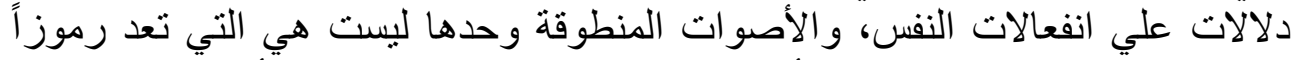

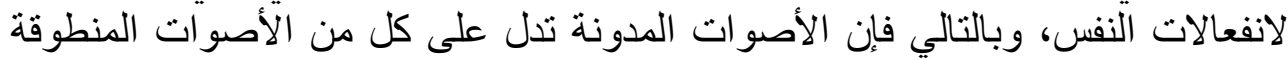
وعلي انفعالات النفس(ب) (Polansky and Kuczewski 1990,p61).

تقول مودرك إن أرسطو يعتبر الأفكار ذات صفة عالمية، في حين أن الكلمات

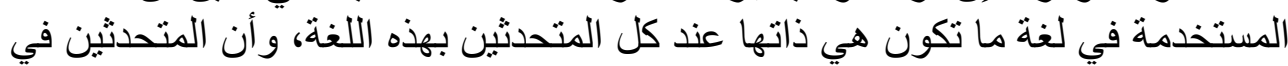
اللغات الآخري يستخدمون مصطلحات متر ادفة synonymous ـ كما أنها تري أن فكرة

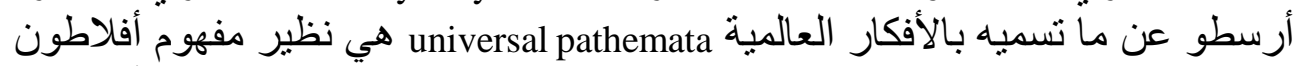

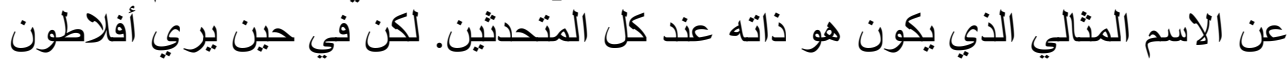

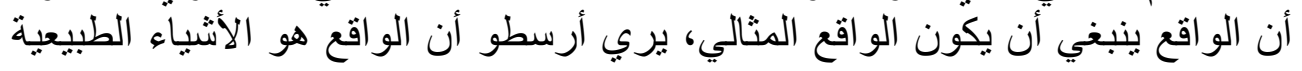




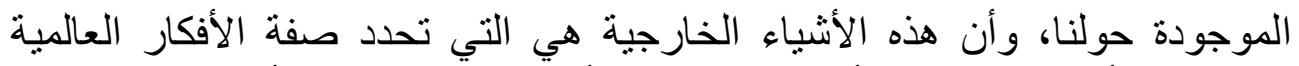

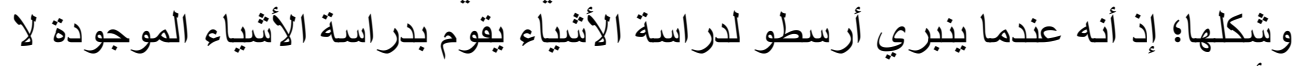
الأفكار المجردة (Modrak 2000,p29).

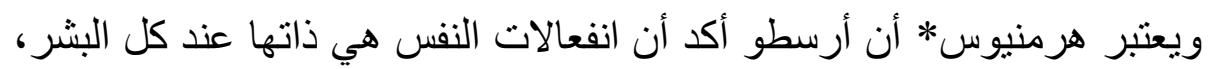
حيث ترجم هرمنيوس كلمة

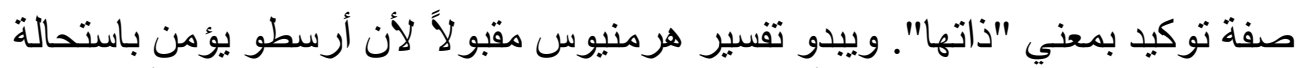

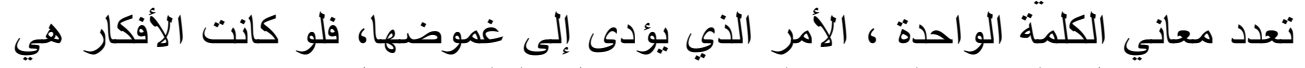

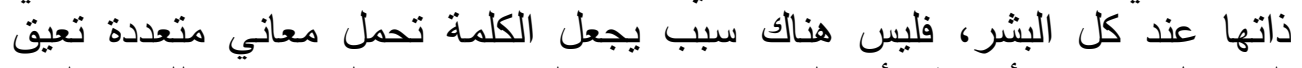

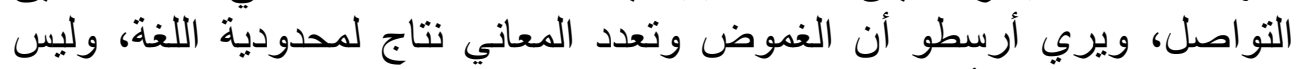

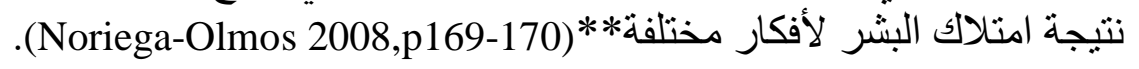

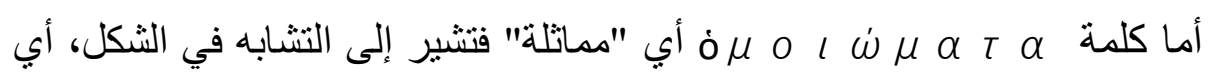

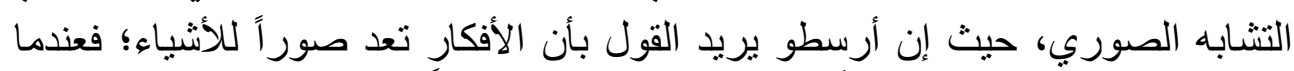

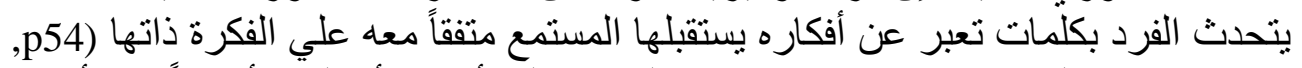

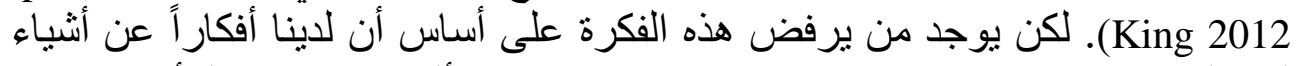

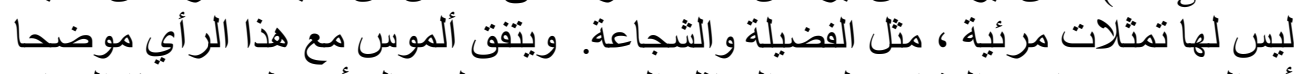

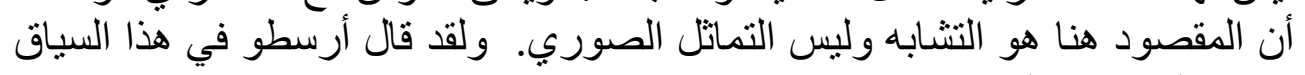

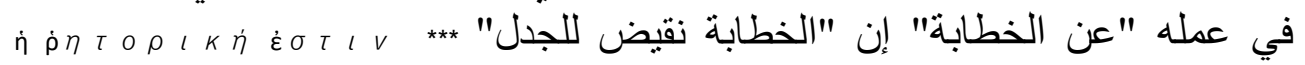

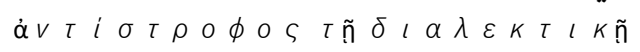
على أساس أن الخطابة تستخدم الفرضيات والألهات الأوات ذاتها، ومنها: الاستقراء

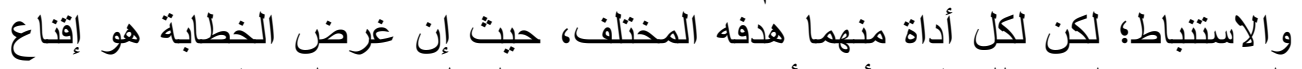

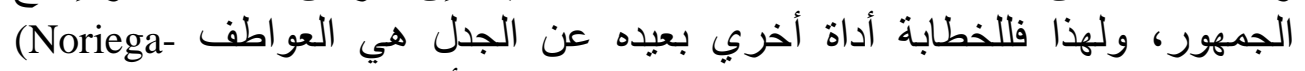

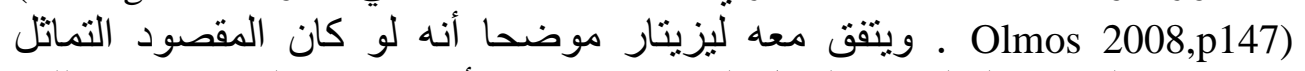
فسيكون هناك استحالة لوجود الجمل الخاطئة. فقد فرق أرسطو بين الو اقع وتعبير اللغة الغة عن هذا الو اقع (Lesetar 1998,p23).

ومن النقد الموجه إلي نظرية أرسطو في اللغة افتراضها أن الن التصنيفات التهات العقلية

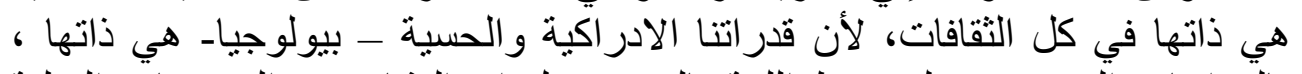

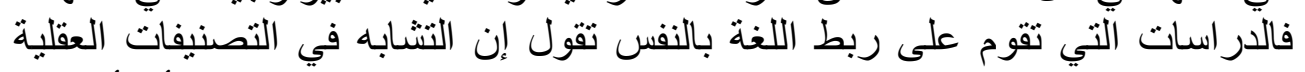

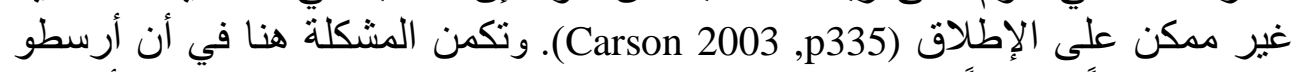

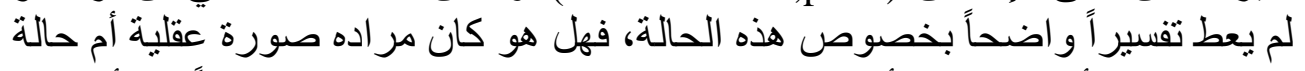
إدر اكية؟ كما أنه لم يوضحاً أن الحالة الداخلية تماثل المظهر الخارجي، فضلاً عن أن أن 


\section{ولاء توفيق فرح}

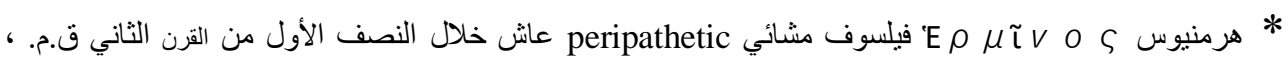

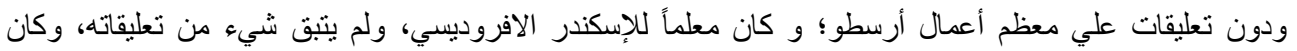

بويثيوس في تعليقاته على أعمال أرسطو يشير إليه. Aristotle, $\Pi \varepsilon \rho i \sigma o \phi \iota \sigma \tau l k \tilde{\omega} V \dot{\varepsilon} \lambda \dot{\varepsilon} \gamma \chi \omega V .165 \mathrm{a} 6-19^{* *}$

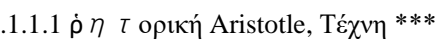

التماثل يحدث نأثيره في النفس تواً ومباشرة وليس من خلال وسيط أو ناقل لمحتوي

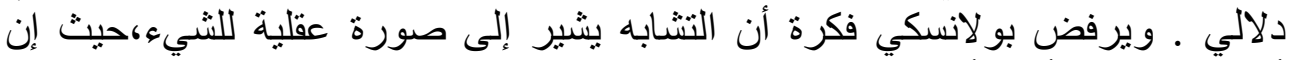

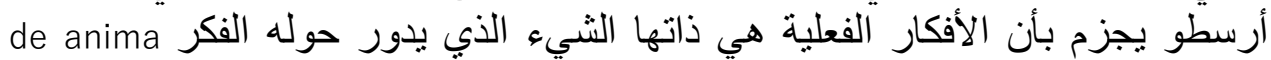

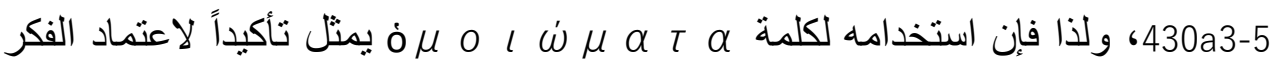

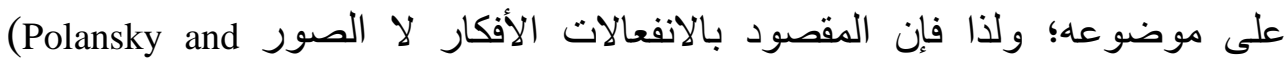

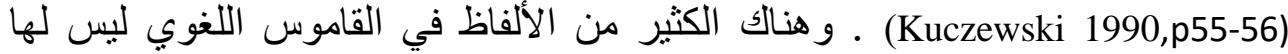

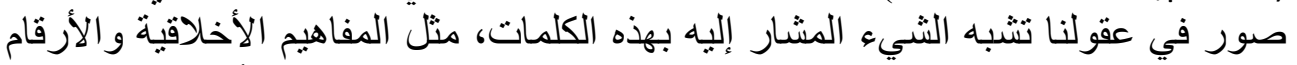

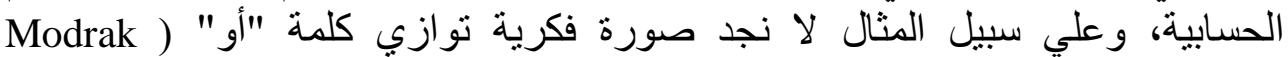

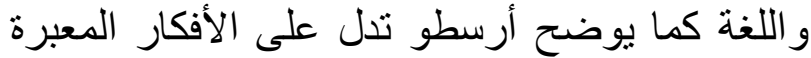

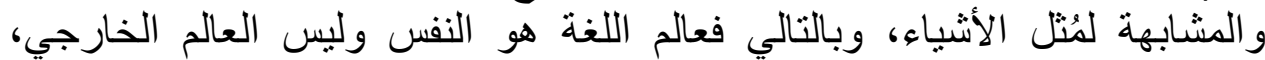

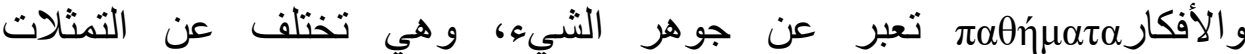

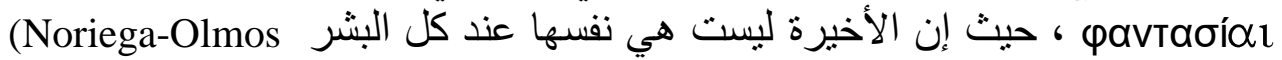

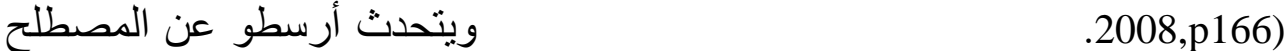
pavtaoía التفكير ، و هو بذلك يمد العقل بالصورة العقلية التي تجعله قادر ا على التفكير ، ومثل هذه العملية العقلية ضرورية لتكوين الرأي عند التفكير العلمي، و لإدراكية الكية الحقيقة فى حالة الفيرة

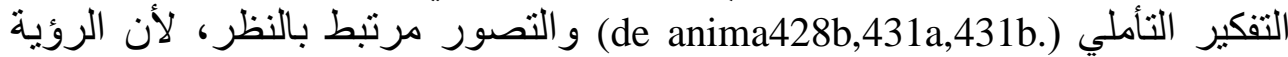

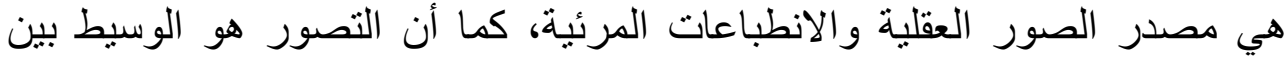
الإدر الك الحسي و العقل (Noriega-Olmos 2008,p115) ، فالإنسان بعمم الألفاظ التي الإني يستخدمها في الإشارة إلى أشياء منشابهة؛ مثال ذلك: إذا تعلم الإنسان أن ذلك الثكل

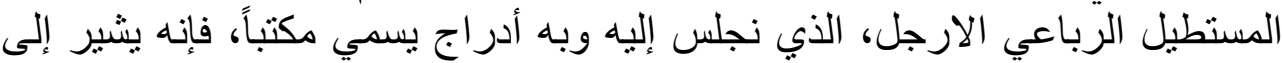
الأشياء المنتابهة فى المواقف المختلفة التي تندرج تحت الاسم ذاته الته ـ ويختلف هذا التفسير عن التفسيرات التقليدية التي تعتبر الأفكار وسيطاً لتعبير اللغة فنة عن العالم الخارجي (Lewis 2011,p355)

يري كينج أن الافكار

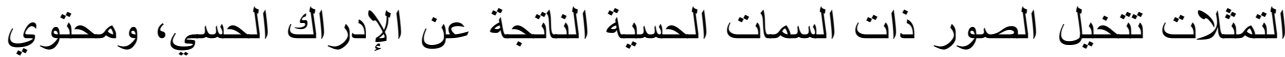

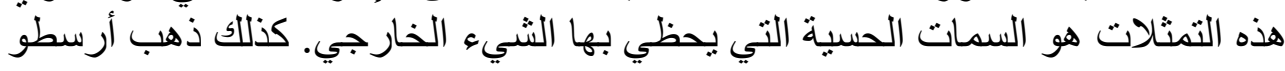


إلي أن الأفكار

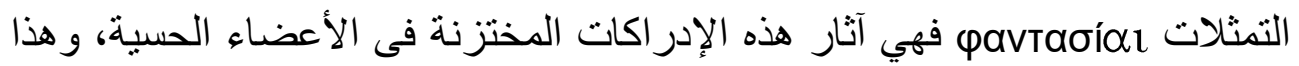

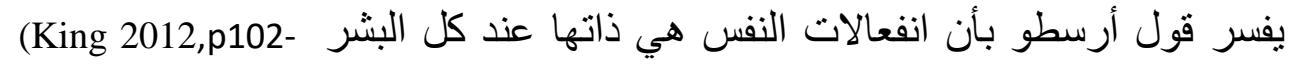

وكلمة ه من القدرة الادراكية إلى القدرة العقلية، وبالتالي لا لا نستطيع النفس أن تفكر بدونها

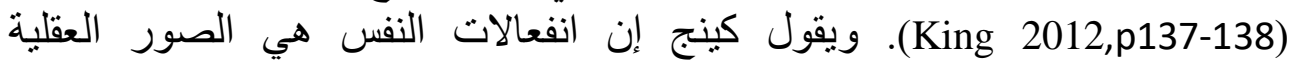

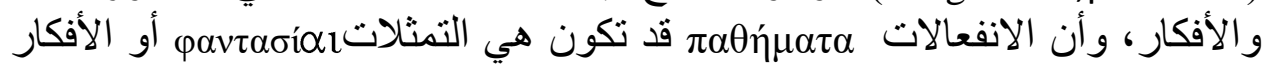

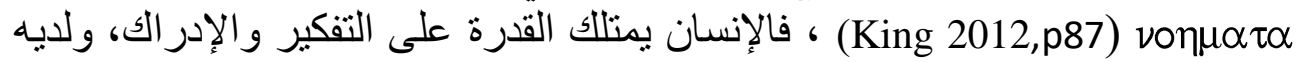

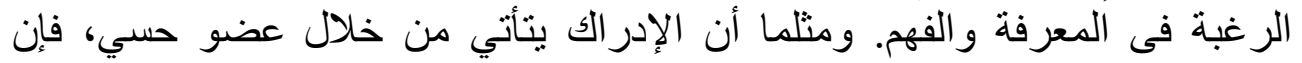

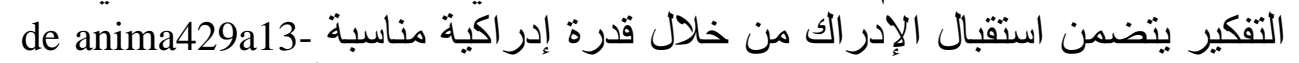

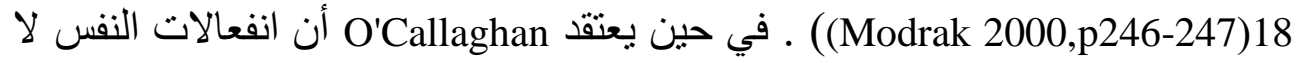

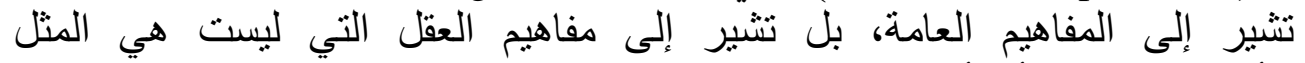

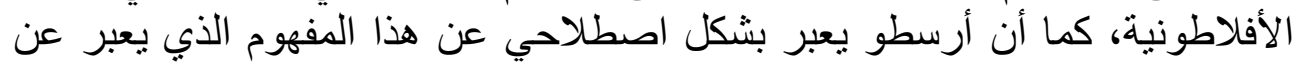
طبيعة الاثنياء المفردة (O'Callaghan 1997,p507).

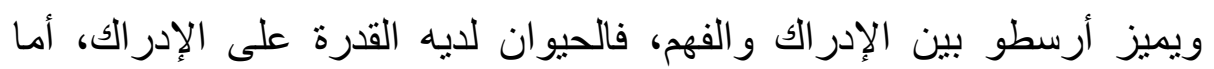

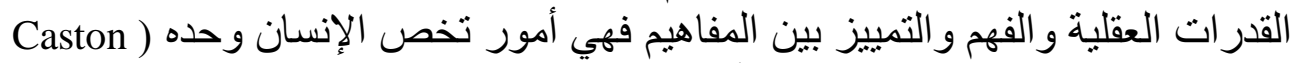

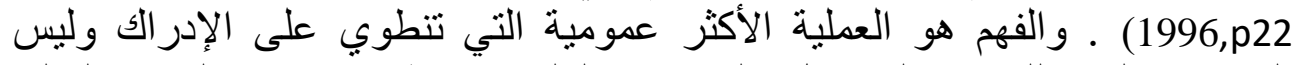

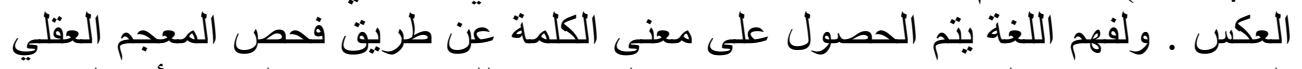

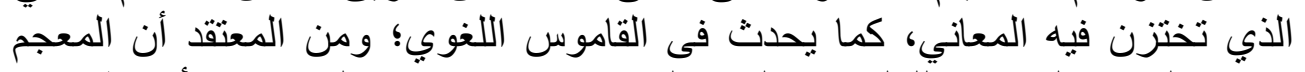

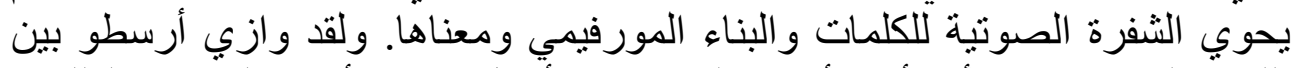

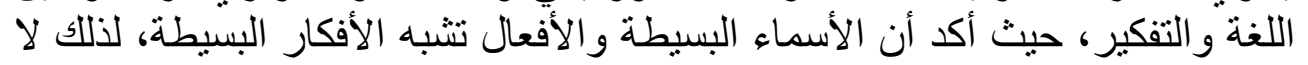

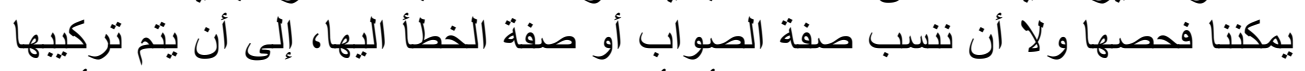

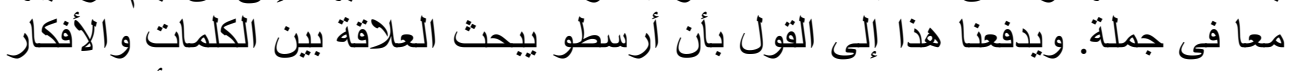

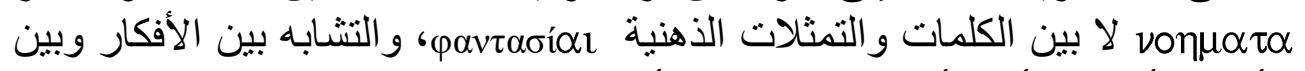

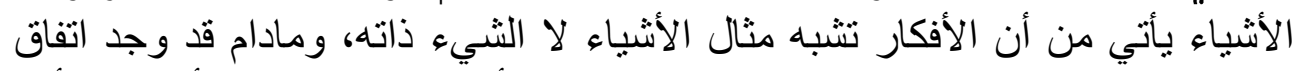

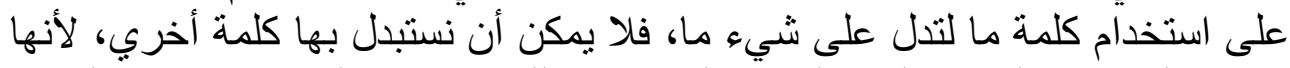

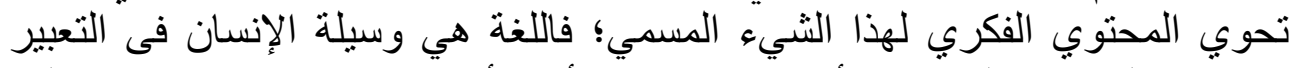

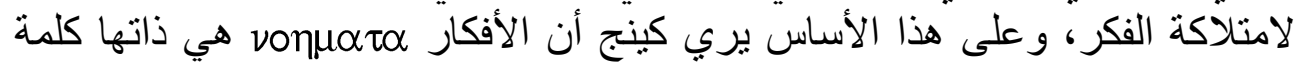
.(King 2012,p92-93) $\pi \alpha \theta \dot{\eta} \mu \alpha \tau \alpha$ 


\section{ولاء توفيق فرح}

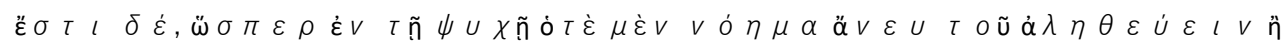

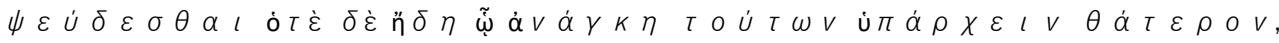
oü $\tau \omega k \alpha i \dot{\varepsilon} v \tau \tilde{n} \phi \omega v \tilde{n} \cdot \pi \varepsilon \rho i \gamma$ à $\sigma u \dot{v} v \theta \varepsilon \sigma l v k \alpha i \delta l \alpha i \rho \varepsilon \sigma i v \dot{\varepsilon} \sigma \tau l \tau \dot{o}$ $\psi \varepsilon \tilde{u} \delta \dot{o} \varsigma \tau \varepsilon \quad k \alpha \grave{i} \tau$ ò $\dot{\alpha} \lambda \eta \theta \dot{\varepsilon} \varsigma$.(De interpretatione16a10-14)

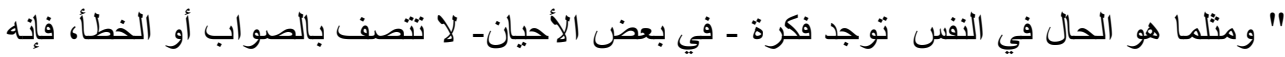

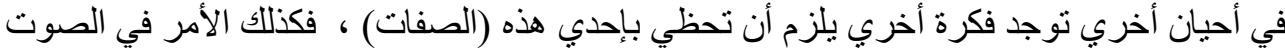

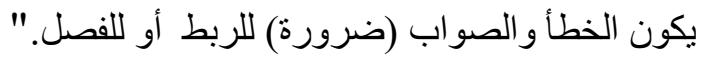

وكل المخلوقات الحية لديها مقدرة فطرية على الإدراك الحسي، وبعض هذه

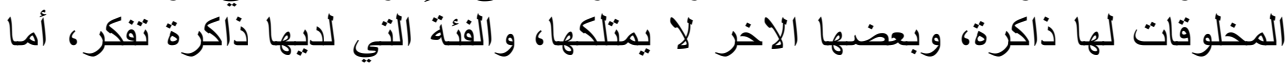

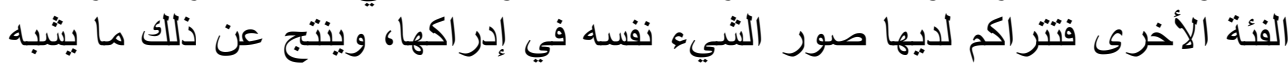

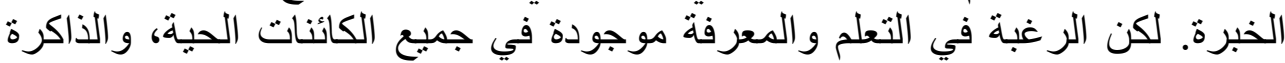

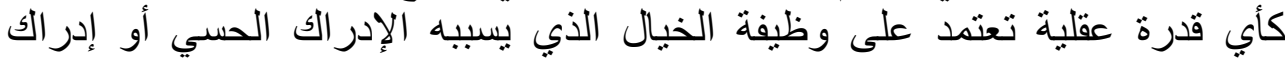

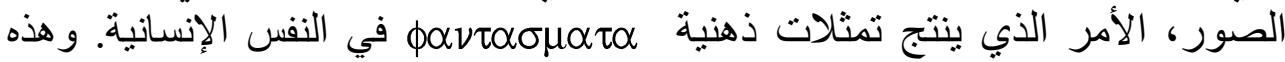

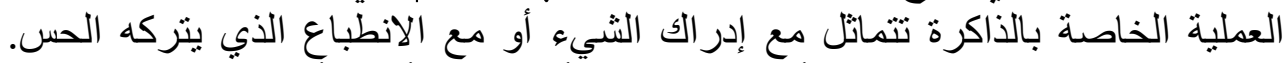

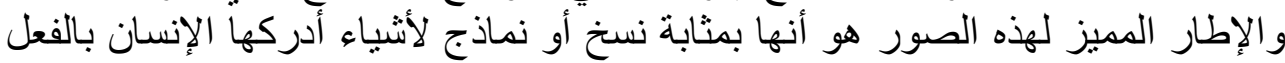

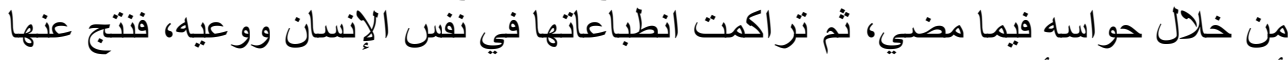

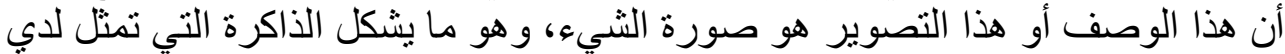

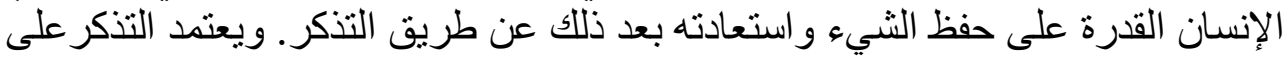

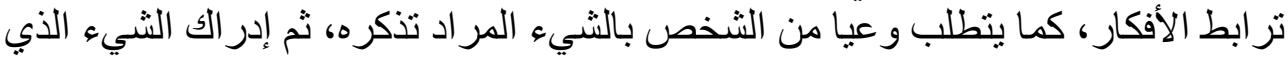

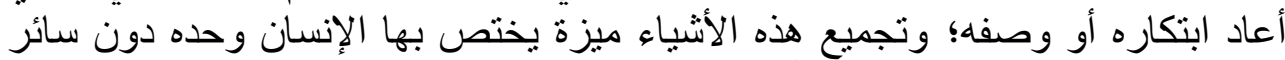

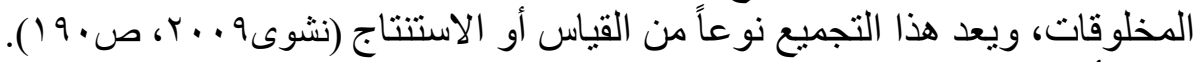

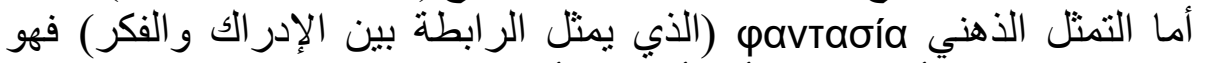

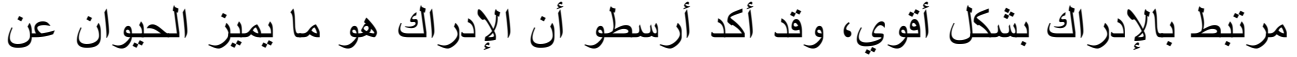

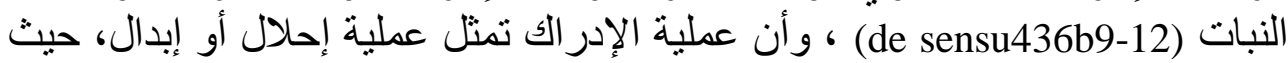

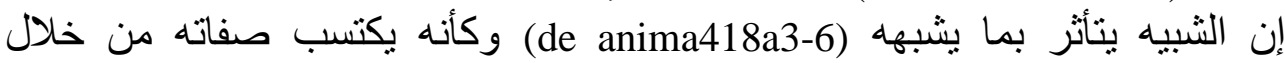
الحو اس الخمسة، وكذا من خلال ما يسمي بالحس المشترك* (de anima418a17-22) .

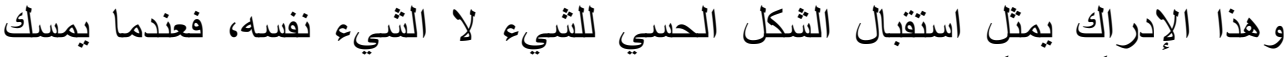

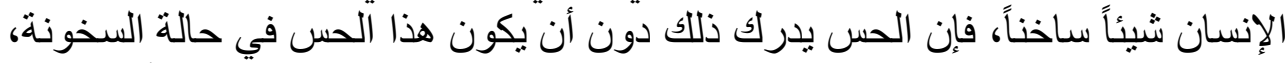

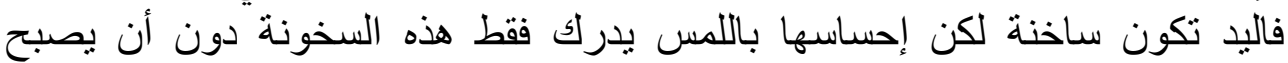

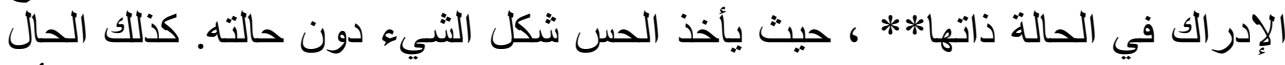

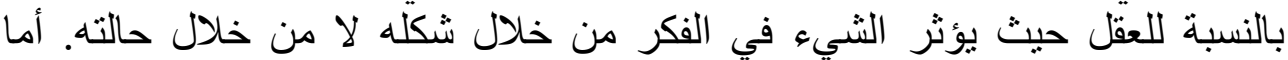

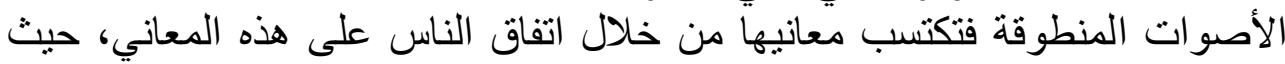

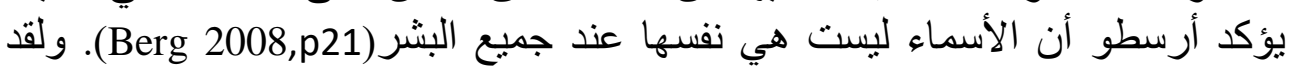




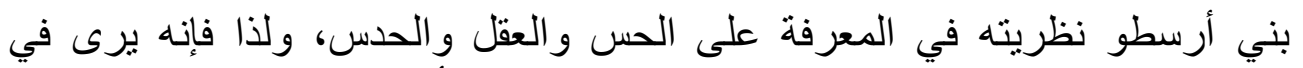

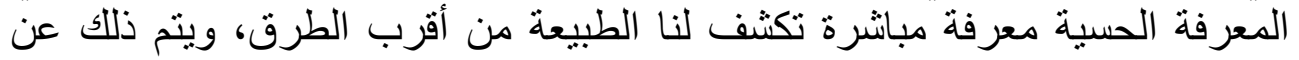

*الحس المشترك هو الذي يتيح وحدة الإحساس: فلو لم يكن هناك حسّ مشترك لتكاثر الإدر اكت بعدد الحو اس. فعلى سبيل

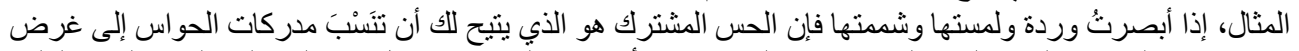

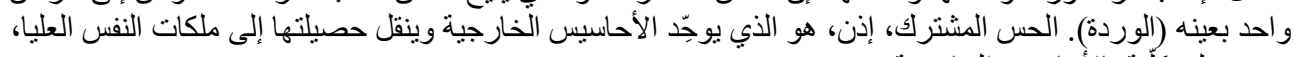
وهو يتعلق كِلية بالأحاسيس الخارجية.

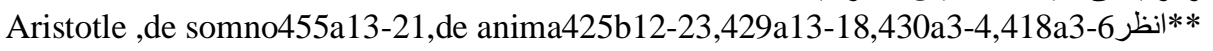
طريقين: الإحساس الظاهر بواسطة الحواس الخمس، والإدرالك الباطن. و و ينتج

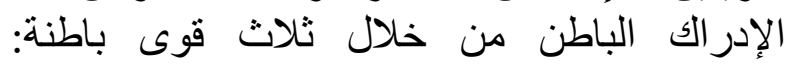
ا ـ الحس المشترك: وهو مركز تتجمّع فيه صول بالطنة المحسوسات بما يسمح بالتآلف و المقارنة بينها.

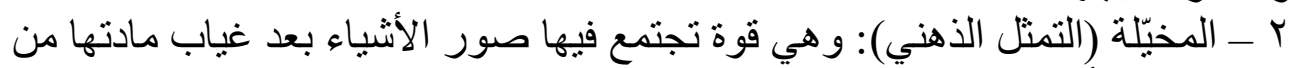

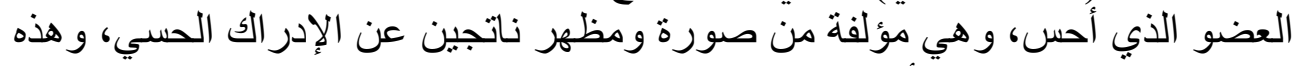

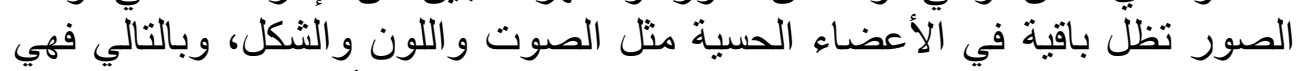

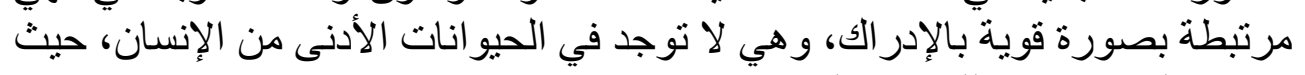

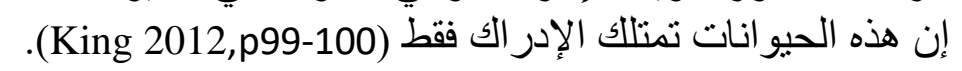

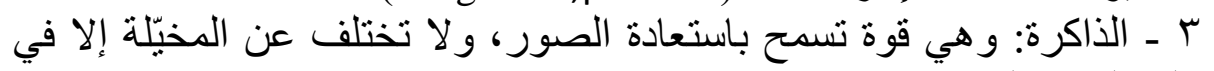

$$
\text { نسبتها إلى الزمن الماضي. }
$$

و الإدر الك دائما صحيح لأنه يعتمد على آلية عقلية بيولوجية، فى حين أن المخيلة

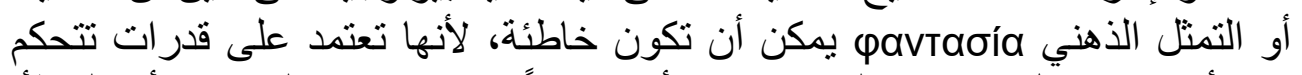

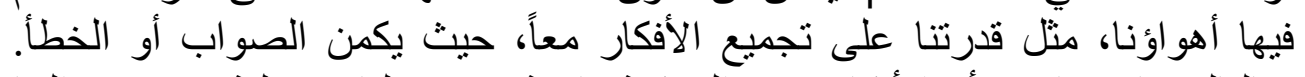

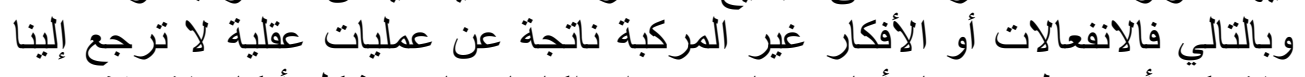

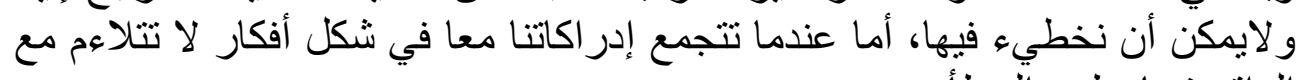

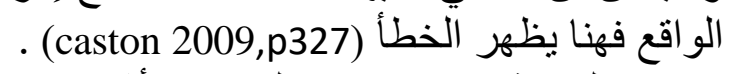

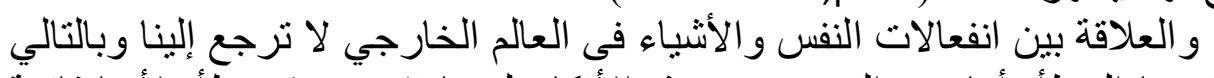

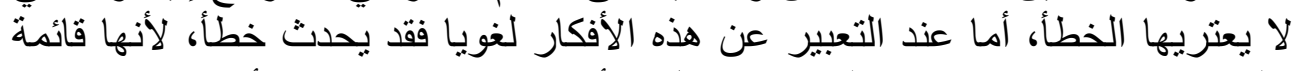

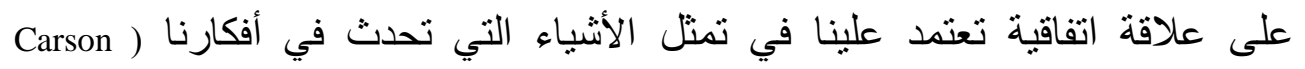

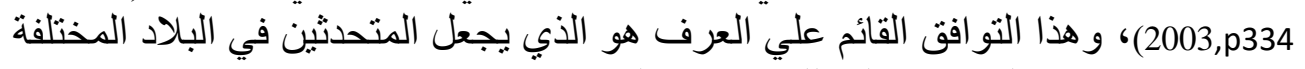

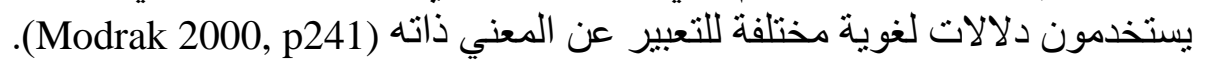
ولقد ميز أرسطو في عمله "في التفسير" (الجزء انفعالات النفس S 


\section{ولاء توفيق فرح}

النفس in de ( أخرى فى النص، بل يندر استخدامهما عند أرسطو. ويخبرنا ألكسندر في تعليقا

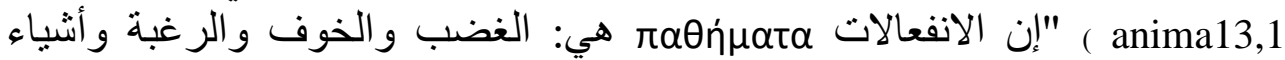
مشابهة لذلك" (Carson 1996,p115). لكن ما هو الفرق بين التعبيرين في اللغة

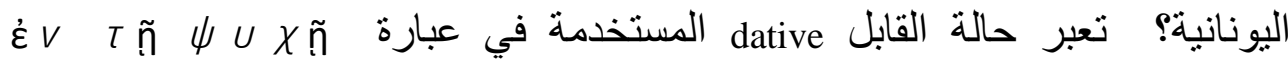
" $\pi \alpha \theta \dot{\eta} \mu \alpha \tau \alpha$ " المضاف إليه المستخدمة في

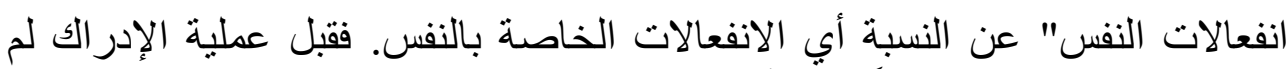

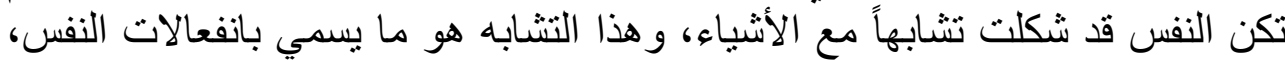

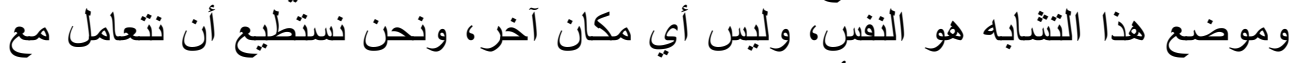

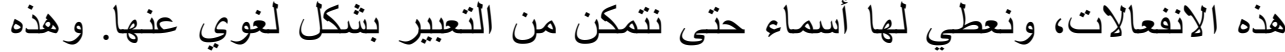

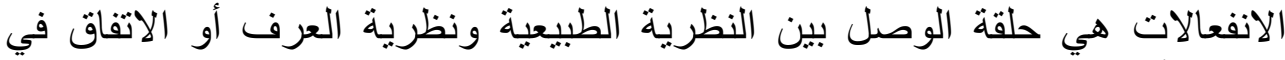

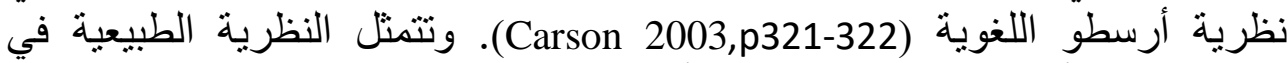

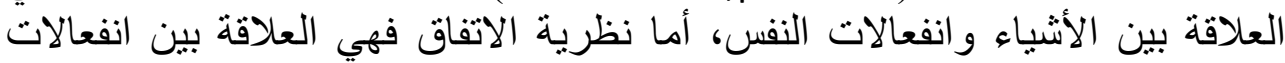

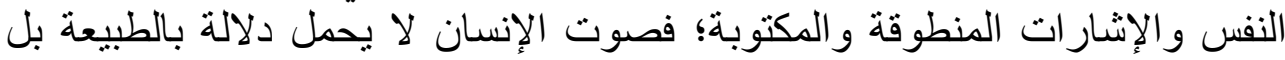

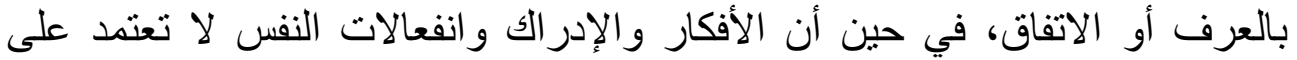

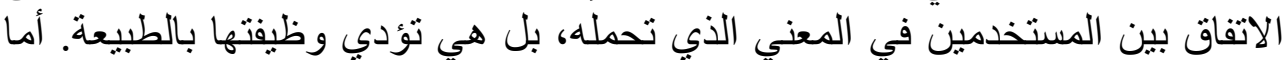

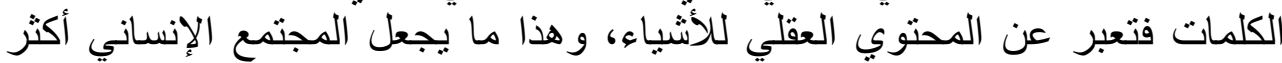

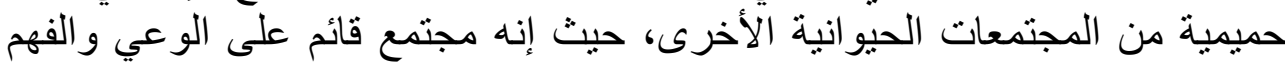
و القدرة على التو اصل من خلال اللغة (189-189 (Berns 1976,p187).

ويمكن القول بأن أرسطو لم يضع علاقة مباشرة بين الأشياء الواقعية الحقيقية

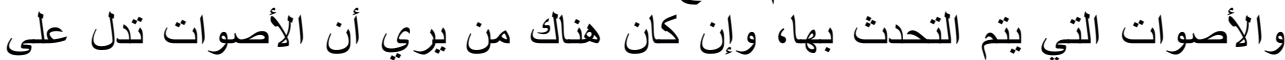

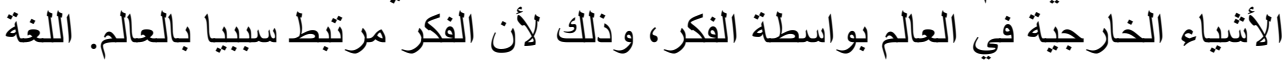

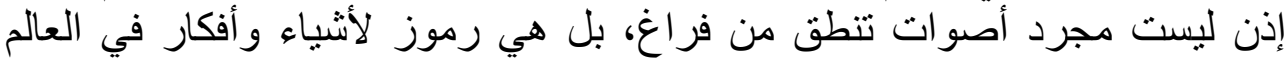

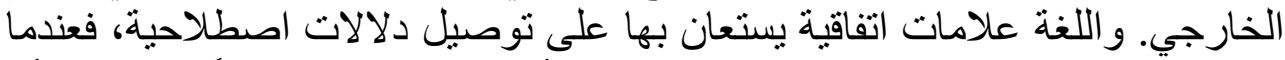

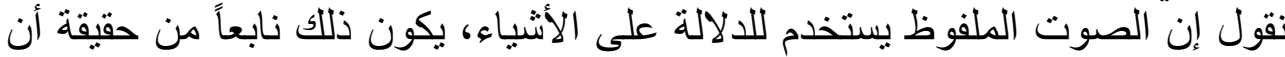

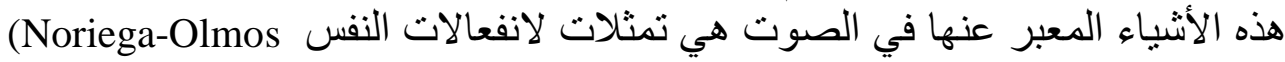
2008,p14)

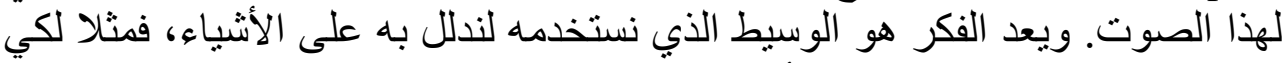

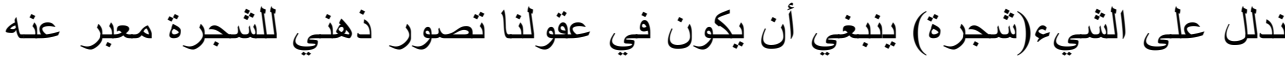
بكلمة شجرة (Noriega-Olmos 2008,p153). 


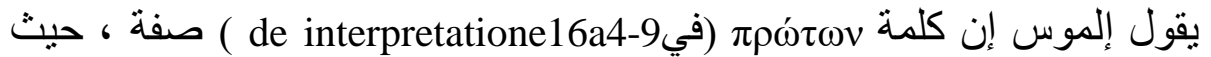
إنها تثنير إلى أن الألفاظ تدل على النى الثكل المثالي FORM للأشياء أي الطبيعة

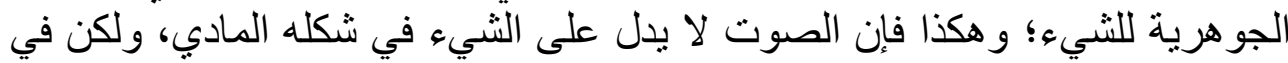

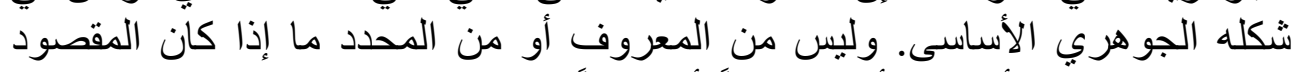

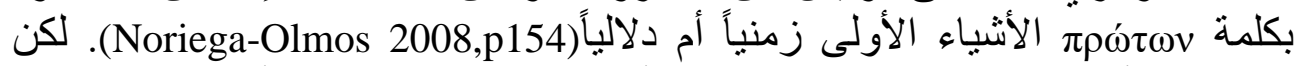

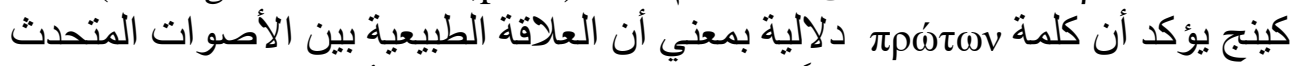

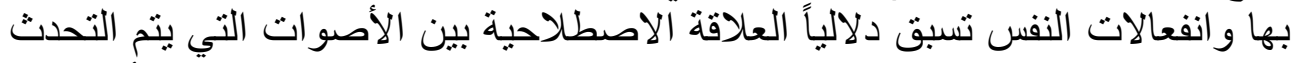

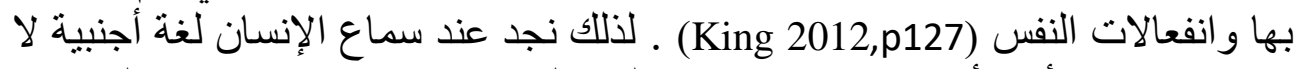

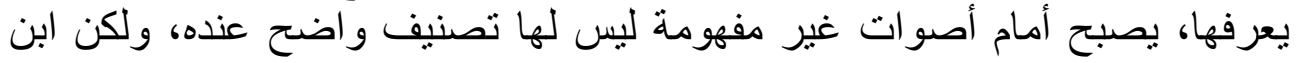
اللغة العارف بها لا يسمع هذه السلسلة الصوتية فحسب، بل يميز لهئ مكوناتها ويفهر

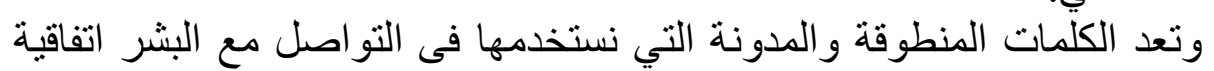
محتو اها الدلالي.

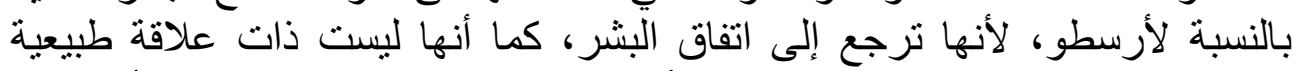

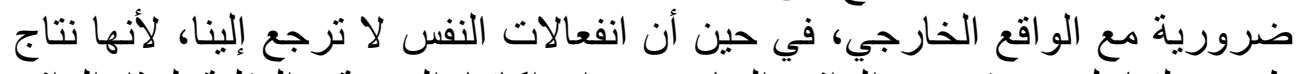

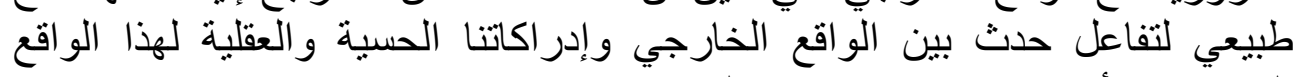
الخارجي، وأنها هي ذاتها عند جميع البشر (O'Callaghan 1997,p510,514).

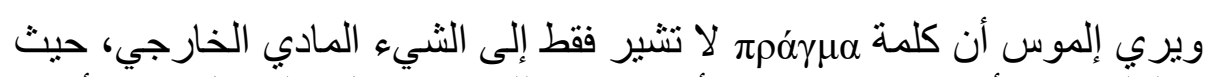

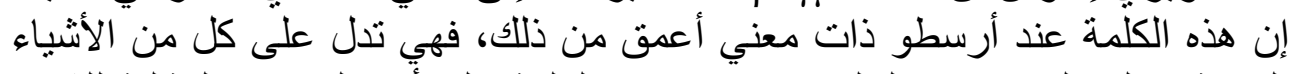

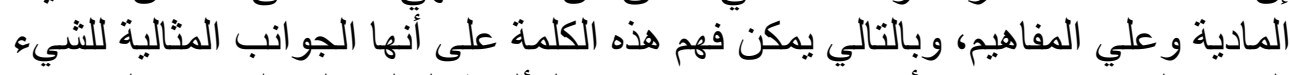

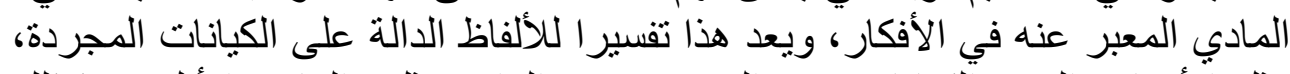

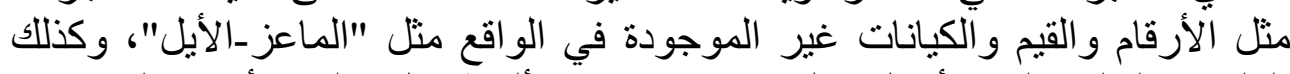

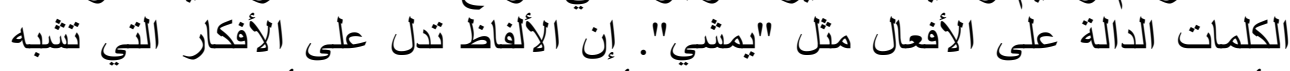

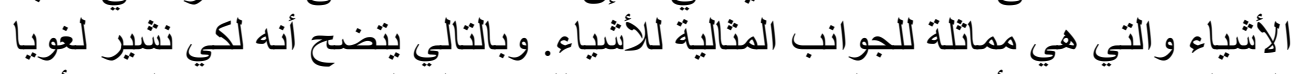

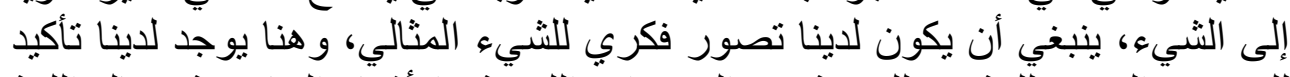

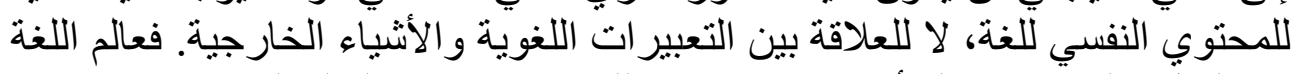

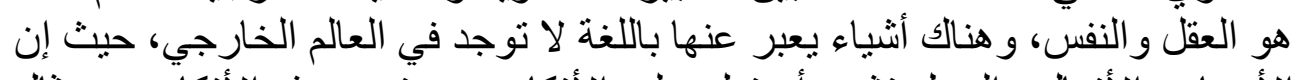

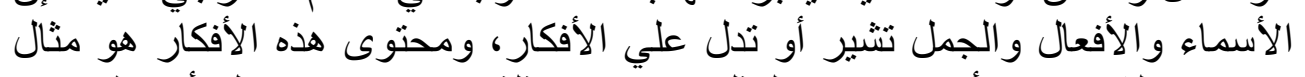

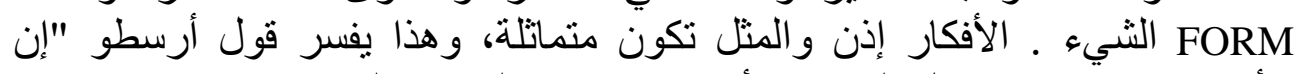

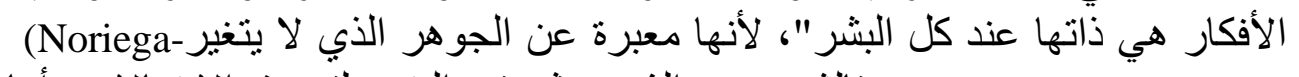

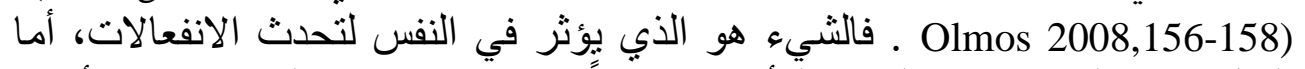

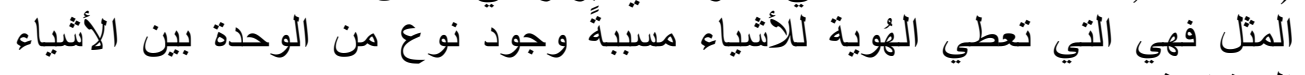
المتنابهة (O'Callaghan 1997,p542). 


\section{ولاء توفيق فرح}

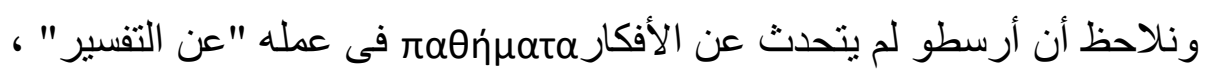

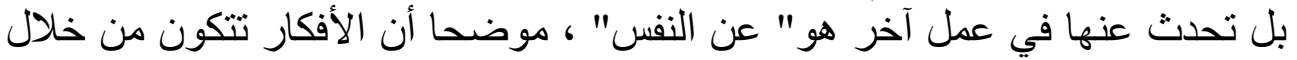

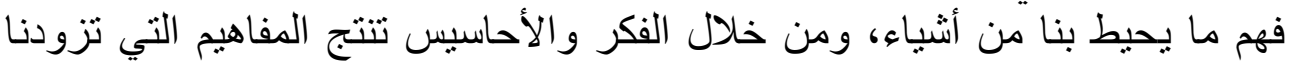

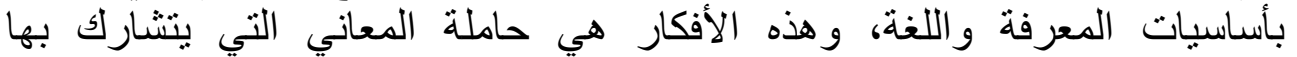
المتحدثون في اللغة ـ ويعتبر أرسطو أن الإدر الك و التفكير شيئان مختلفان الأني

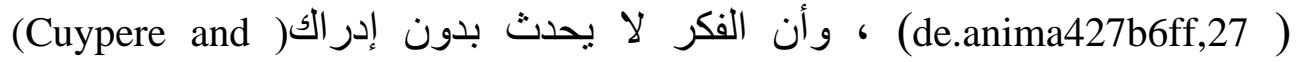

.(Willems 2008,p321,323

يقول إلموس إن الفكر هو ذاته عند كل البشر لأنه يعد تمثناً لمثال الأشياء أي الثي

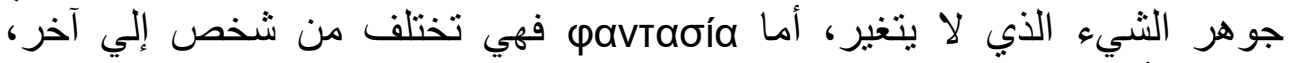

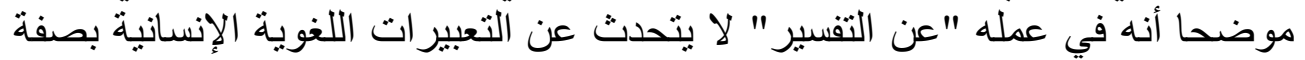

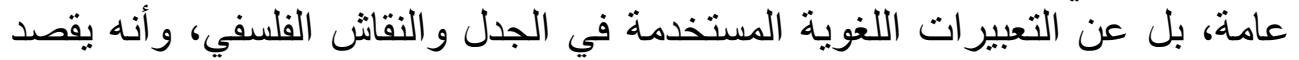

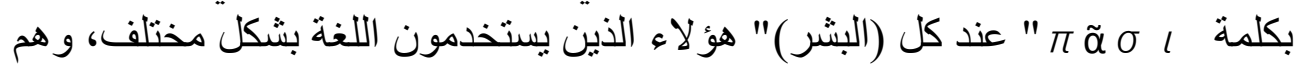

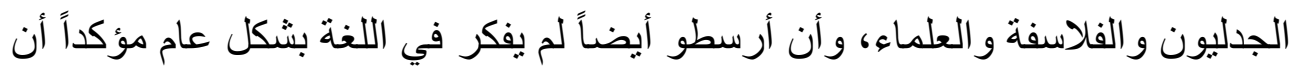

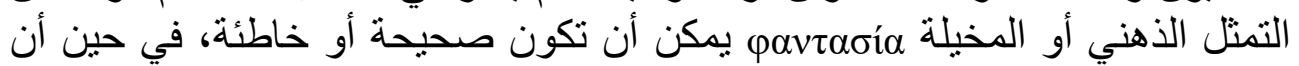

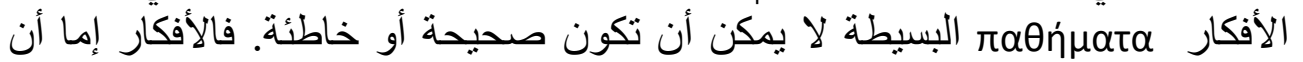
تعبر عن الثيء وإما أن لا تعبر عنه على الإطلاق، أما التمثل الذهني الذهن أو أو المخيلة

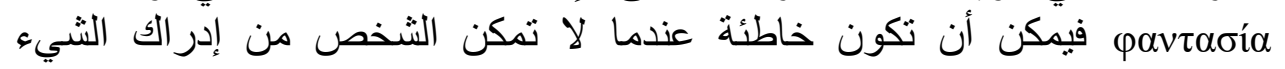

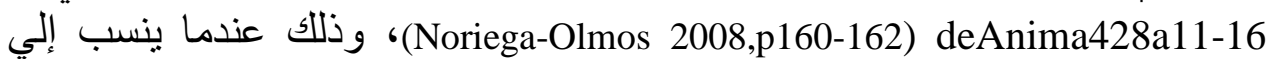

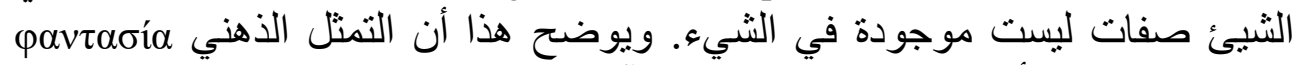

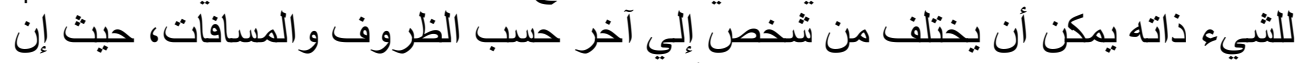

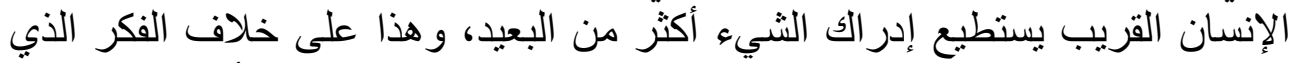

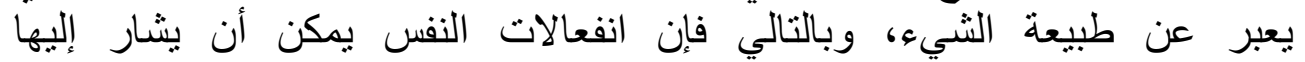
بالأفكار .(Noriega-Olmos 2008,p164)

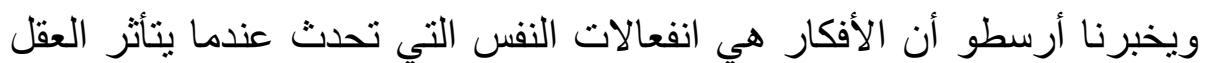
بالثيء فئكون العقل حينئذ أنموذجا لهذه الأشياء الفعالاء، وتكون الأفكار أنموذج لهذه الأشياء

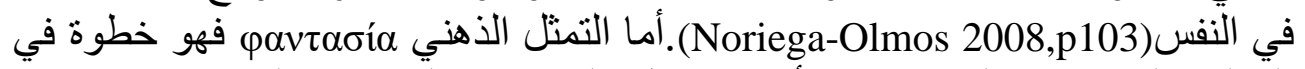
العملية التي تقود إلى إنتاج الأفكار، فكل الحيوانات لديها إدراكي الك حسي

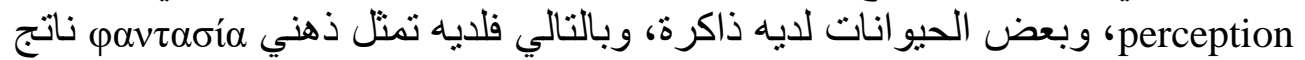

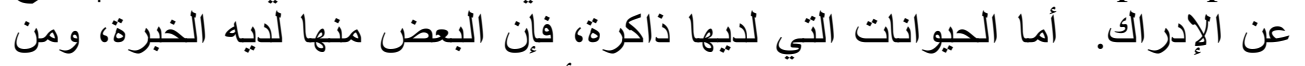
بينها-- الإنسان الذي يمتلك العقل. فالحيو انات الأرقى من غير هات الدان لإيها القدرات العقلية 
التي يمتلكها من هو أقل منها في الرقي بالإضافة إلى قدرات عقلية أخري تميزه عنها جميعاً (Noriega-Olmos 2008,p105).

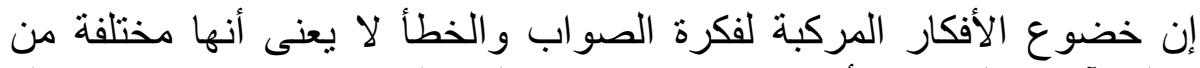

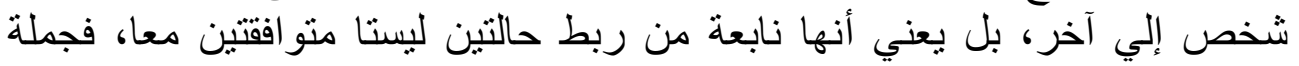

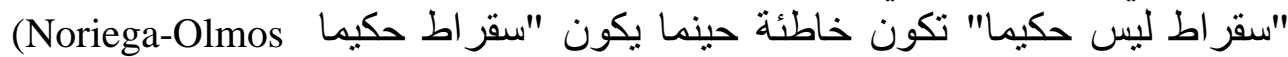
.2008,p165)

و السؤ ال الذي ينبغي الإجابة عليه الآن هو: ما المقصود بهاتين العبارتين

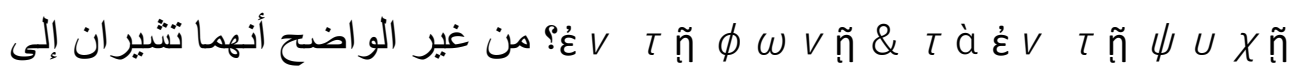

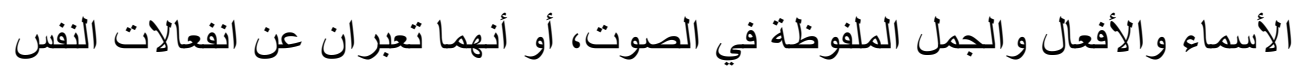

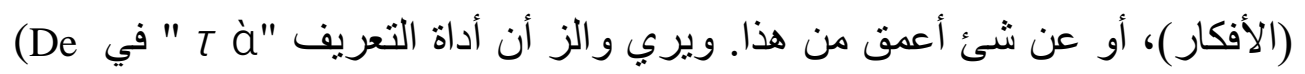

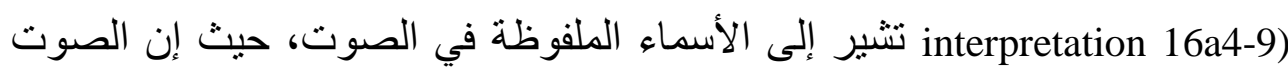

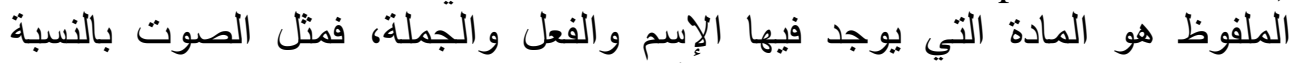

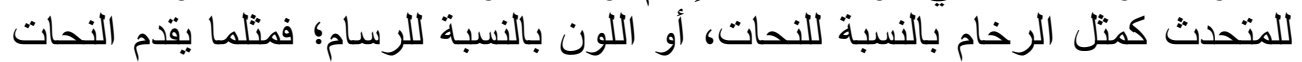

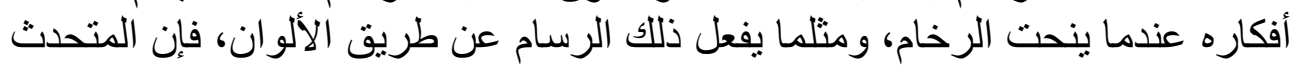

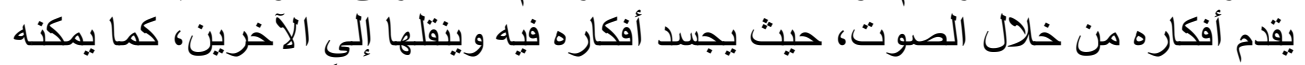

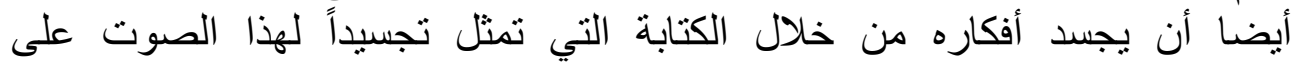
الورق(Walz 2006,p241-242).

ويؤكد بو لانسكي أن المقصود بالدلالة ليس في كونها علاقة طبيعية بل علاقة

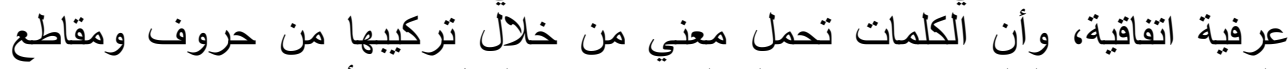

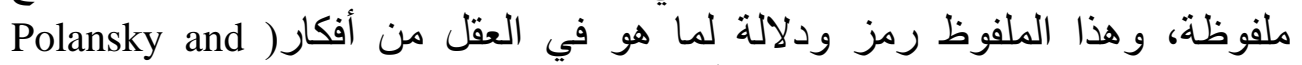

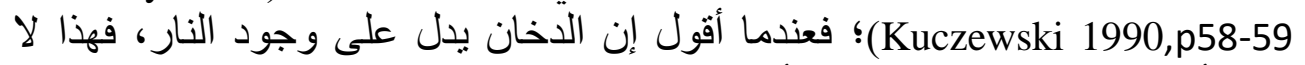

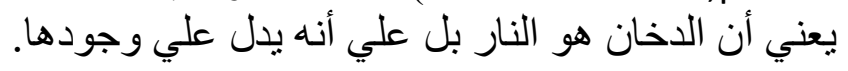

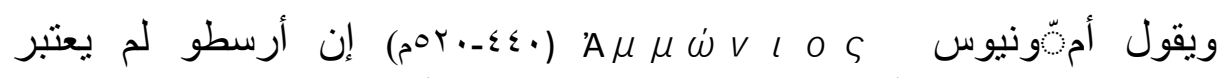

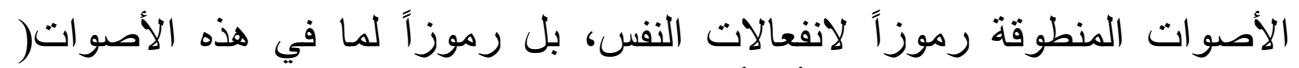

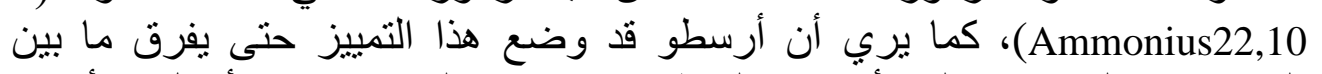

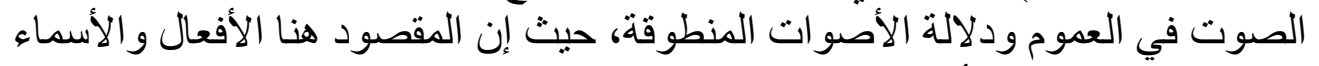

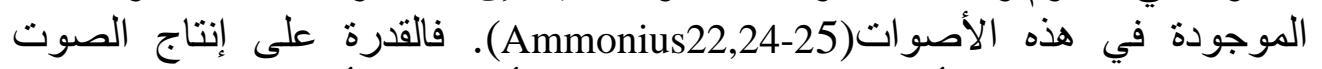

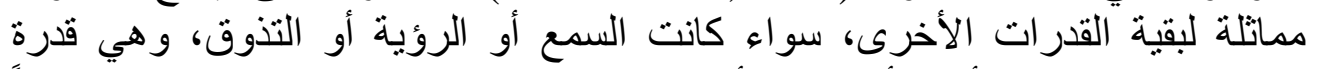

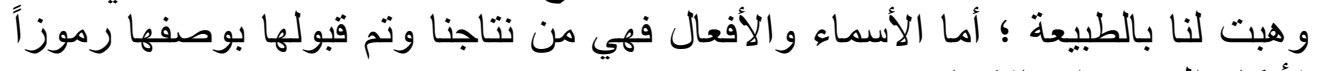
لأفكار النفس وانفعالاتها 


\section{ولاء توفيق فرح}

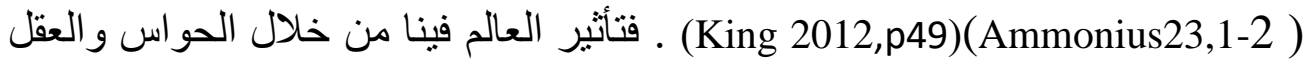
ينتج المفاهيم التي هي أساس اللغة والمعرفة(Modrak 2000,p51).

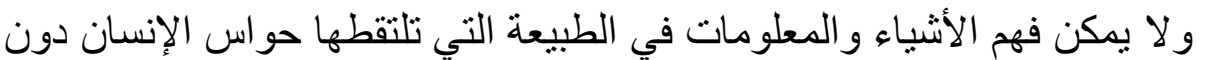

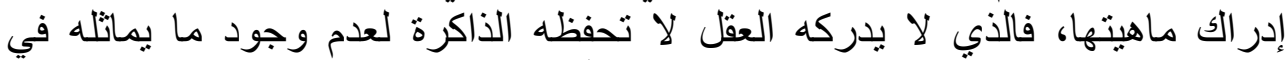

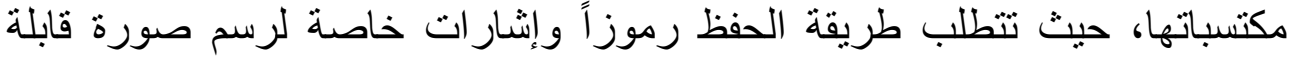

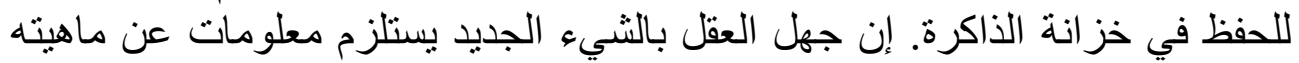

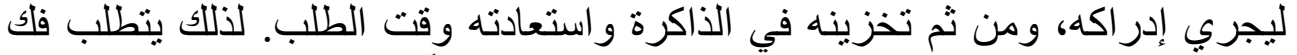

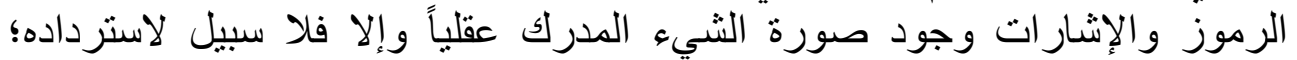

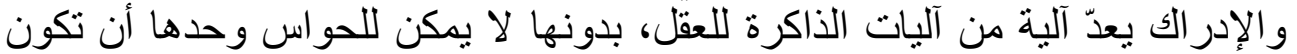

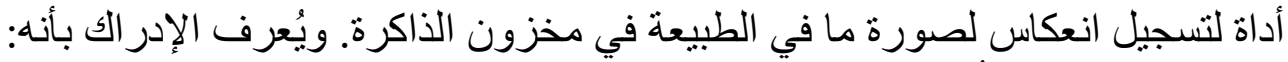

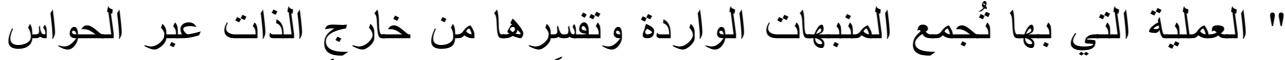

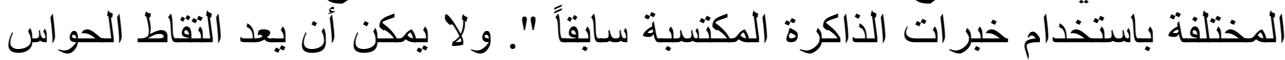

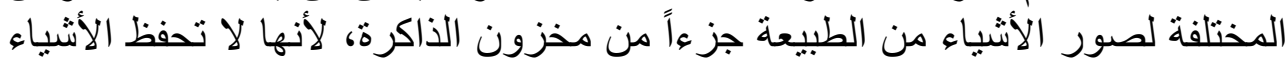

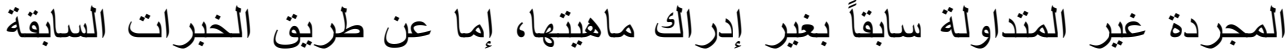

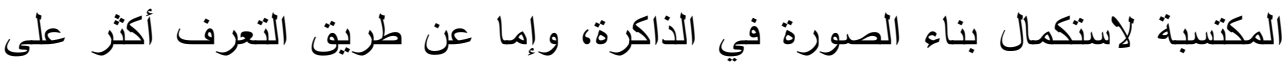

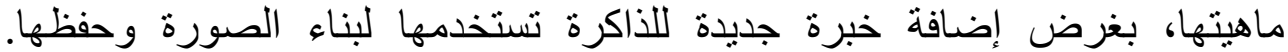

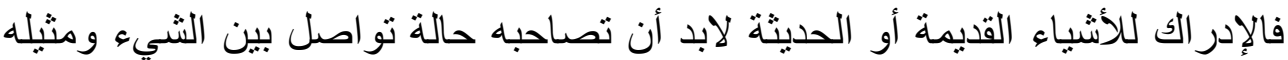

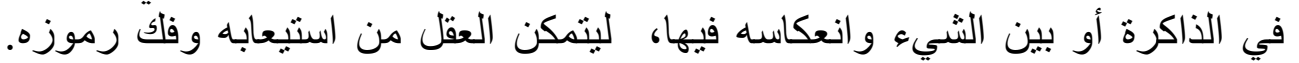

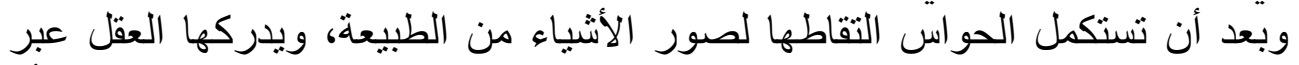

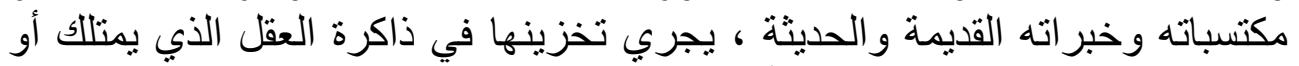

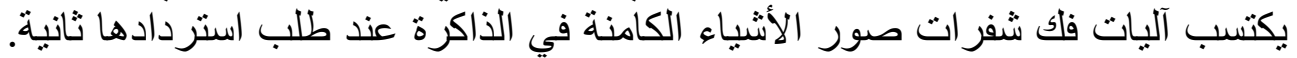

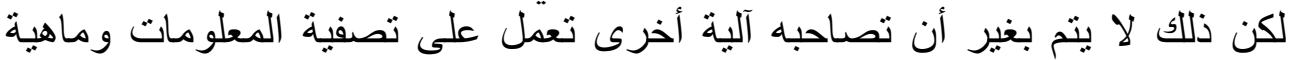
الأشياء التي صورتها الحواس المختلفة وجرى إدراكها لخزنها في الذاكرة .

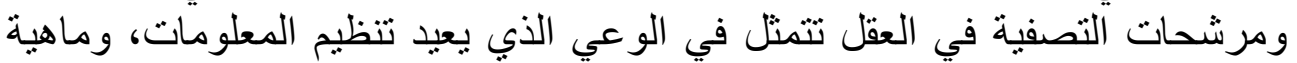
الأشياء وصور ها القديمة أو الحديثة ،على شكل أرشفة نو عية تحفظ في خز انة التهات الذاكرة

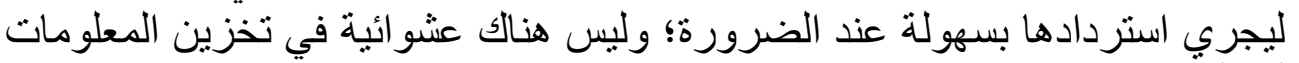
أو الأشياء وصور ها فئرداء في الذاكرة.

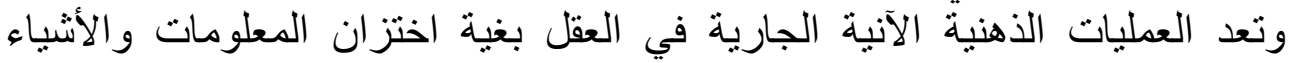

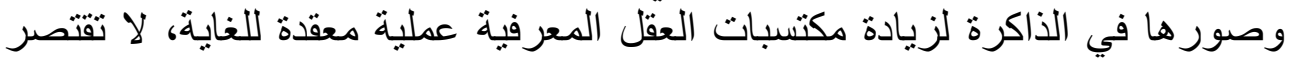

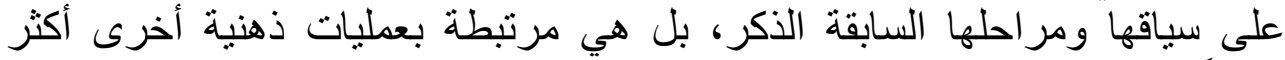

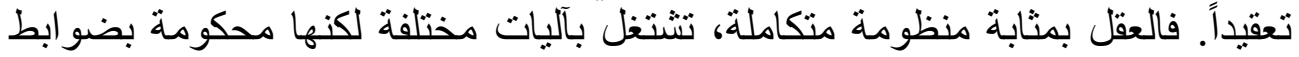
و إيعاز ات خاصة يصدر ها العقل وفق نظم معقدة لإنتاج فكرة جديدة. والعملية الذهنية 
هي جملة العمليات الواعية للتفكير، منل ربط كل فكرة تجري في مساره ومقارنتها

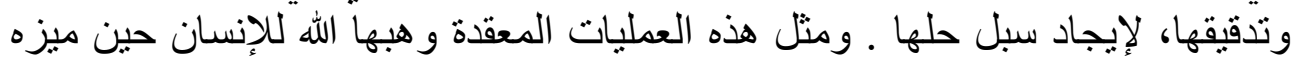

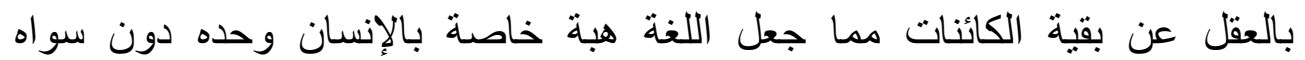
.(Polansky and Kuczewski 1990,p87-89)

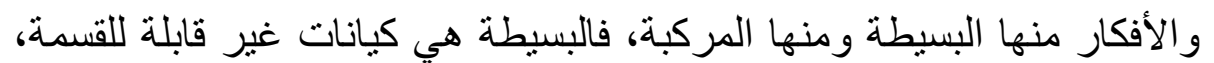

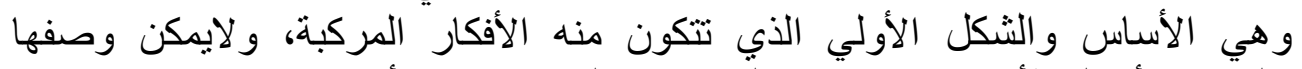

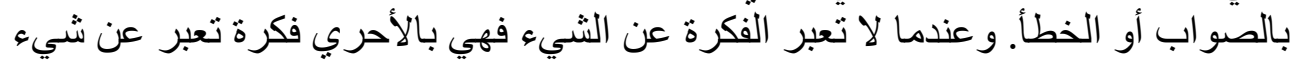

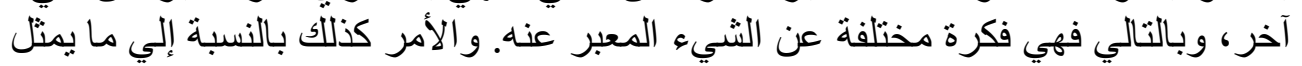

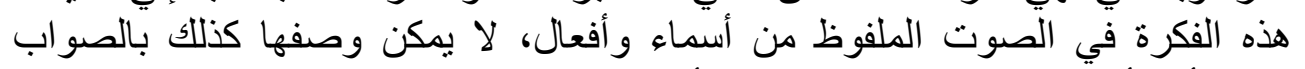

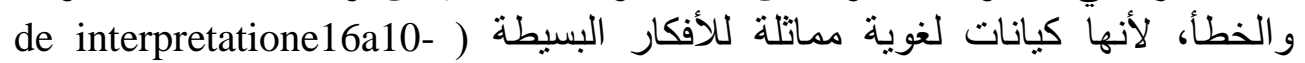
(19,16b19-25) ـ وينطبق هذا الأمر أيضا على الجمل غير التوكيدية، أي التي ليس بها لأليا

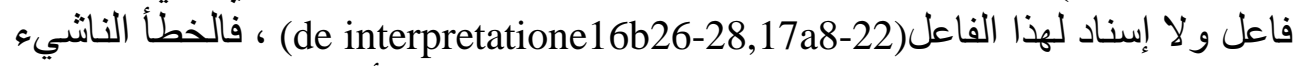

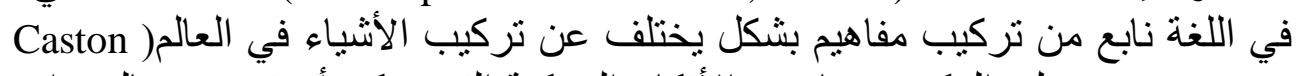

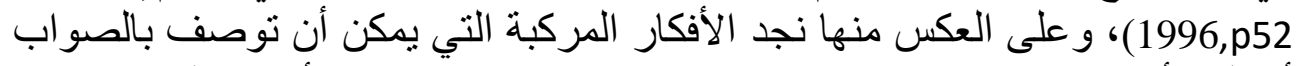

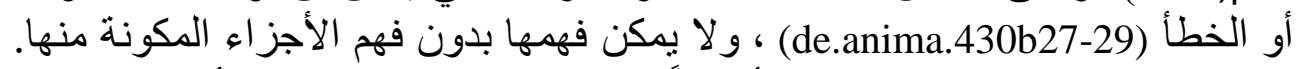

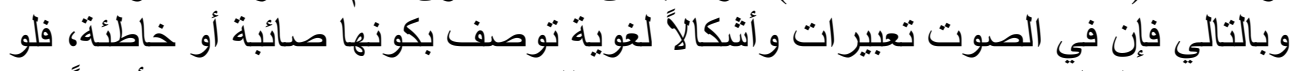

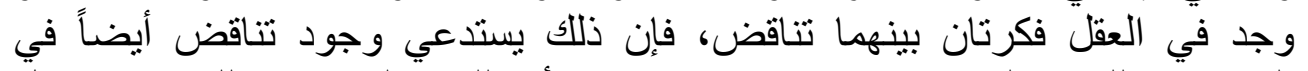

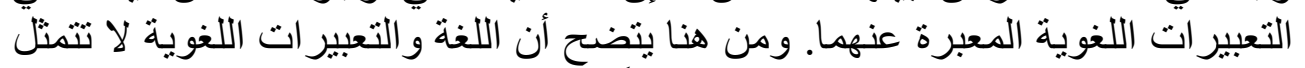

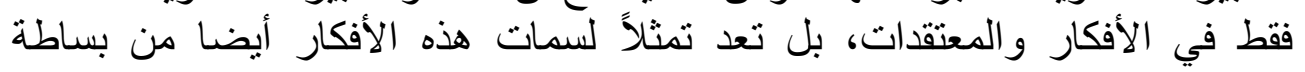

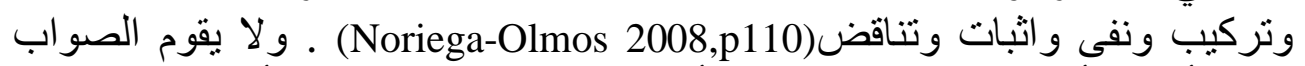

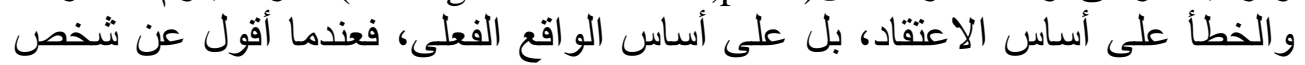

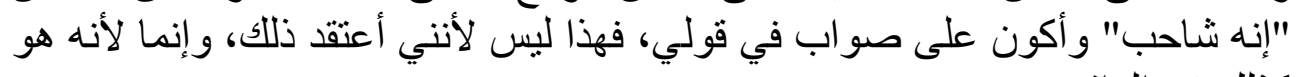
كذلك في الو اقع (Modrak 2000,p56).

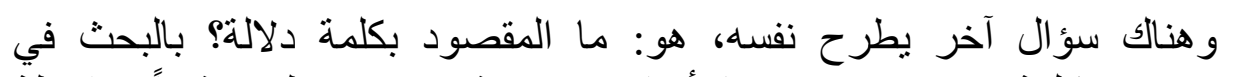

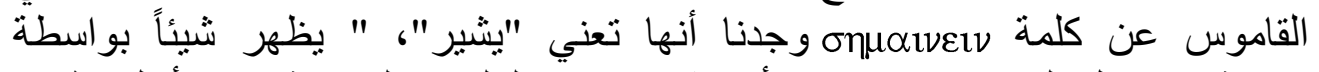

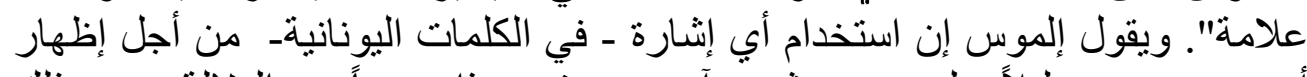

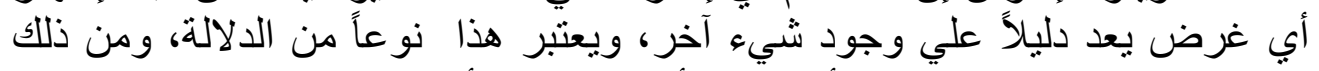

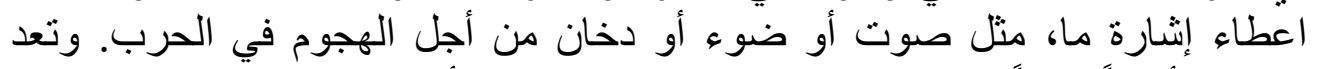

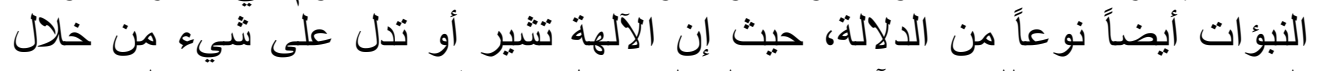

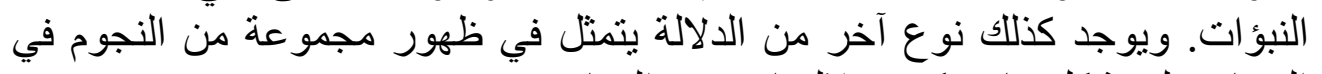

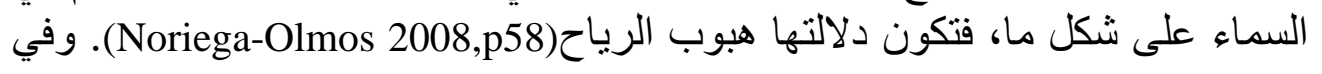




\section{ولاء توفيق فرح}

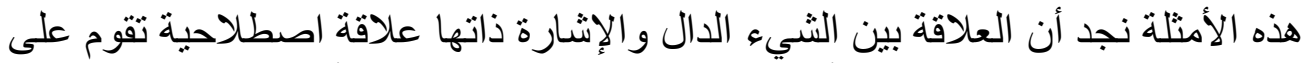

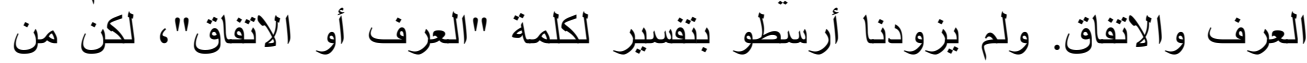

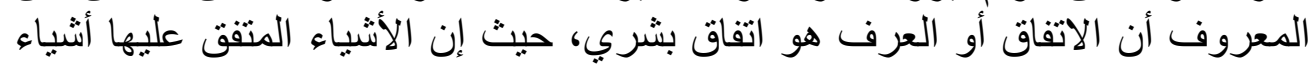

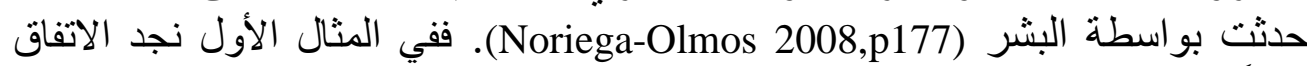

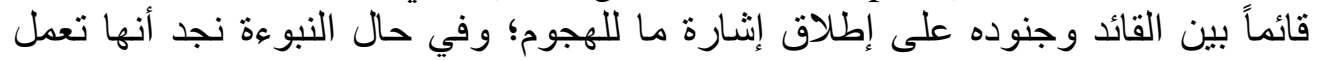

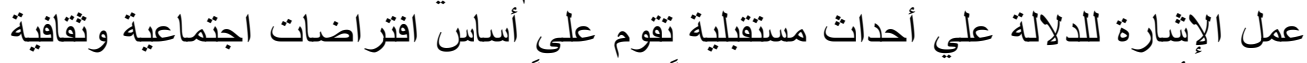

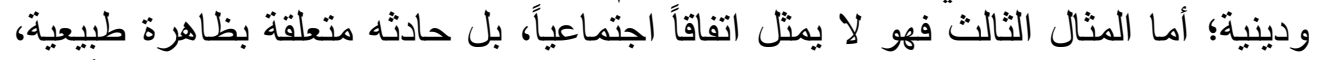

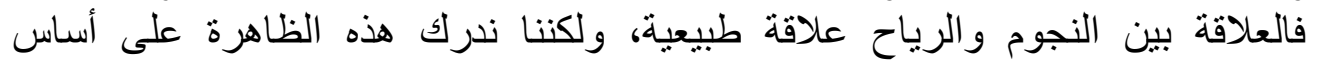
الملاحظة والتجربة والوعلي المعتمد على المعلى المعرفة أكثر من كونها اتفاقاً اجتماعياً

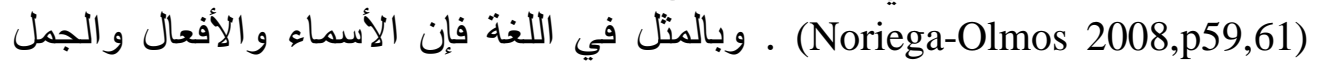

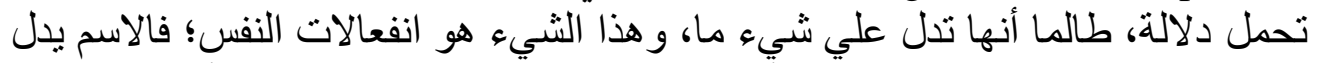

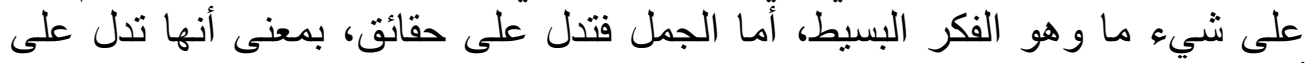

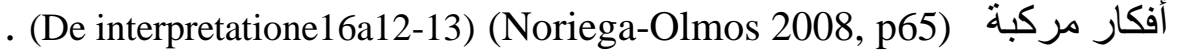

ويقول كارسون إن هنالك تعاقباً طبيعياً لتفاعلات سببية يبدأ من الأشياء مروراً

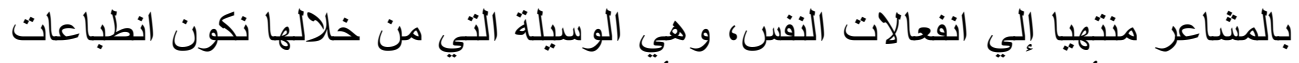

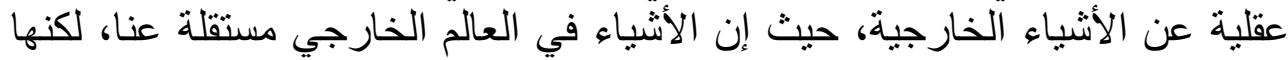

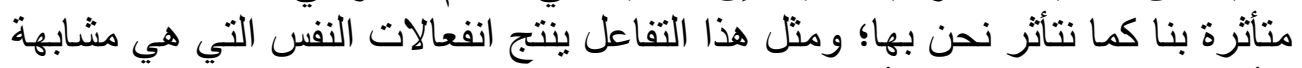

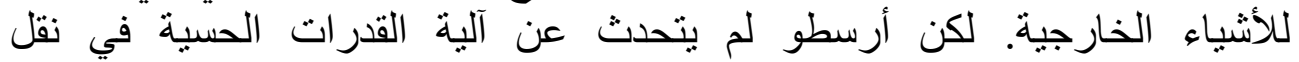
الإدر اك(Carson 1996,p121-122)، بل أكد أن إدر اكنا للشيء داء دائما صحيح

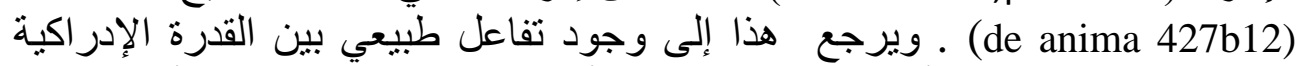

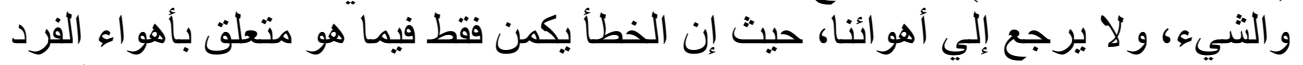
وقدراته. هنالك إذن اختاف بين التفكير والإدراك ( de anima417b16-28) فالأشياء

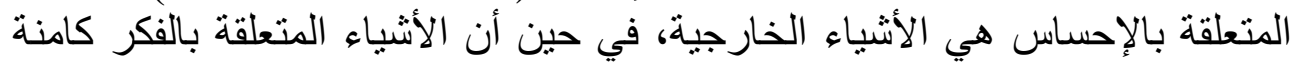

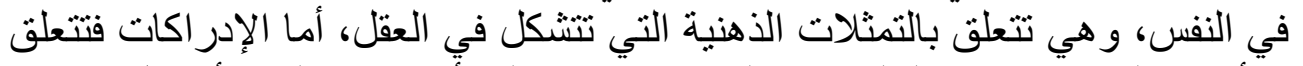

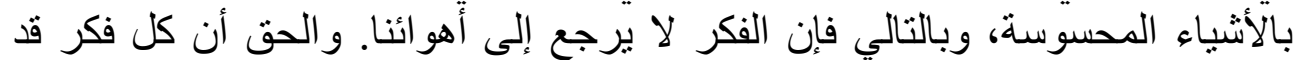

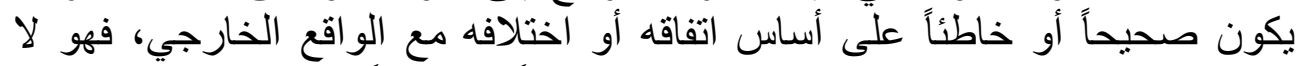

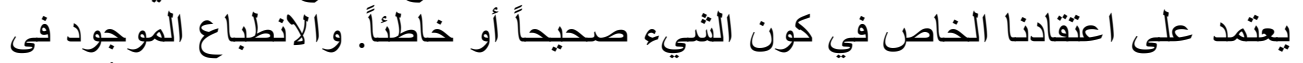

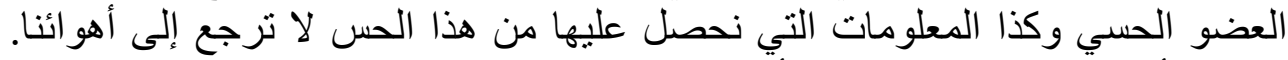

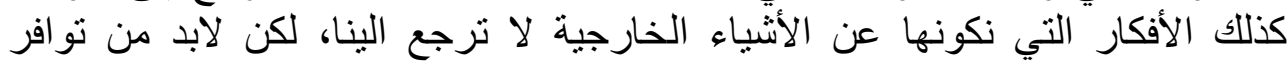

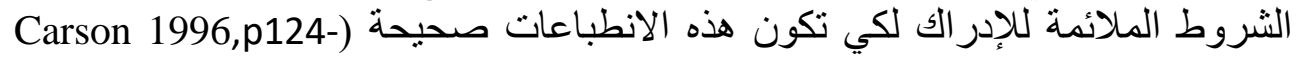


ouv $0 \dot{\eta} k \eta$

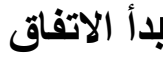

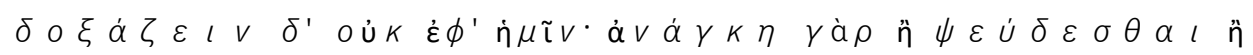
$\dot{\alpha} \lambda \eta \theta \varepsilon \dot{u} \varepsilon \iota v$. (de.anima427b21-22)

$$
\text { " لكن ليس في مقدورنا أن نشكل الأفكار (كما يحلو لنا) ، حيث إن من الضرورة بحري (أن نفكر) }
$$

و الخلاصة أن انفعالات النفس ليست هي التي تحدد تكوين التعبيرات اللغوية، التهاته

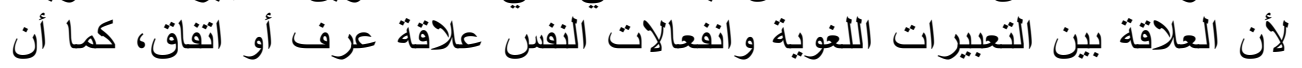

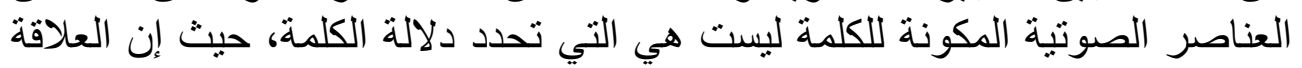

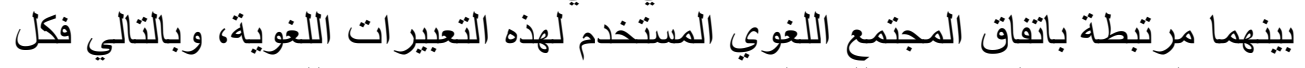

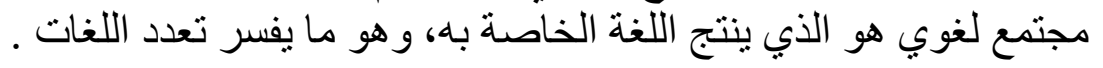

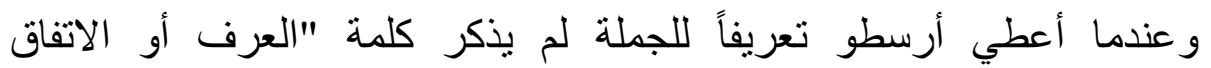

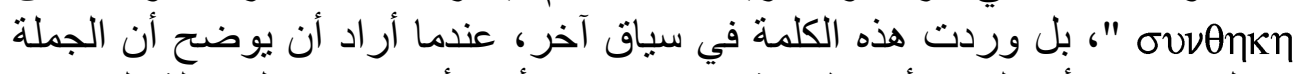

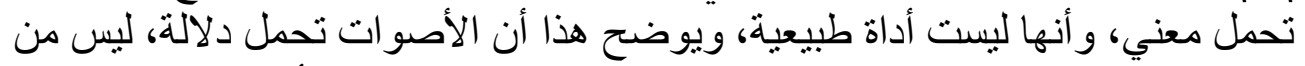

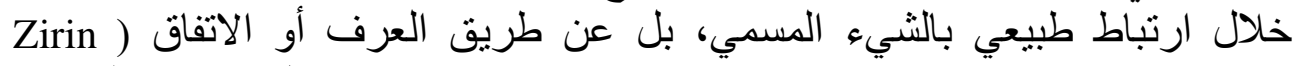

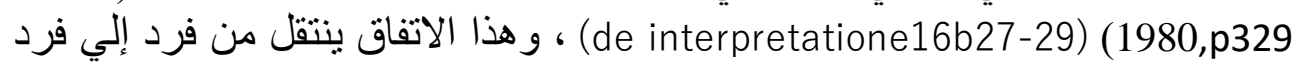

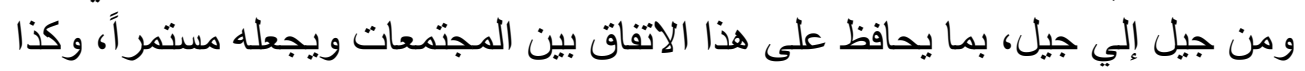

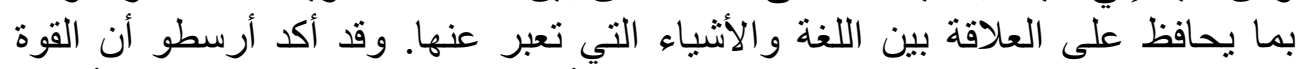

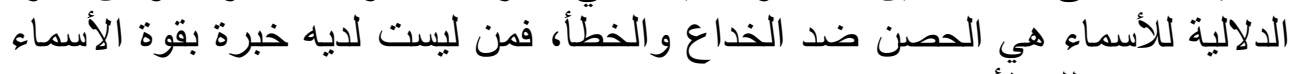

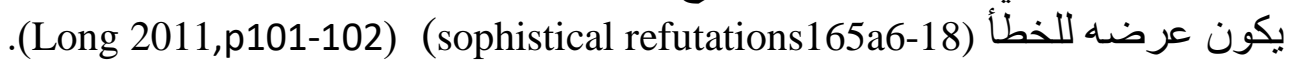

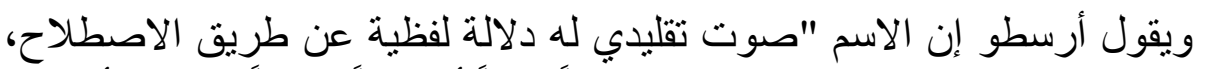

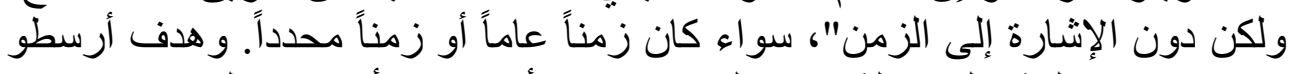

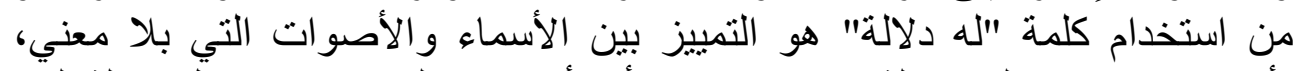

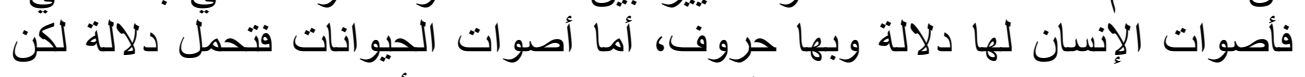

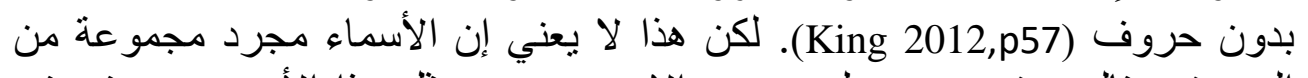

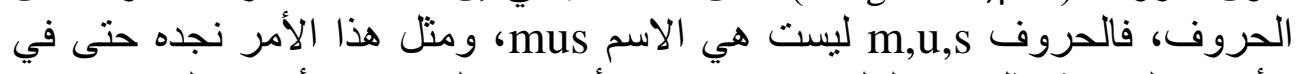

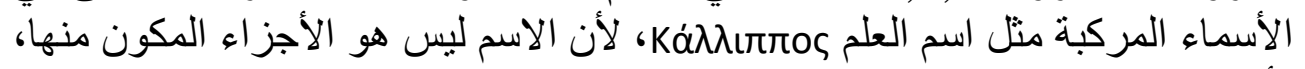

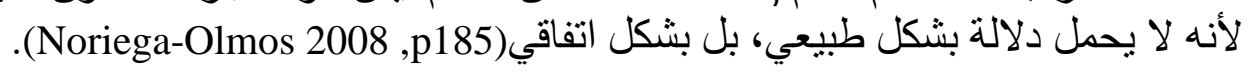

"O $v O \mu \alpha \mu \dot{\varepsilon} v \quad O \tilde{u} v \dot{\varepsilon} \sigma \tau \grave{i} \phi \omega v \dot{\eta} \sigma \eta \mu \alpha v \tau l k \grave{\eta} k \alpha \tau \dot{\alpha} \sigma u v \theta \dot{\eta} k \eta v \ddot{\alpha} v \varepsilon u$ $\chi \rho \dot{o} v O u, \tilde{n} \varsigma \mu \eta \delta \dot{\varepsilon} v \mu \dot{\varepsilon} \rho \circ \varsigma \dot{\varepsilon} \sigma \tau \dot{\mathrm{i}}$

$\sigma \eta \mu \alpha v \tau l k \grave{o} v$

$\kappa \varepsilon \chi \omega \rho \iota \sigma \mu \dot{\varepsilon} \vee \circ v$. (De interpretatione16a20-22) 


\section{ولاء توفيق فرح}

"وبناء علي ذلك فإن الاسم صوت يحمل دلالة من خلال الاتفاق أو العرف بدون (الإشارة)

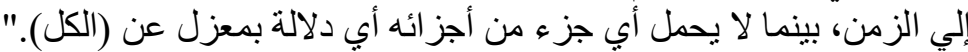

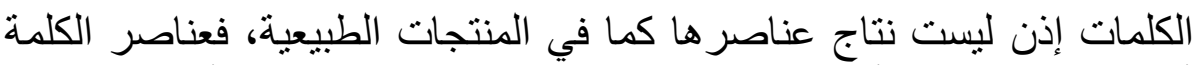

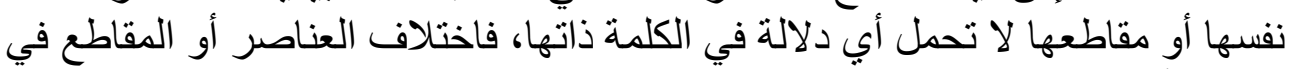

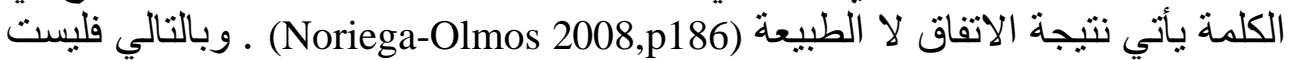

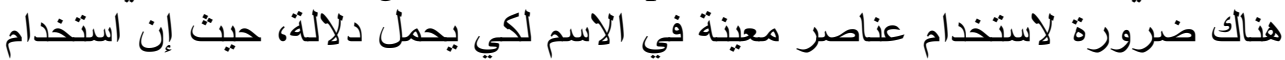

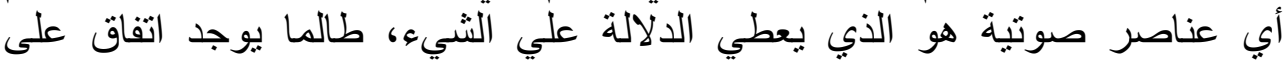

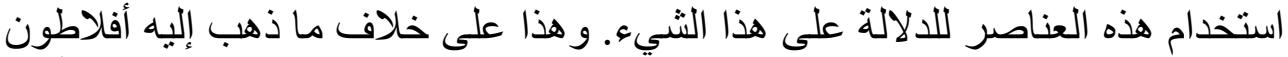

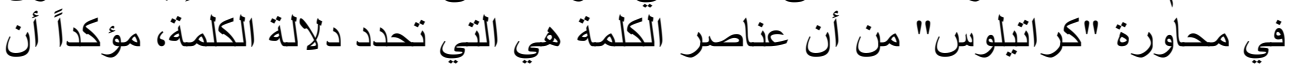

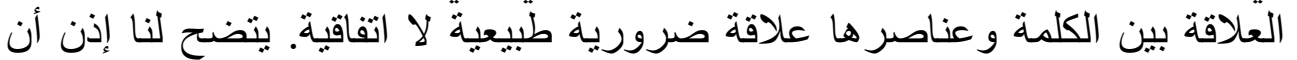

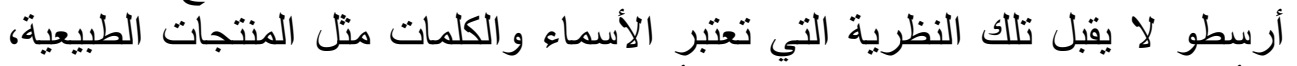

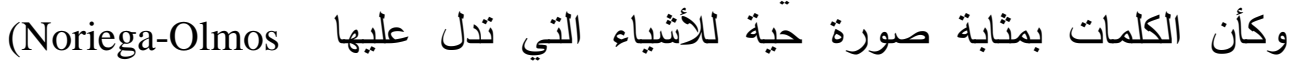
. 2008,p194)

ومثلما أعطي أرسطو تعريفاً للاسم، نجده يعرف الفعل بأنه صوت ينقل معني

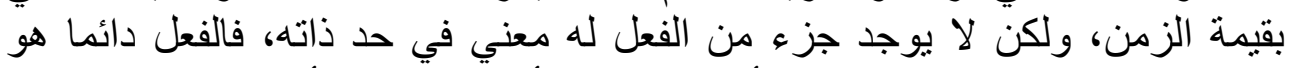

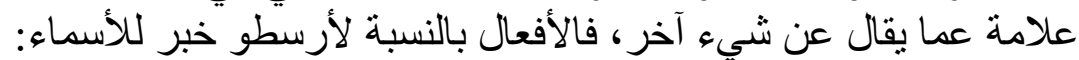

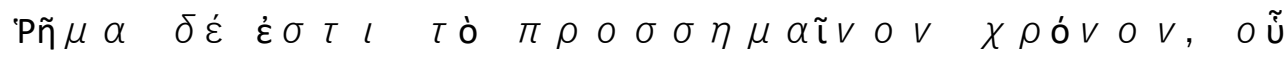

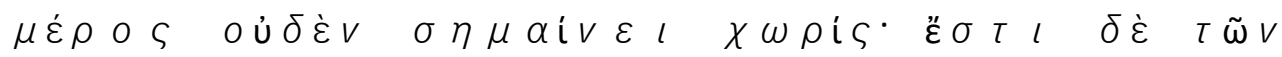

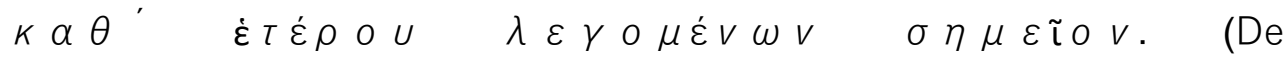
interpretatione16b6-8)

" إن الفعل بمثابة (إعلان) دال عن الزمن، وليس هناك جزء هـ منه يحمل دلالة بشكل منفصل؛ إذ أنه علامة أو إشارة تقال عن شيء إعلان دال آخر. الزع،

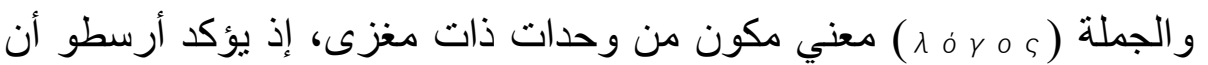

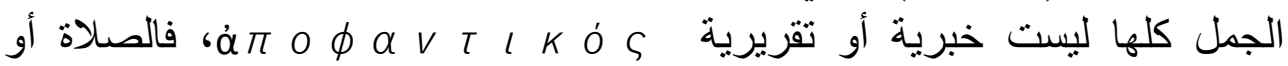

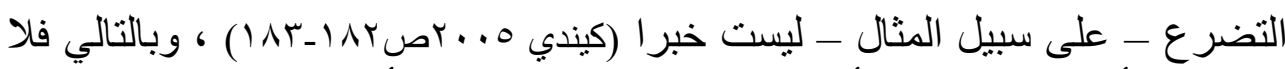

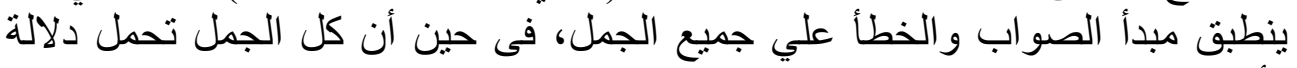

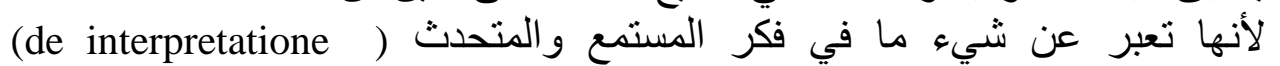
(McCutchen 1994,p96)16b33ff 
ouv $0 \dot{\eta} k \eta$

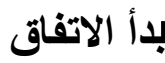

$\ddot{\varepsilon} \sigma \tau l \delta \dot{\varepsilon} \lambda \dot{o} \gamma O \varsigma \quad \ddot{\alpha} \pi \varsigma \quad \mu \dot{\varepsilon} V \quad \sigma \eta \mu \alpha v \tau l k \dot{O} \varsigma, \quad O \dot{u} \chi \dot{\omega} \varsigma$ ö $\rho \gamma \alpha \vee \circ v \delta \dot{\varepsilon}, \dot{\alpha} \lambda \lambda{ }^{\prime} \ddot{\omega} \sigma \pi \varepsilon \rho \varepsilon \ddot{\imath} \rho \eta \tau \alpha \iota k \alpha \tau \dot{\alpha} \sigma u v \theta \dot{\eta} k \eta v$.

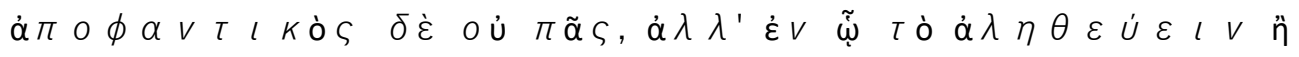
$\psi \varepsilon \dot{u} \delta \varepsilon \sigma \theta \alpha l \dot{u} \pi \dot{\alpha} \rho \chi \varepsilon l \cdot O \dot{u} k \dot{\varepsilon} V$ ä $\pi \alpha \sigma l \delta \dot{\varepsilon} \dot{u} \pi \dot{\alpha} \rho \chi \varepsilon l$, o $0 v \dot{\eta} \varepsilon \dot{u} \chi \dot{\eta} \lambda \dot{o} \gamma O \varsigma \mu \dot{\varepsilon} v, \dot{\alpha} \lambda \lambda^{\prime} O u ̈ \tau^{\prime} \dot{\alpha} \lambda \eta \theta \dot{\eta} \varsigma \quad O u ̈ \tau \varepsilon$ $\psi \varepsilon \cup \delta \dot{\eta} \varsigma$.

(de interpretatione 17a1-6)

" في حين أن كل جملة تحتوي علي معني، لا كأداة لكن كما قلنا عن طريق العرف ألف أو الاتفاق،

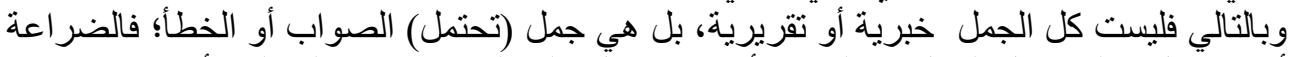

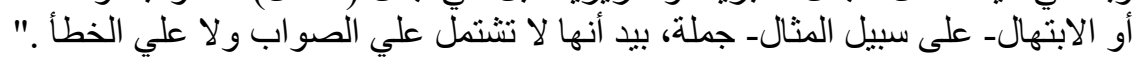

لكن كيف تكون دلالة الجملة عند أرسطو قائمة على العرف أو الاتفاق ؟ أي

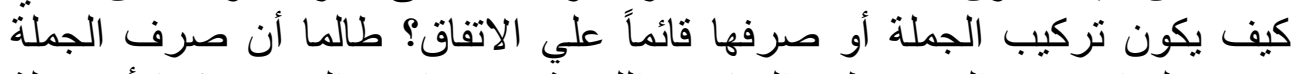

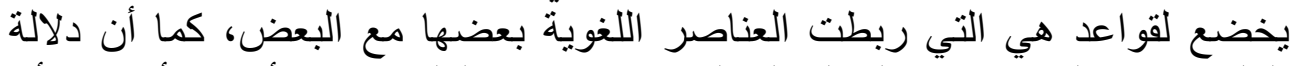

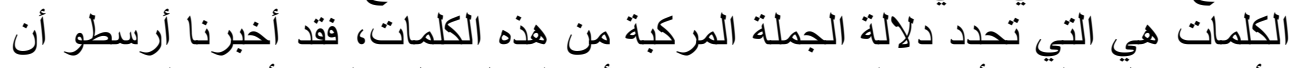

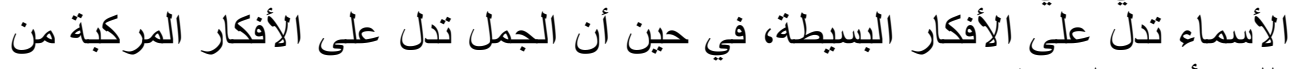

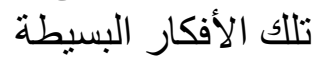

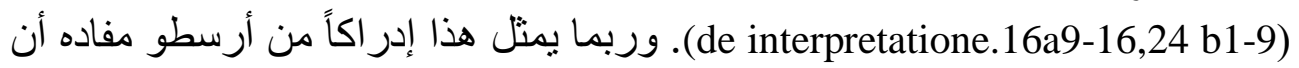

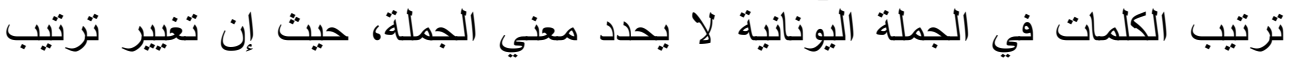

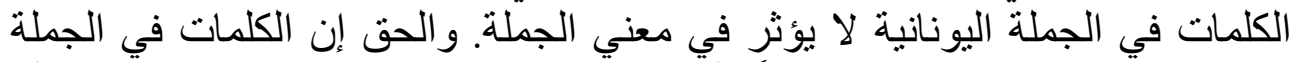

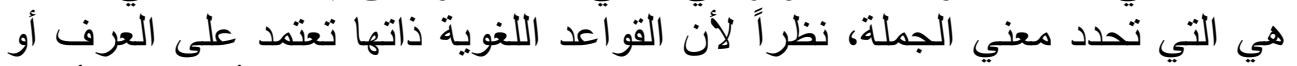

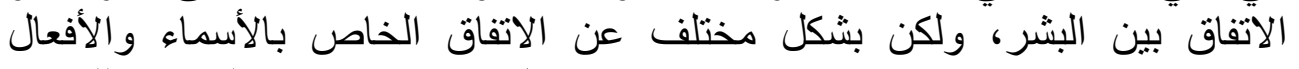

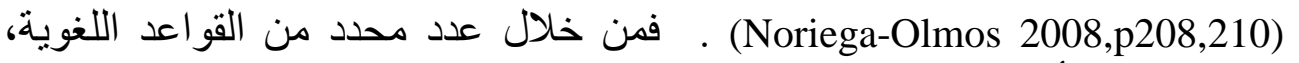

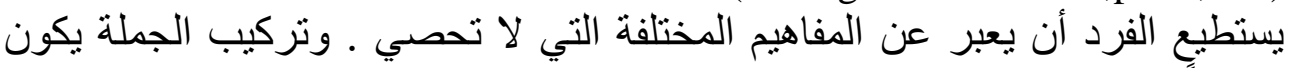

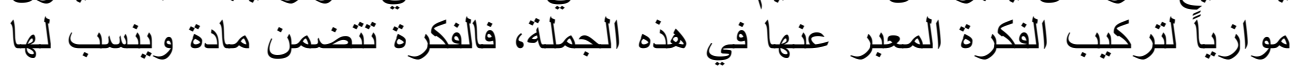

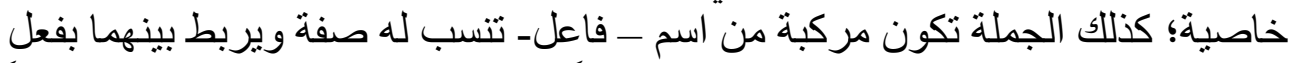

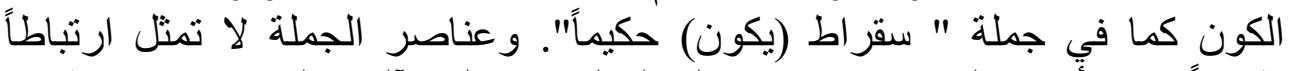

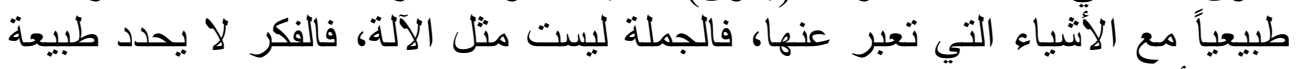

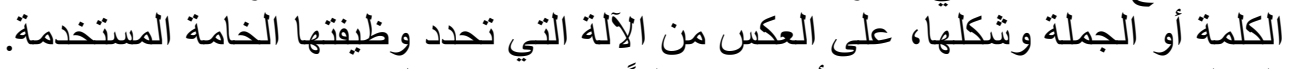

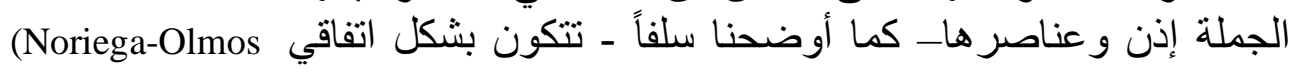

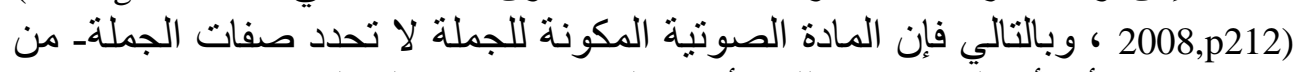
صواب وخطأ لأن الأي يحدد ذللك الأفكار المعبر عنها في الجملة. 


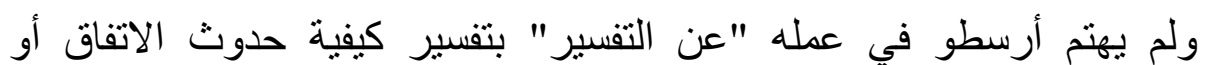

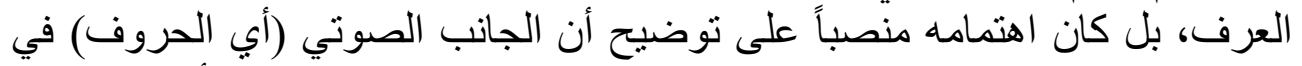

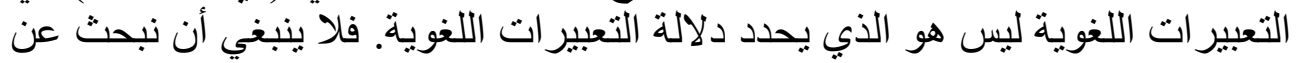

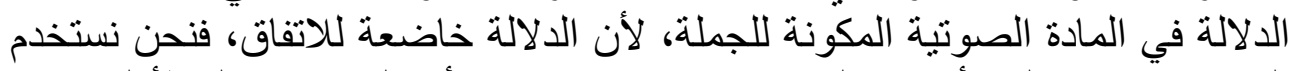

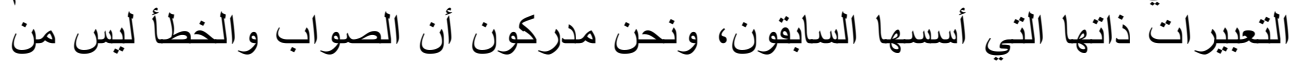
صفات الجمل فقط، بل من صفات الأفكار التي تدل عليها هذه الكلمات أو هذه الجمل الجل :(Noriega-Olmos 2008,p213)

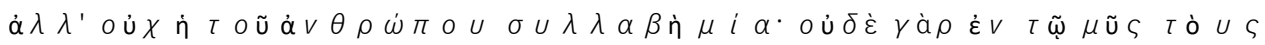
$\sigma \eta \mu \alpha v \tau \iota k \dot{o} v, \dot{\alpha} \lambda \lambda \dot{\alpha} \phi \omega v \dot{\eta} \dot{\varepsilon} \sigma \tau l$ $v \tilde{u} V \mu \dot{O} v O V \cdot \dot{\varepsilon} v \delta \dot{\varepsilon}$

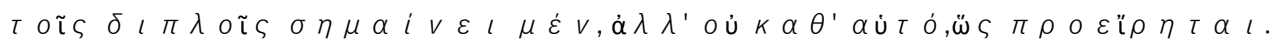
(De interpretatione16b30-34)

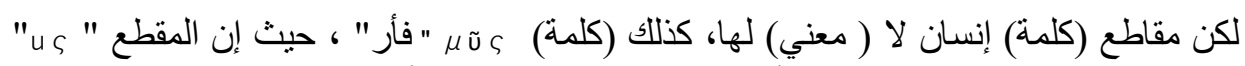

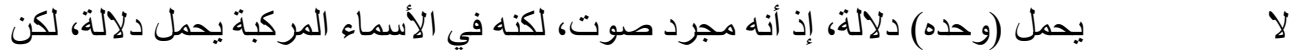
ليس في حد ذاته كما سبق أن ذكرنا."

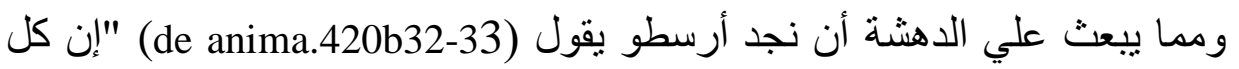

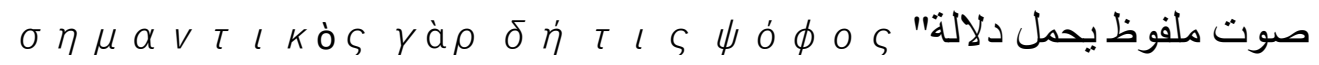

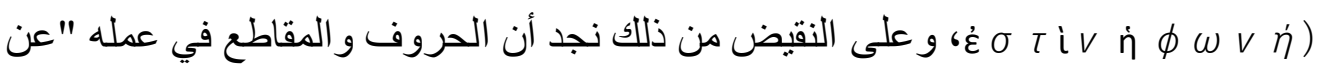

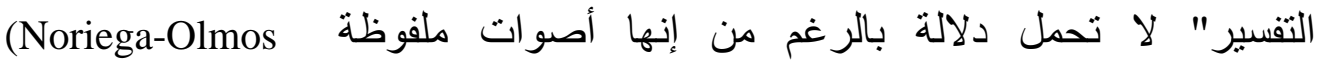

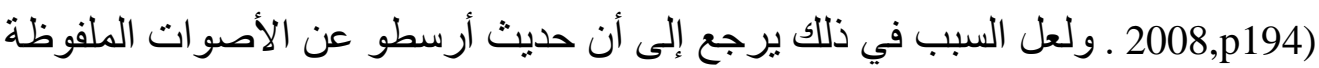

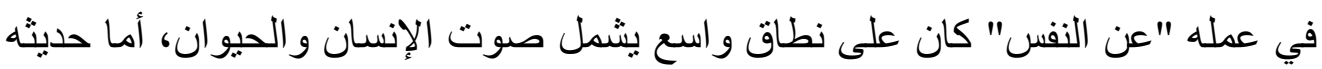

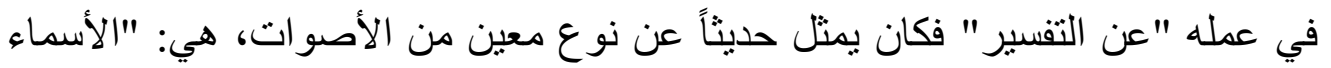

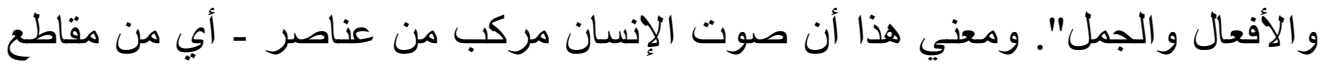

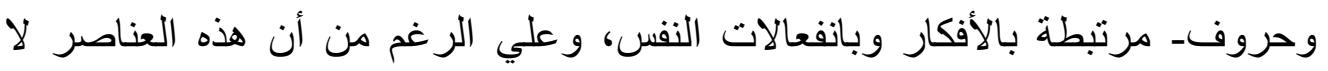

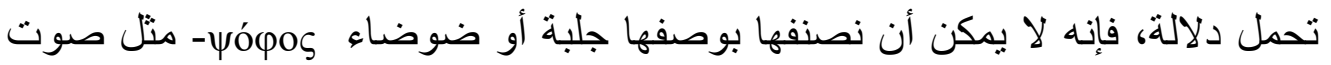

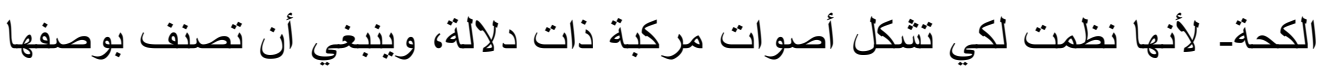

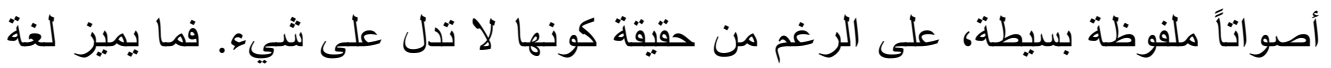

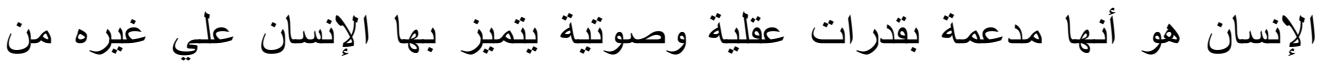

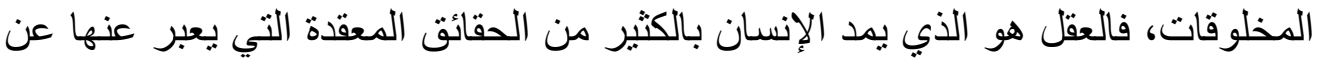

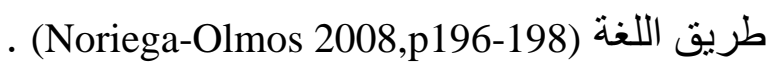




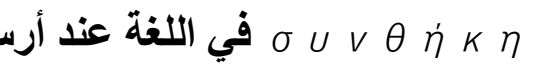

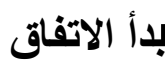

ونلاحظ أن أرسطو قد اعتبر أن أجزاء الأسماء المركبة لا تحمل دلاله بوصفها

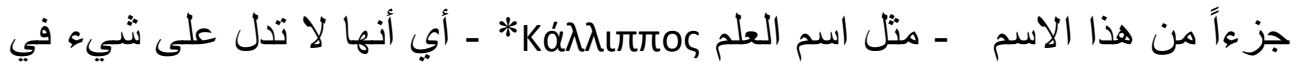
هذا الاسم، لكنها في ذاتها تدل أو تعبر عن أشياء مختلفة، فالإسم.

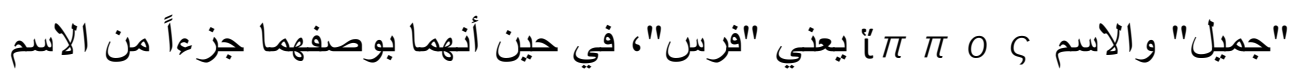

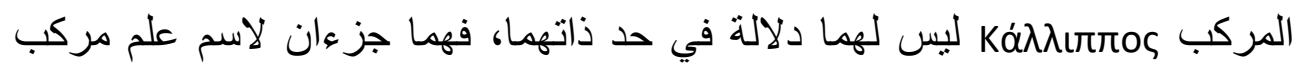

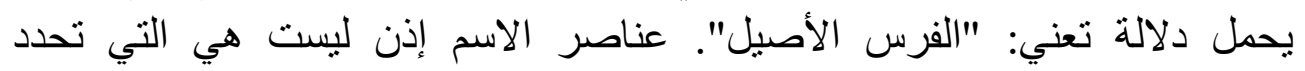

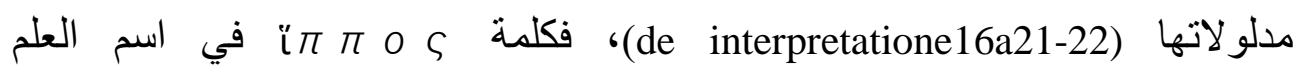

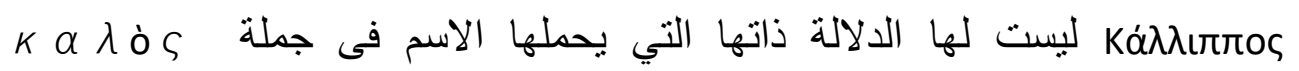

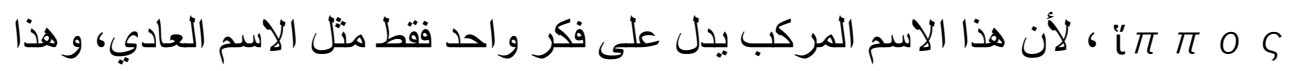

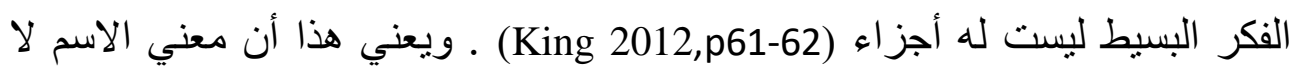

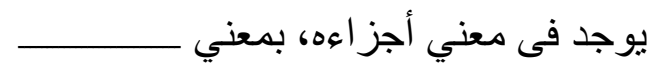

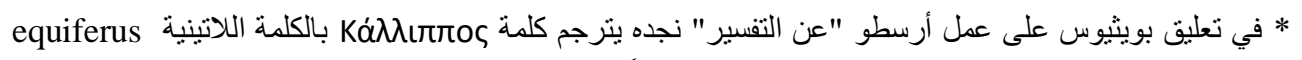

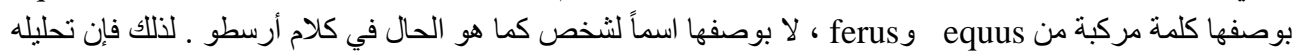

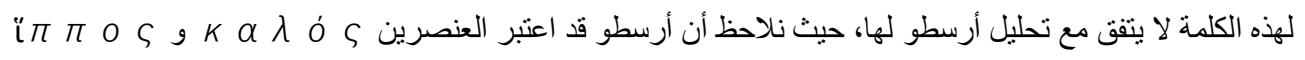

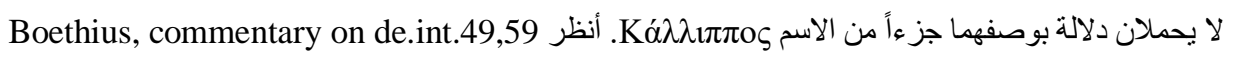

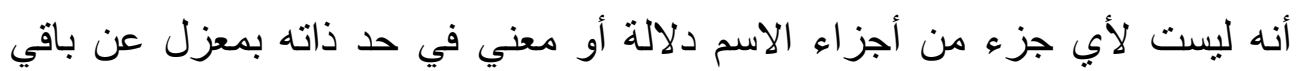

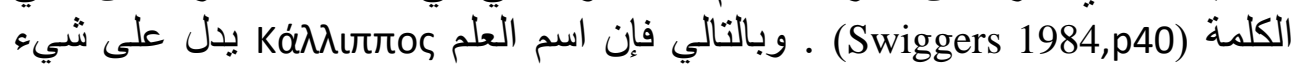

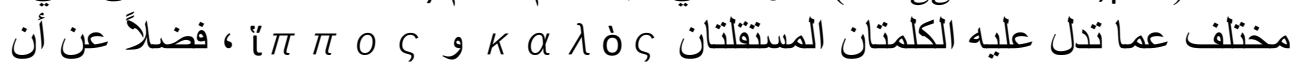

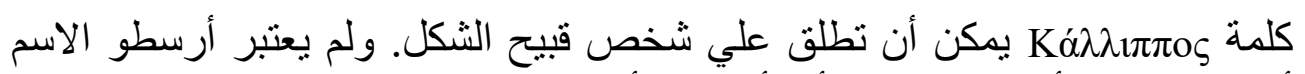

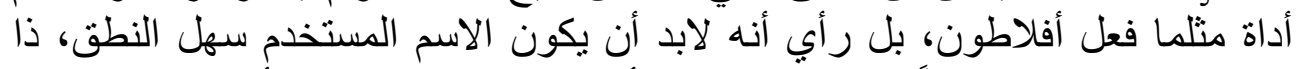

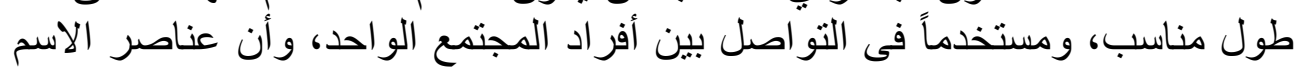
لا تحدد الثنيء المسمي(Noriega-Olmos 2008,p187).

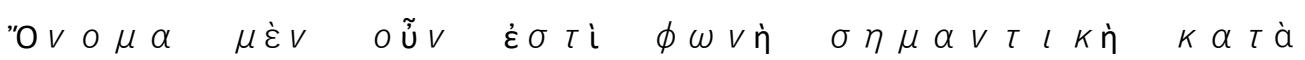

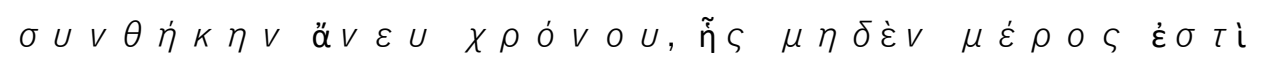

$\sigma \eta \mu \alpha v \tau l k \dot{o} v \quad k \varepsilon \chi \omega \rho l \sigma \mu \dot{\varepsilon} v o v \cdot \dot{\varepsilon} v \quad \gamma \dot{a} \rho \quad \tau \tilde{\omega}$

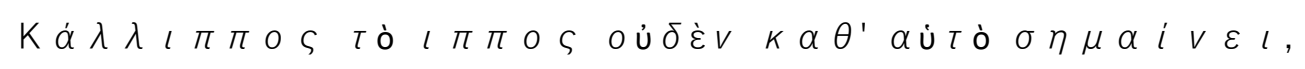

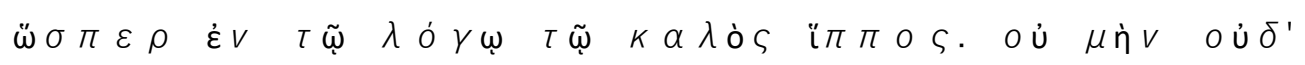

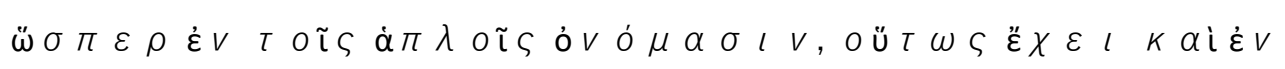




\section{ولاء توفيق فرح}

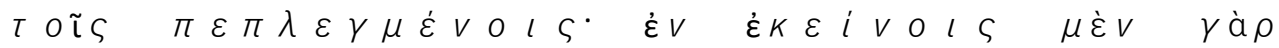

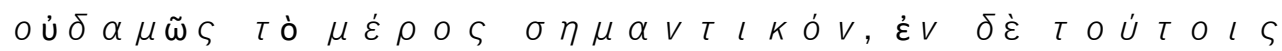

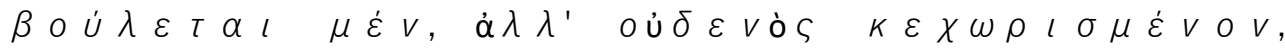
(de interpretatione 16a20-27)

"إن الاسم صوت يحمل دلالة من خلال الاتفاق أو العرف بدون (إنشارة) إلي الزمن، في حين لا

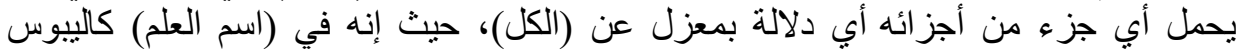

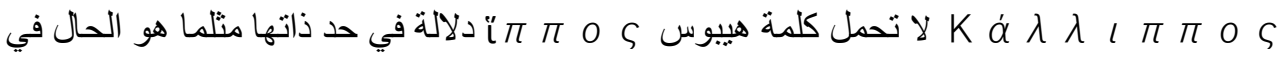

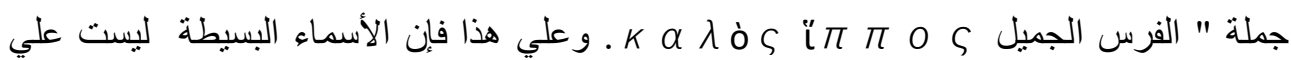

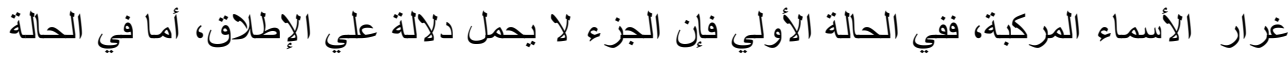

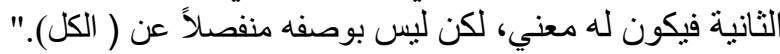

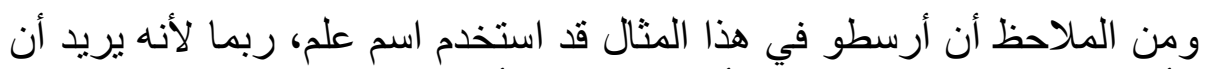

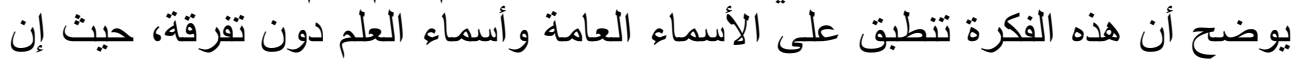

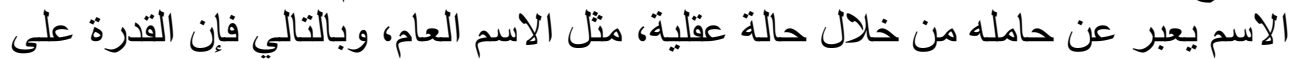

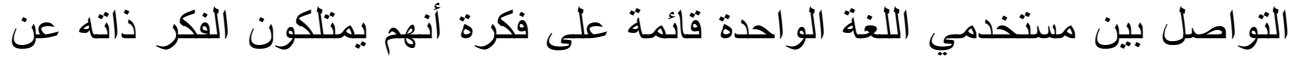
الأشياء المتحدث عنها (Modrak 2000,p44) ، وما ينطبق على فئى الاسم العام ينطبق على اسم العلم. - اء.

ويؤكد أرسطو ضرورة أن يدل الرمز على شيء واحد محدد. لأنه في حال

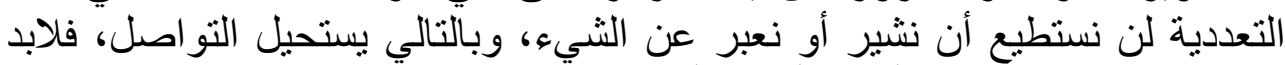

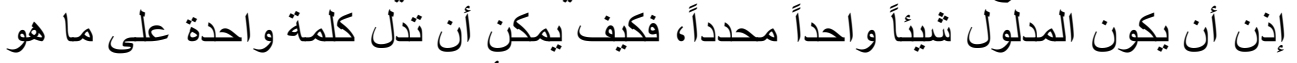

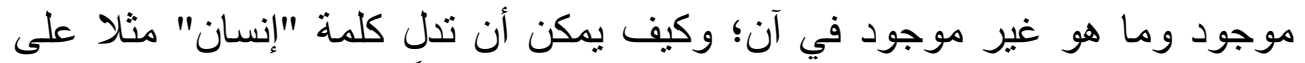

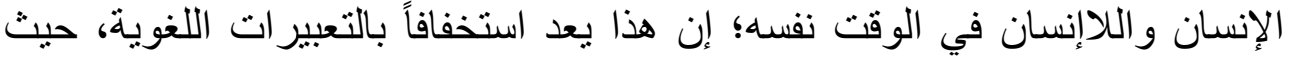

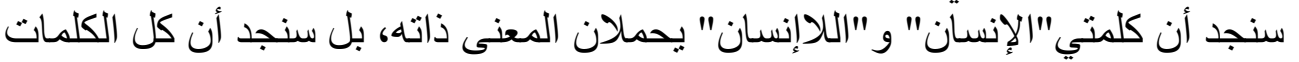

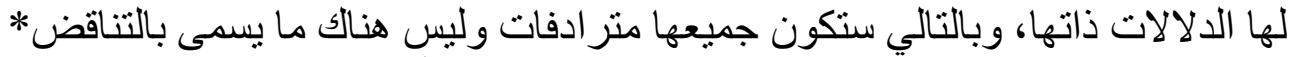

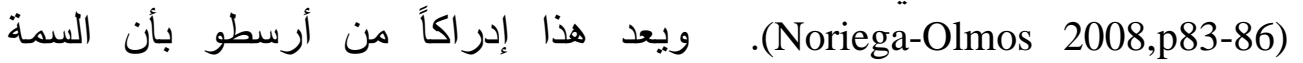
الضرورية للغة الإنسان هي أن تكون للكلمات و الجمل مدلو لات مختلفة، والا سيختفي

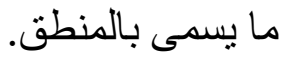

اللغة إذن تعد تهذيباً للصوت بواسطة اللسان والثفاة، فاللغة لبست مجرد

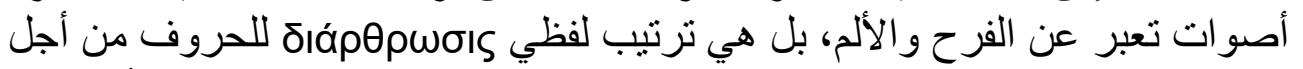

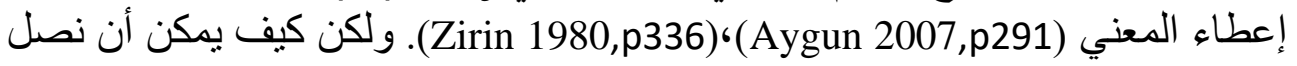

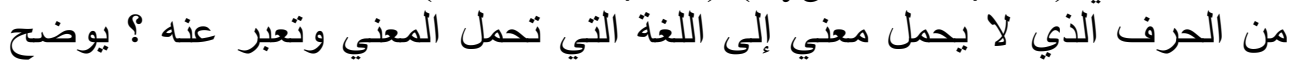


أرسطو أن المقاطع تتكون من الحروف الصامتة والحروف الصائتة، ومن المقاطع

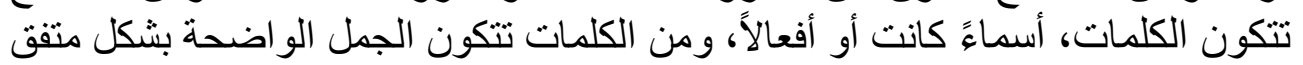

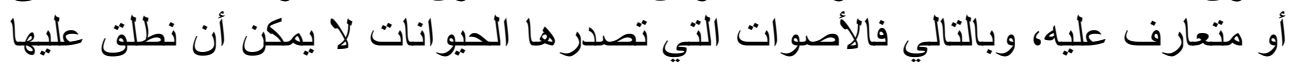

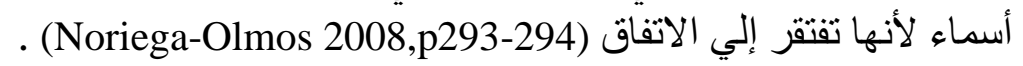

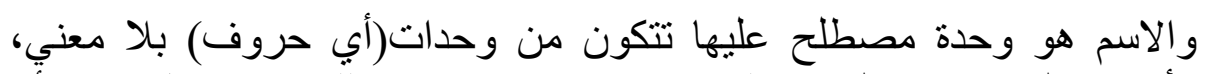

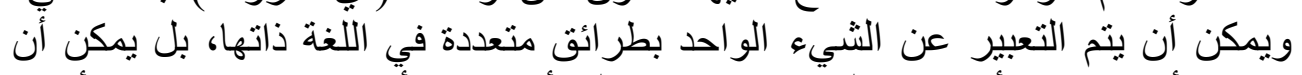

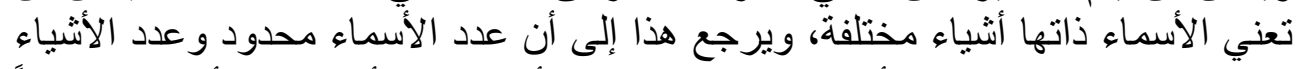

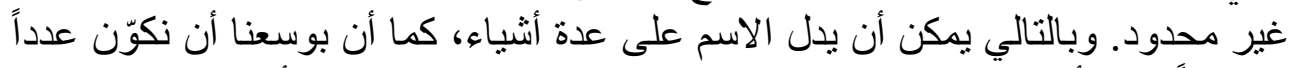

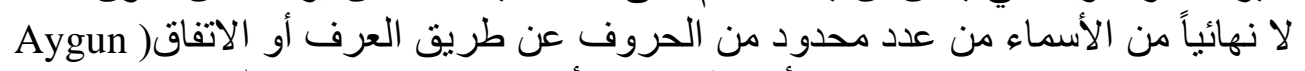

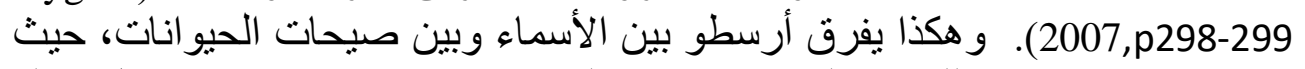

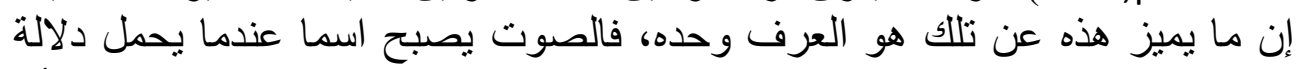

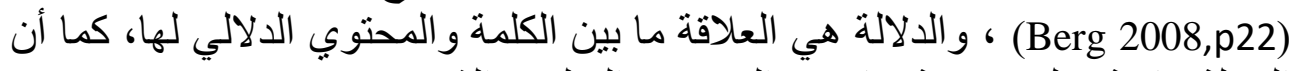

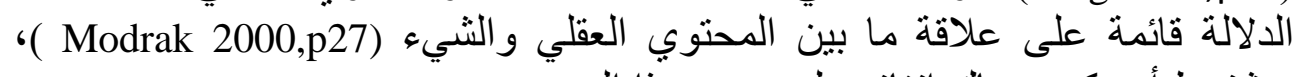

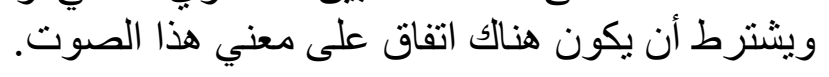

$\tau$ ò $\delta \dot{\varepsilon} k \alpha \tau \grave{a} \sigma u v \theta \dot{\eta} k \eta v$, ö $\tau$ l $\phi \dot{u} \sigma \varepsilon l \tau \tilde{\omega} v$ ó $v o \mu \dot{\alpha} \tau \omega v$ o $\delta \dot{\varepsilon} v$

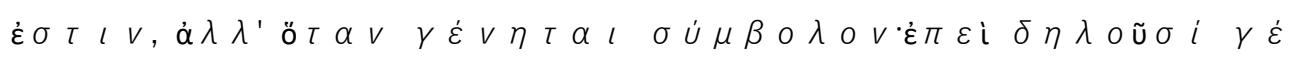

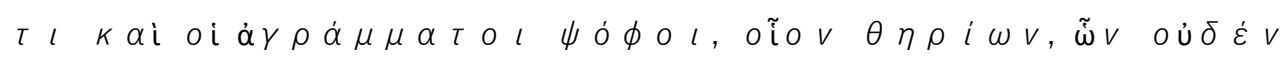
$\dot{\varepsilon} \sigma \tau \iota \vee$ ö $v O \mu \alpha$. de interpretatione.16a26-29

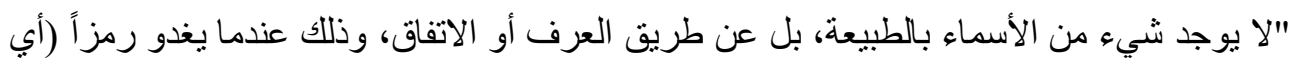

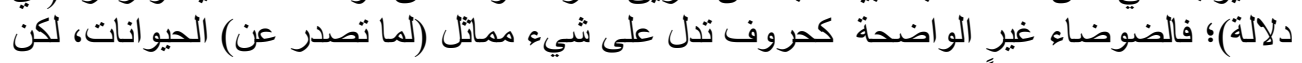

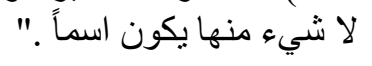
metaphysics 1007b18-23 أنظر وماذا إذن عن الكلمات التي لا تدل على شيء مادي ملموس في الو الواقع مثل

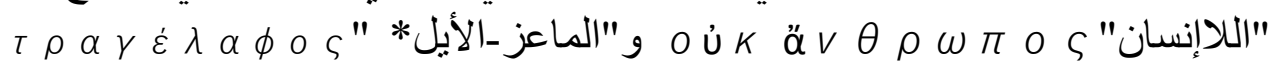

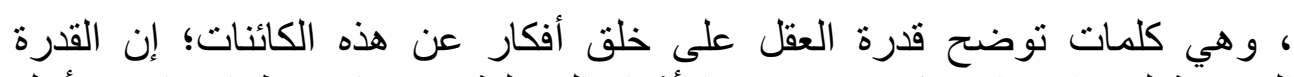

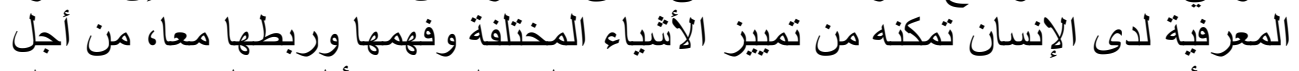

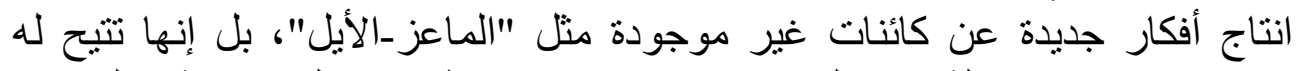

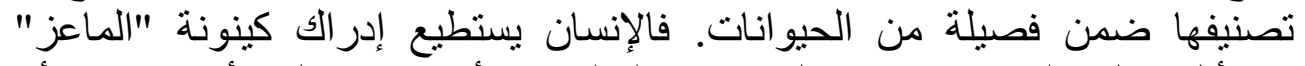

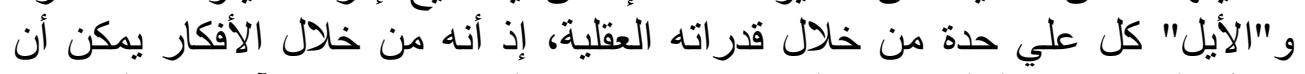

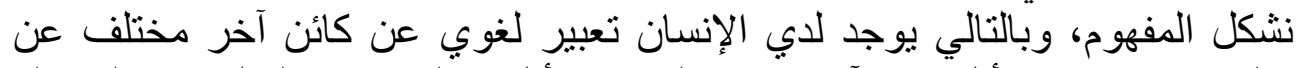

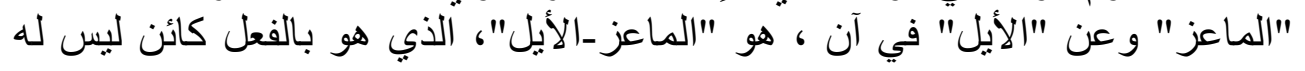




\section{ولاء توفيق فرح}

مثيل في الواقع الخارجي. ويكمن الخطأ في محاولة الربط بين هذا التعبير اللفظي

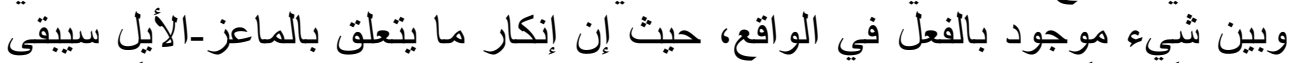

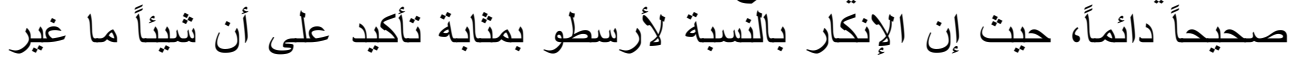

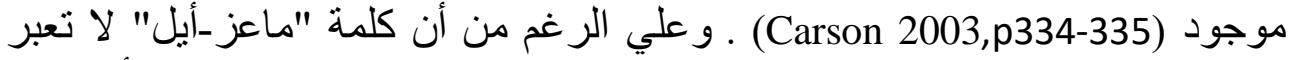

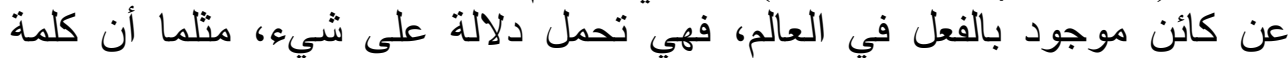

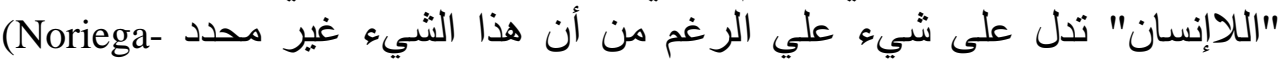

.Olmos 2008,p91)

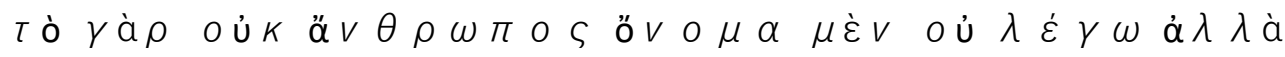
áó $\rho$ l $\sigma \tau O V$ ö $v o \mu \alpha, \ddot{\varepsilon} v \quad \gamma \dot{\alpha} \rho \pi \omega \varsigma \quad \sigma \eta \mu \alpha i v \varepsilon l$ áó $\rho$ l $\sigma$ T $O$ O $V$, (de interpretatione19b8-10)

" لا سواه . " "اللا إنسان" لبس اسماً، غير أني أدعوه اسماً غير محدد، حيث إنه يدل علي شيء واحد

والثئ الواحد لا يمكن أن يوصف بصفة ونقيض الصفة في الوقت فئ ذاتها،

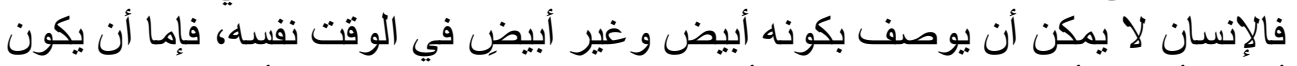

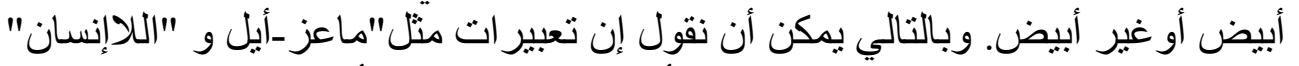

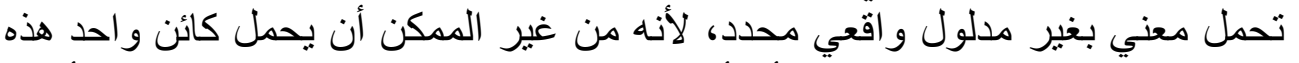

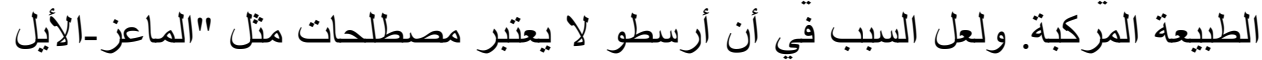

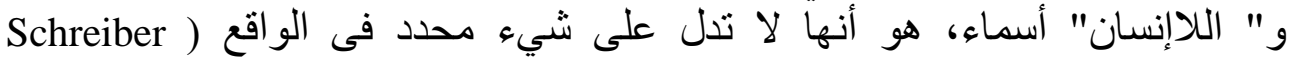

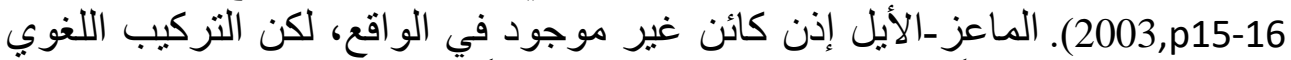

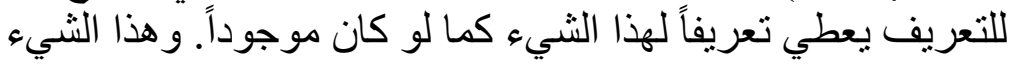

* الماعز-الأيل: كلمة مكونة من لفظين ؟ تثشير إلي كائن غير موجود علي شكل أيل وماعز في الوقت نفسه.

الدال علي هذا الكائن غير الموجود من خلق اللغة فقط، ويعرف هذا "بالتعريف

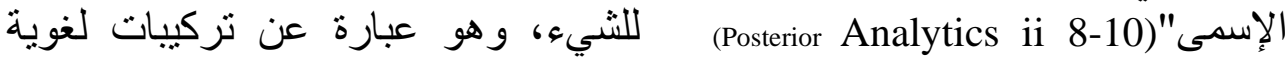

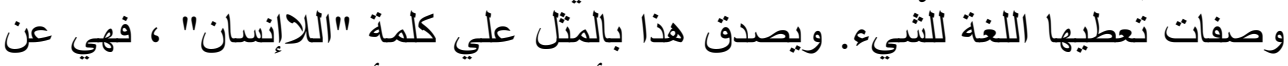

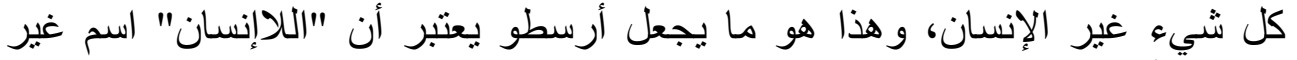

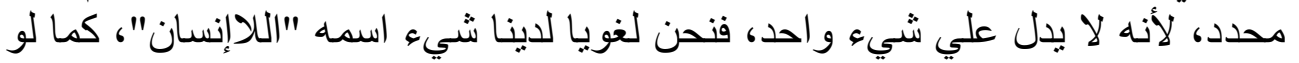

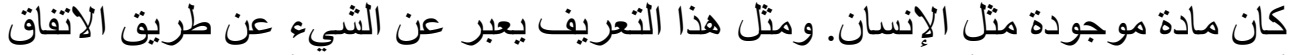

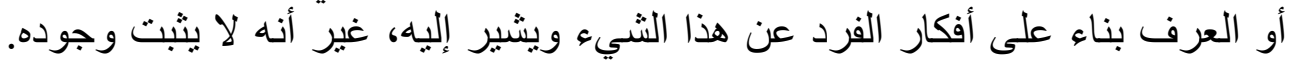


ويمكن أن نقول إن " التعريف الإسمي" هو التعريف بالثيء الذي لا يمكن الاستدلال

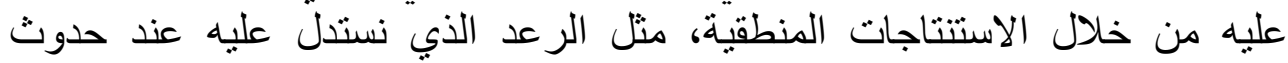

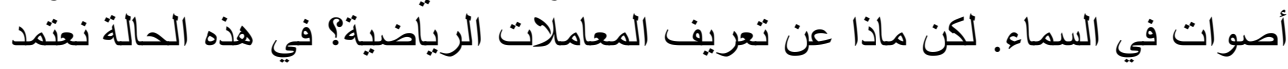

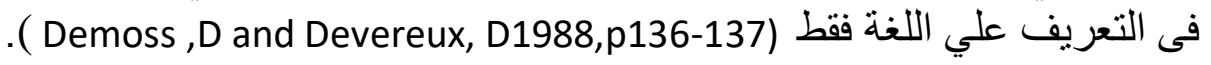

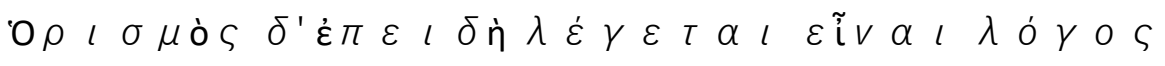
$\tau$ o ũ $T \dot{\varepsilon} \sigma \tau l, \phi \alpha V \varepsilon \rho$ ò $V$ ö $\tau$ l ó $\mu \dot{\varepsilon} V \tau$ l $\varsigma$ है $\sigma \tau \alpha l$

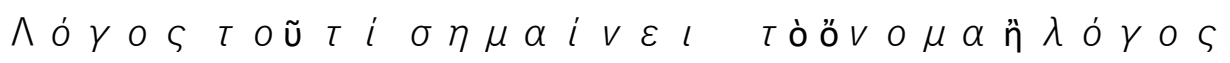

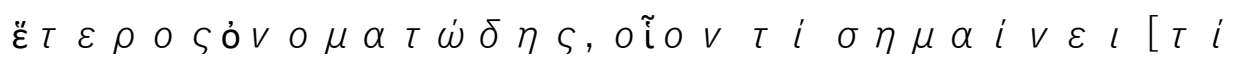
$\dot{\varepsilon} \sigma \tau l] \tau \rho i \gamma \omega V O V . \ddot{o} \pi \varepsilon \rho \ddot{\varepsilon} \chi O V T \varepsilon \varsigma$ ö $\tau$ । $\tilde{\varepsilon} \sigma \tau l$,

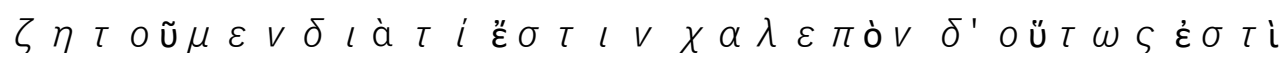

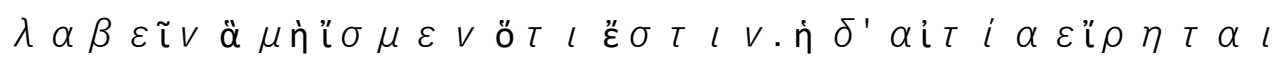

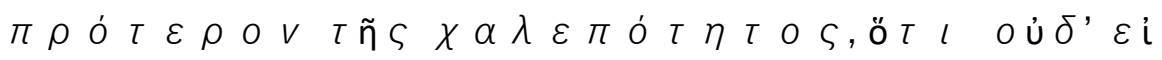

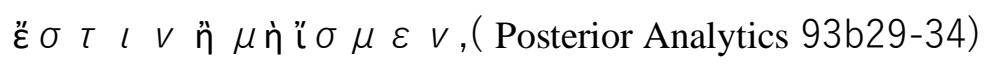

طالما قيل إن التعريف هو القول (الجامع) عن كينونة الثيه، فمن الواضح أن أحد (التعريفات)

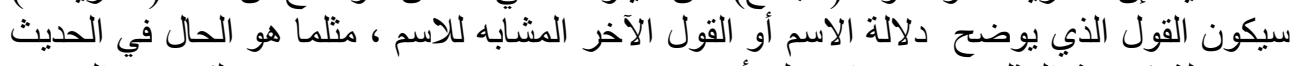

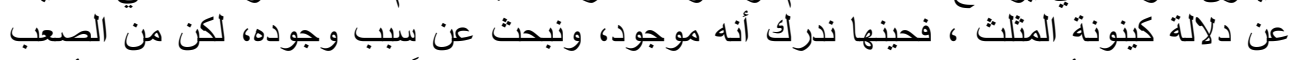

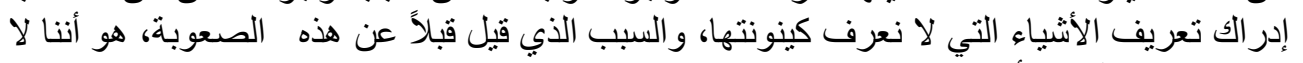

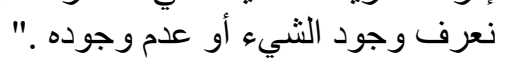

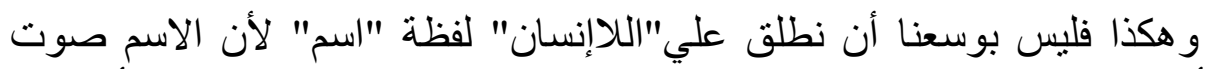

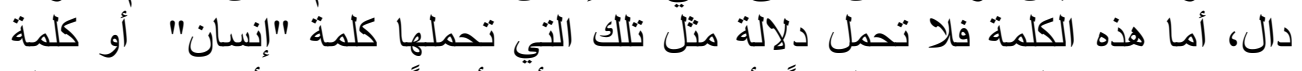

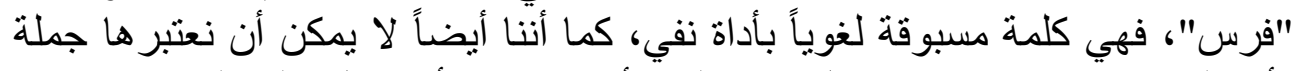

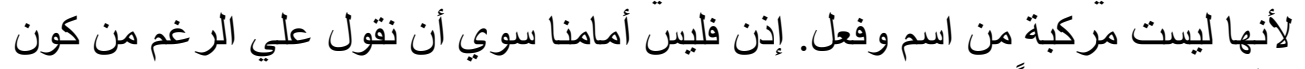

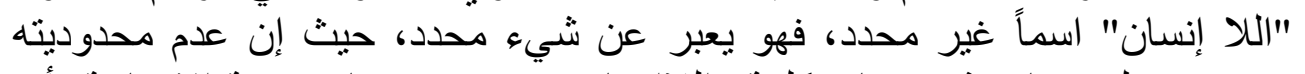

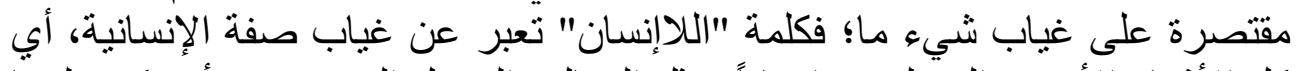

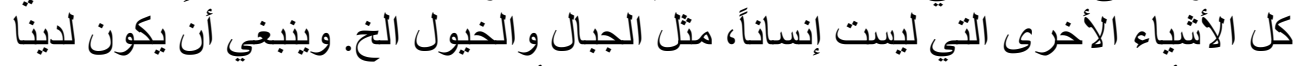

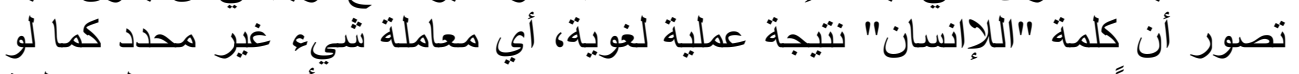

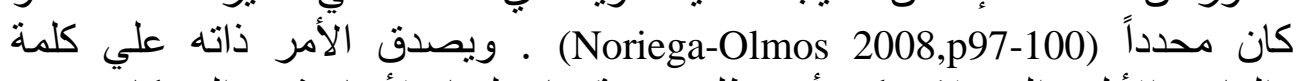

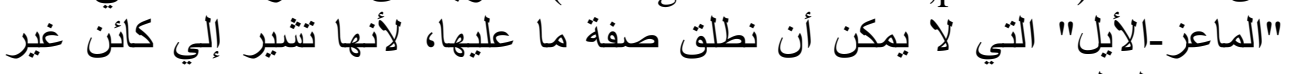

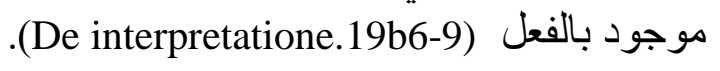




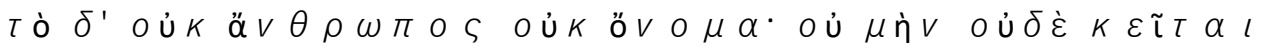

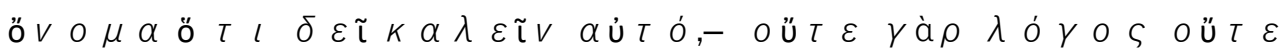

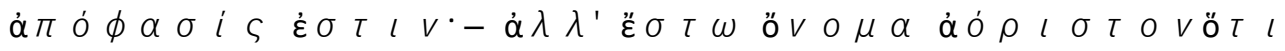

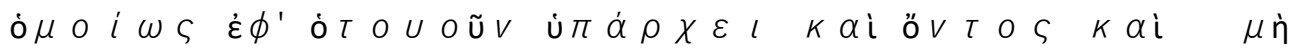
ö $v$ t o s.(de interpretatione16a30-34)

إن "اللاإنسان" لبس اسماً، حيث إنه لا يوجد هناك اسم ينبغي أن بسمي بهذه التسمية، كما أنه ليس

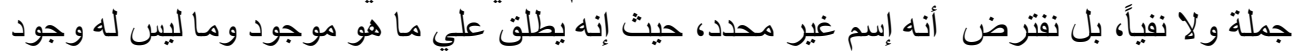
سواء بسو اء." ملاء

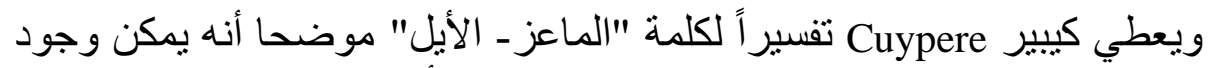

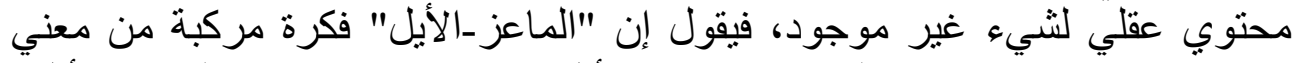

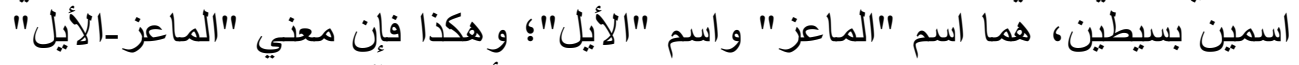

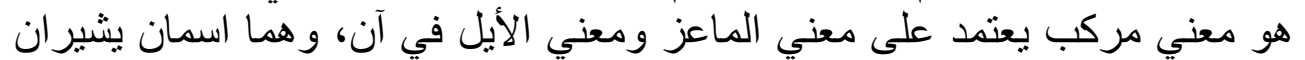

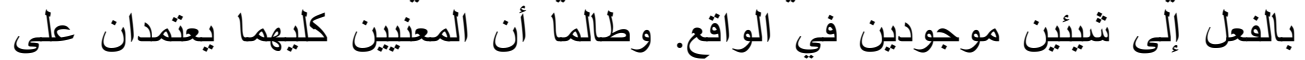

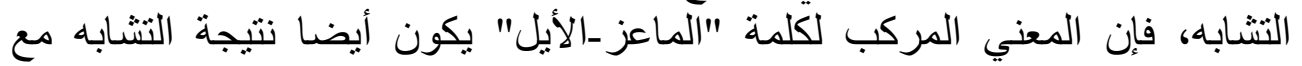

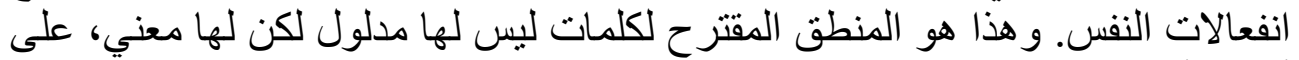

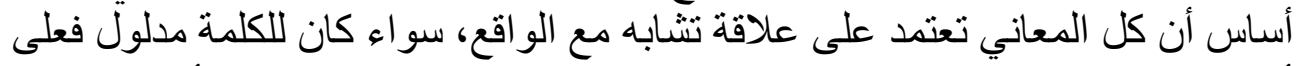

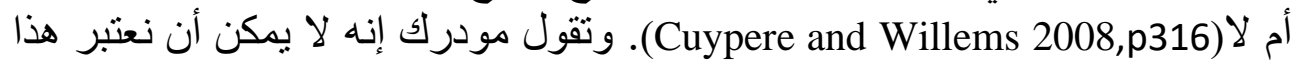

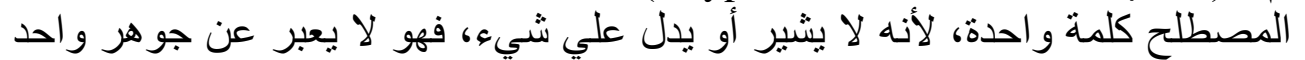
حقيقي، بل يعبر عن جو هرين معاً (Modrak 2000,p25).

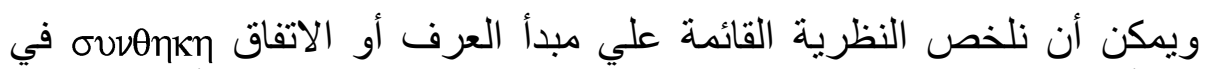

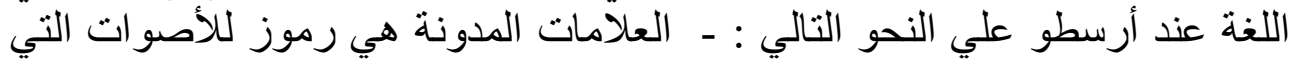

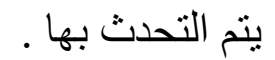
ـ الأصوات التي يتم التحدث بها هي رموز لانفعالات النفس. وانفعالات النفس تشبه

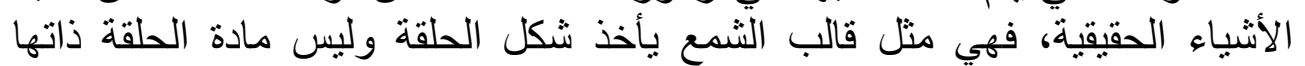

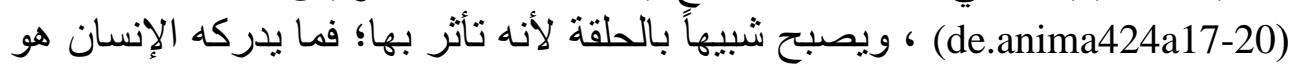

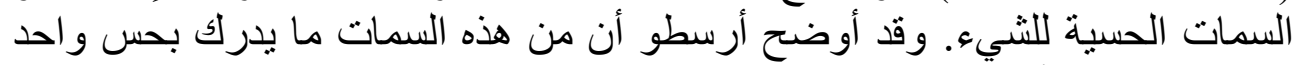

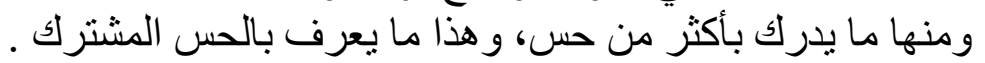
(Bynum 1987,p165-166) (Aristotle,de anima 418a11-19) هي: - العلامات المدونة ليست هي ذاتها عند كل البشر.

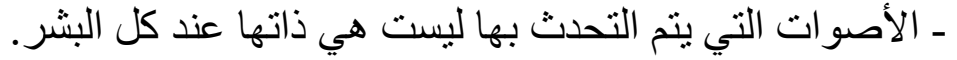

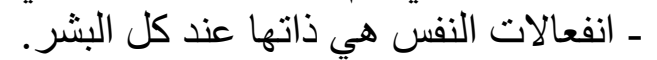


ـ الأشياء الحقيقية الو اقعية هي ذاتها عند كل البشر(Berg 2008,p20).

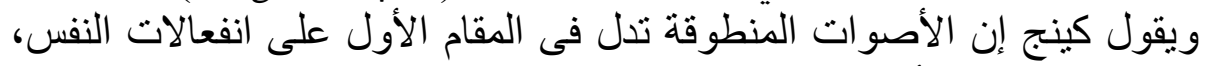
وفى المقام الثاني على الأشياء الموجودة ذاتهات (King 2012,p125).

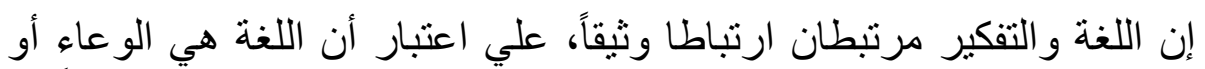

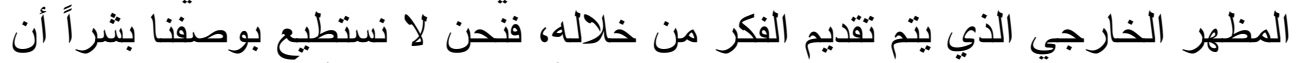

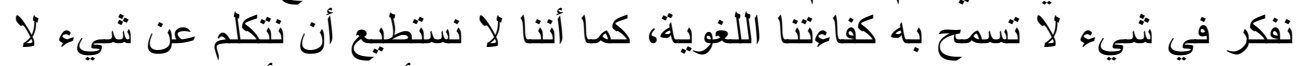

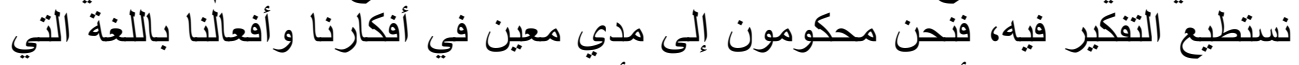

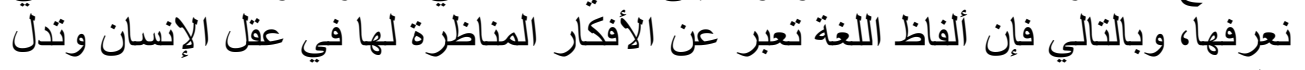
عليها.

و لا تعد لغة الإنسان مجرد تعبير عن صور فكرية، فمثلما بستخدم الإنسان اللغة الإنة

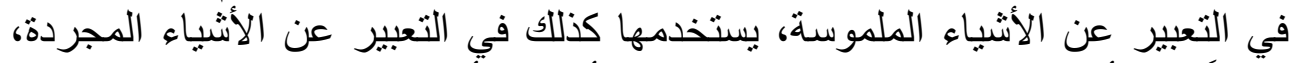

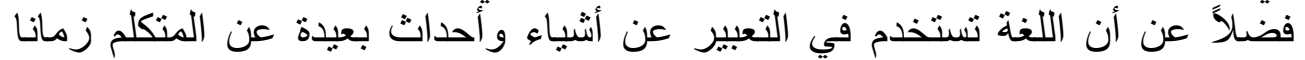

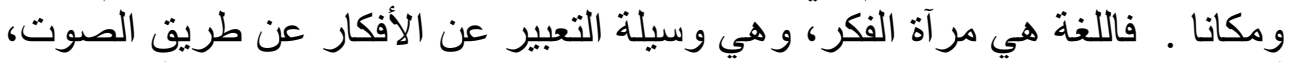

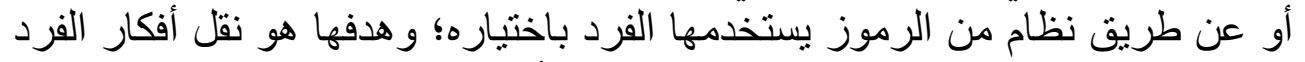

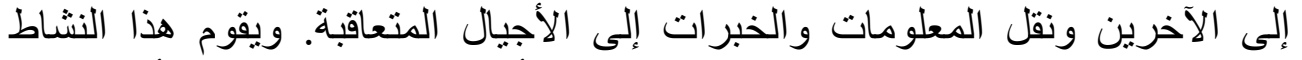

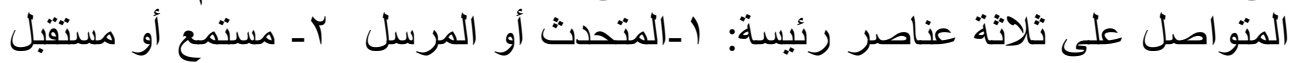

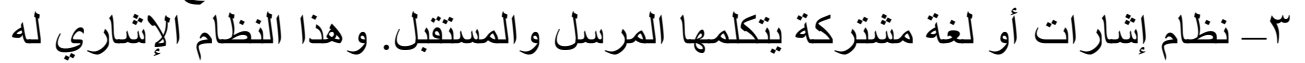

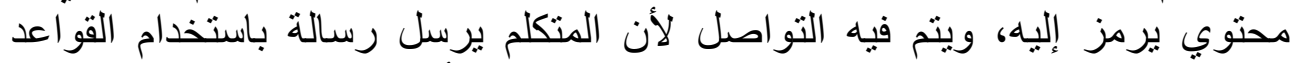

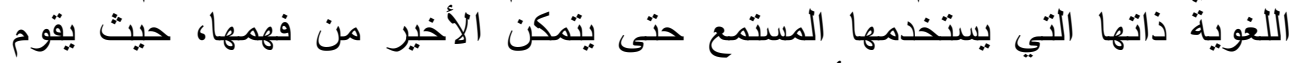
المستقبل بترجمة الكلمات إلى أفكار.

\section{قائمة المصادر والمراجع}

Aristotle, de Interpretatione, L.C.L,1955.

Idem, de Anima , L.C.L,1957.

Idem, Posterior Analytics , L.C.L, 1960.

$$
\begin{aligned}
& \text { جورج كيندي ه . . ب : موسو عة كمبريدج في النقد الأدبي ، الجزء الأول (النقد الأدبي الكلاسيكي) } \\
& \text { مر اجعة و إنشر اف أحمد عتمان، المجلس الأعلى للثقافة . ل. }
\end{aligned}
$$

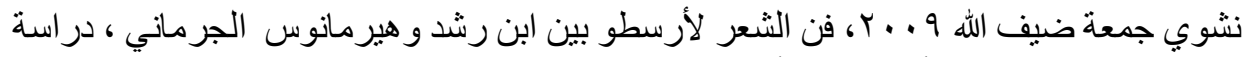

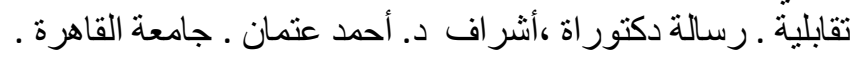




\section{ولاء توفيق فرح}

Aygun, O. O. (2007). The Included Middle: "Logos" in Aristotle's Philosophy, United States, The Pennsylvania State University. Ph.D.

Berg, R. M. (2008). Proclus' Commentary on the Cratylus in Context :

Ancient Theories of Language and Naming, Leiden, Brill.

Berns, L. (1976). "Rational Animal-Political Animal: Nature and Convention in Human Speech and Politics", The Review of Politics 38(2): 177-189.

Carson, D. S. (1996). Being and Truth: Elements of Aristotle's Philosophy of Language, United States - North Carolina, Duke University. Ph.D.

Carson, S. (2003). "Aristotle on Meaning and Reference", History of Philosophy Quarterly 20(4): 319-337.

caston, v. (2009). Phantasia and Thought, a Companion to Aristotle G. Anagnostopoulos, wiley blackwell.

Cuypere, L. and K. Willems (2008). "Meaning and Reference in Aristotle's Concept of the Linguistic Sign", Foundations of Science 13(3/4): 307-324.

Demoss, D and Devereux, D(1988). "Essence, Existence, and Nominal Definition in Aristotle's "Posterior Analytics" II 8-10 ", Phronesis, Vol. 33, No. 2, pp. 133-154

Formigari,L. (2004).A History of Language Philosophies, John Benjamins Publishing Company.

Joseph, J. E. (2000). Limiting the Arbitrary : Linguistic Naturalism and its Opposites in Plato's Cratylus and Modern Theories of Language, Amsterdam, Benjamins.

King, R. C. (2012). Semantics and Mental Representation in Aristotle's "Peri Hermeneias", United States - New York, University of Rochester. Ph.D.

Lesetar, P. (1998). Signs: Language in Semiotics, Canada, University of Alberta (Canada). Ph.D.

Lewis, F. A. (2011). "'Predication, Things, and Kinds in Aristotle's Metaphysics'", Phronesis 56(4): 350-387.

Long, C. P. (2011). Aristotle on the Nature of Truth, Cambridge University Press. 
McCutchen, B. D. (1994). A Rhetorico-Semiotic Inquiry into Ancient Greek Sophistic and Philosophic Discourses: Gorgianic and Aristotelian Theories of Language, United States -New York, Rensselaer Polytechnic Institute. Ph.D.

Modrak,D (2000.). Aristotle Theory of Language and Meaning, Cambridge University Press

Noriega-Olmos, S. (2008). Language, Thought, and Reality in Aristotle's "De Interpretatione" and "De Anima", United States -- New Jersey, Princeton University. Ph.D.

O'Callaghan, J. P. (1997). "The Problem of Language and Mental Representation in Aristotle and St. Thomas", The Review of Metaphysics 50(3): 499-545.

Polansky, R. and M. Kuczewski (1990). "Speech and Thought, Symbol and Likeness: Aristotle's "De Interpretatione" 16a3-9" , Apeiron: A Journal for Ancient Philosophy and Science 23(1): 51-63.

Roochnick, d. (1990). "Homeric Speech Acts :Word and Deed in the Epics", the Classical Journal 85(4): 289-299.

Schreiber, S. G. (2003). Aristotle on False Reasoning : Language and the World in the Sophistical Refutations, Albany, State University of New York Press.

Swiggers, P. (1984). "Cognitive Aspects of Aristotle's Theory of Metaphor" , Glotta 62(1/2): 40-45.

Walz, M. D. (2006). "The Opening of "On Interpretation": Toward a More Literal Reading", Phronesis 51(3): 230-251.

Zirin, R. A. (1980). "Aristotle's Biology of Language" , American Philological Association (110) 325-347. 